Florida International University FIU Digital Commons

$11-20-2012$

\title{
The State of our Toolbox: A Meta-analysis of Reliability Measurement Precision
}

Krzysztof Duniewicz

Florida International University, kduni001@fiu.edu

DOI: $10.25148 /$ etd.FI13040901

Follow this and additional works at: https://digitalcommons.fiu.edu/etd

\section{Recommended Citation}

Duniewicz, Krzysztof, "The State of our Toolbox: A Meta-analysis of Reliability Measurement Precision" (2012). FIU Electronic Theses and Dissertations. 818.

https://digitalcommons.fiu.edu/etd/818

This work is brought to you for free and open access by the University Graduate School at FIU Digital Commons. It has been accepted for inclusion in FIU Electronic Theses and Dissertations by an authorized administrator of FIU Digital Commons. For more information, please contact dcc@fiu.edu. 


\title{
FLORIDA INTERNATIONAL UNIVERSITY
}

Miami, Florida

\section{THE STATE OF OUR TOOLBOX: A META-ANALYSIS OF RELIABILITY MEASUREMENT PRECISION}

\author{
A thesis submitted in partial fulfillment of the \\ requirements for the degree of \\ MASTER OF SCIENCE \\ in \\ PSYCHOLOGY \\ by \\ Krzysztof Duniewicz
}

2012 
To: Dean Kenneth G. Furton

College of Arts and Sciences

This thesis, written by Krzysztof Duniewicz and entitled The State of our Toolbox: A Meta-analysis of Reliability Measurement Precision having been approved in respect to style and intellectual content, is referred to you for judgment.

We have read this thesis and recommend that it be approved.

Victoria L. Pace

Chockalingam Viswesvaran

Jesse S. Michel, Major Professor

Date of Defense: November 20, 2012

The thesis of Krzysztof Duniewicz is approved.

Dean Kenneth G. Furton
College of Arts and Sciences

Dean Lakshimi N. Reddi
University Graduate School

University Graduate School

Florida International University, 2013 


\section{ABSTRACT OF THE THESIS \\ THE STATE OF OUR TOOLBOX: A META-ANALYSIS OF RELIABILITY MEASUREMENT PRECISION \\ by \\ Krzysztof Duniewicz}

Florida International University, 2012

Miami, Florida

Jesse S. Michel, Major Professor

My study investigated internal consistency estimates of psychometric surveys as an operationalization of the state of measurement precision of constructs in industrial and organizational (I/O) psychology. Analyses were conducted of samples used in research articles published in the Journal of Applied Psychology between 1975 and 2010 in five year intervals $(K=934)$ from 480 articles yielding 1427 coefficients. Articles and their respective samples were coded for test-taker characteristics (e.g., age, gender, and ethnicity), research settings (e.g., lab and field studies), and actual tests (e.g., number of items and scale anchor points). A reliability and inter-item correlations depository was developed for I/O variables and construct groups. Personality measures had significantly lower inter-item correlations than other construct groups. Also, internal consistency estimates and reporting practices were evaluated over time, demonstrating an improvement in measurement precision and missing data. 


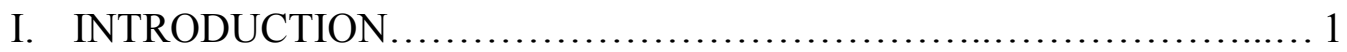

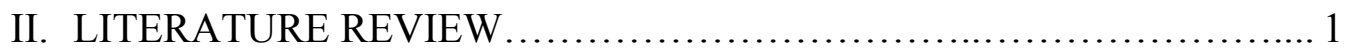

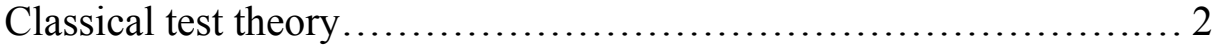

Study Purpose.................................................. 5

Characteristics that influence reliability:

a. Individuals ................................................... 6

b. Testing situations................................................ 7

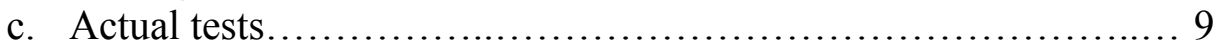

Reliability according to I/O constructs.......................... 12

Trends and reporting practices................................... 15

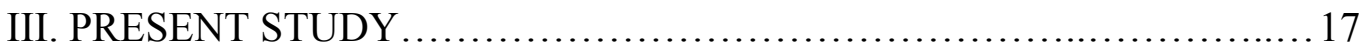

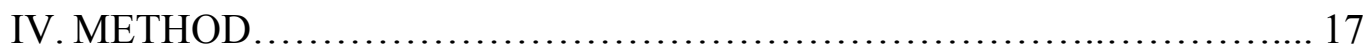

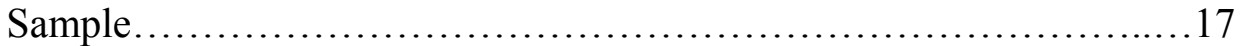

Coding procedure ................................................. 18

Analyses................................................................

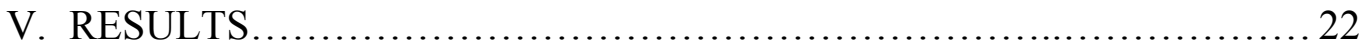

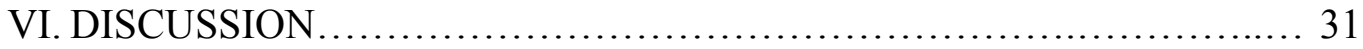

Recommendations for reliability precision......................... 41

Limitations and future research................................... 42

REFERENCES............................................................ 45

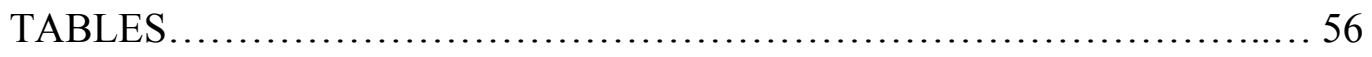




\section{LIST OF TABLES}

TABLE

PAGE

Table 1: Descriptive statistics for test-takers................................ 56

Table 2: Descriptive statistics for actual tests...............................6 60

Table 3: Means, standard deviations, and correlations among variables (data

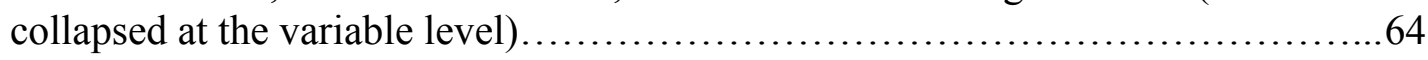

Table 4: Means, standard deviations, and correlations among variables (data collapsed at the construct group level).

Table 5: Summary of reliability and inter-item correlation coefficients

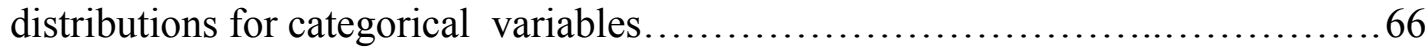

Table 6: Summary for regression analysis for predictive variables (data collapsed at the variable level)

Table 7: Summary for regression analysis for predictive variables (data collapsed at the construct group level)....

Table 8: Summary for regression analysis predicting inter-item correlations ......... 70

Table 9: Summary for regression analysis predicting reliability ................... 71

Table 10: Summary of I/O construct reliability and inter-item correlations coefficient distributions.

Table 11: Summary of scale-specific descriptives, reliability, and inter-item correlations coefficient distributions........................................... 75

Table 12: Summary for average reliability for I/O construct groups by year.........78

Table 13: Summary for average inter-item correlations for I/O construct groups

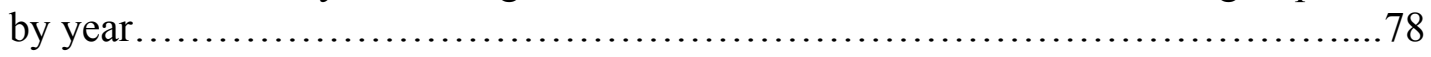

Table 14: Summary for regression analysis for trends among I/O constructs.........79

Table 15: Summary for variable missing data by year........................... 79

Table 16: Summary for regression analysis for trends in missing data............. 80

Table 17: Distribution of content in the Journal of Applied Psychology by year.....81 
Table 18: Summary of regression analyses for trends in content...................85 
THE STATE OF OUR TOOLBOX: A META-ANALYSIS OF RELIABILITY

\section{MEASUREMENT PRECISION}

\section{INTRODUCTION/LITERATURE REVIEW}

Industrial and organizational (I/O) researchers often measure unobservable human characteristics such as job attitudes, perceptions of various work features (e.g., fairness), and individual characteristics such as leadership capacity and personality. In order to provide meaningful information in regards to such abstract concepts, called latent constructs, psychometric tests are designed that are hypothesized to represent actual behaviors (i.e., by measuring their underlying construct). Yet, developing hypotheses and making inferences by eliciting these behaviors is not sufficient for adequate psychological measurement. Psychometric test scores that are ascribed to actual behaviors should exhibit two important properties: First, test scores should be consistent across different types of measurements, and second, test scores must lead to adequate interpretations of the underlying constructs under investigation. In other words, test scores should be reliable and valid and the users of test scores have to convince their audience that the scores adhere to specific statistical principles. The main overarching statistical principles are, defined by the taxonomy of Cook and Campbell (1976) and Scandura and Williams (2000), internal validity, external validity, construct validity, and statistical conclusion validity. The central focus of the present study pertains to issues of construct validity and the internal consistency of psychometric tests. Specifically, the goal was to meta-analytically examine measurement precision and reporting practices of item-level reliability used in I/O research. The current exploratory study consisted of an examination of the characteristics and research design choices that impact the precision 
of measurement tools and the development of benchmarks and commentary for the appropriate use and future improvements of psychometric tests.

\section{Classical Test Theory and Reliability Coefficients}

Measures of internal consistency derive from Classical Test Theory (CTT) and are meant to inform how two or more scores or conditions on a test are inter-related. Importantly, there are many factors that can affect the internal consistency of any estimate. For example, the passing of time, the use of different items, testing conditions, and individual differences can all contribute to measurement error. Before describing in detail the sources of error and their impact on reliability estimates, the following section reviews the development of these estimates and their proliferation in test usage.

In the early $20^{\text {th }}$ century, Spearman (1910) had devised the first recognized measure of internal consistency: the split-half procedure. The mathematical equation involved measuring the correlation of test items by separating them into odd and even numbers. For example, a 20 item test would be split into two columns of 10 items and the correlation of both column scores would be assessed. The Spearman method was sound but it did not allow for deeper level statistical evaluations because simple alterations to the formula provided inconsistent results. For example, instead of using odd and even numbers, correlating values derived from multiples of three would result in different coefficients estimates. Kuder and Richardson (1937) later developed the KR-20 measure (i.e., named after the $20^{\text {th }}$ formula in their seminal article) that resolved the split-half issue but their method was still limited because it could only be applied to binary values (e.g., data defined by zeros and ones such as 'yes/no' or 'agree/disagree'). In order to allow more widespread application of reliability estimates, Cronbach (1951), who was largely 
influenced by the work of Fisher (e.g., Fisher, 1918), developed a more general estimate of internal consistency called 'coefficient alpha' that could be applied to any form or test and allowed multiple mathematical permutations. Fisher, an English statistician and evolutionary biologist formulated the concept of analysis of variance (ANOVA) to determine optimal conditions for agricultural crop growth. Cronbach's coefficient alpha incorporated ANOVA principles and the KR-20 equation to create an estimate represented by a matrix of scores that could evaluate item relationships as well as multiple observers and/or observations.

Concurrent and subsequent advancements in CTT provided other ways to estimate reliability of test scores (e.g., various other coefficients of internal consistency, test-retest, form equivalence, etc.). However, the most commonly used reliability estimate today is Cronbach's alpha (Hogan, Benjamin, \& Brezinksi, 2000). According to Cronbach and Shavelson (2004), Cronbach's original article has been cited over five thousand times and approximately 350 times each year. As of August 2012, the article has been cited 17, 172 times (Google Scholar).

The widespread usage of Cronbach's alpha as well as other statistical tools in research studies is typically demonstrated through archival and simulation research efforts. Such meta-analyses allow researchers to keep track of past research practices, trace the use of methods and statistics over time, and envision future improvements. For example, to display the ubiquitous use of coefficient alpha, Peterson (1994) reviewed 24 journals and reported 4,286 alpha coefficients ranging between .06 and .90 with a median of .79. Rodriguez and Maeda (2006) conducted a meta-analysis of coefficient alpha and used mathematical adjustments to account for changes in alpha as a result of test length 
and observed score variance. Using general linear modeling, including ordinary least squares modeling analysis of variance and regression to determine variance among coefficient alphas, Rodriguez and Maeda conducted two studies to evaluate the efficacy of coefficient alpha in learning consistency. As an example, their first study included a sample of 67,821 students taking a mathematics test in different schools. The results yielded a coefficient alpha of .93 across schools indicating a high consistency of teaching standards.

Comparing psychometric tests and determining global estimates for measured constructs can also be achieved using validity generalization. On the basis of the same meta-analytic principles the particular method for internal consistency is reliability generalization (RG). Reliability analysis carried out through generalization theory allows for sampling from multiple sources as well as from test takers. The RG method permits measurement error to derive from multiple sources and the influence of these sources on a construct can be estimated. For example, researchers have applied RG to a variety of psychometric scales such as the UCLA loneliness scale (Vassar \& Crosby, 2008), the Life Orientation Test (Vassar \& Bradley, 2010), the Maslach Burnout Inventory (Wheeler, Vassar, Worley, \& Barnes, 2011), the Perception of Organizational Politics Scale (Miller, Byrne, Rutherford, \& Hansen, 2009), the Ways of Coping Scale (Rexrode, Peterson, \& O’Toole, 2008), the Survey of Perceived Organizational Support (Hellman, Fuqua, \& Worley, 2006), as well as to larger-scale constructs and their respective measures such as the Big Five Factors (Viswesvaran \& Ones, 2000). Although these studies provide useful aggregate data for scale interpretation, the current study focused on 
observed reliability coefficients rather than theory-generated coefficients, and primarily on observed coefficient alpha.

The formula for Cronbach's alpha is characterized by the number of components or items that measure a variable, the variance of scores on these components, and the sample size or number of responses to these components. Alpha is represented by the Greek letter ' $\alpha$ ' and the closer the alpha value is to one, the stronger the estimated internal consistency. According to Nunnally (1967), an acceptable reliability coefficient should be at least .70 and that is the generally accepted standard in basic research and scale development. In the realm of I/O psychology, certain psychometric tests are used for important personnel decisions and should be held to higher norms of reliability precision. In other words, higher coefficients should be required for important personnel decisions. The acceptable level of internal consistency should be relative to the importance of the consequences related to test use, calling for a need for reliability benchmarks or a depository of reliabilities for I/O constructs.

\section{Study Purpose}

The aim of my exploratory study was threefold. First, an investigation into individual influences of test-takers that can contribute to error and variance in reliability estimates was conducted. Individual characteristics such as the age, gender, and ethnicity of sample participants can elicit differences in how test-takers respond and therefore increase sample variance that contributes to measurement error and affects score reliability. Also, situational influences such as conducting field surveys or experimental lab studies and characteristics of the actual test such as the number of items and the range of scale responses were examined. Second, my study compared average levels of 
reliability estimates according to categories of constructs measured in order to supplement RG studies by developing a depository for I/O related reliability estimates. Specifically, reliability estimates were grouped into measures of behaviors, attitudes, personality traits, abilities, and health-related outcomes. The reliability and inter-item correlations of specific I/O variables within the five categories such as feedback seeking (behavior), job commitment (attitude), conscientiousness (trait), leadership (ability), and work stress (health-related outcome) were evaluated and compared. Third, I explored trends in regards to reliability precision and how reliability estimates are reported in peerreviewed journals in order to ensure and encourage adequate sharing and interpretation of reliability statistics. In short, the central theme of this study was to [1] explore the influence of (a) individual, (b) situational, and (c) test characteristics on internal consistency; [2] develop a summary and depository of reliabilities across types of I/O variables and construct groups, and; [3] examine trends in reliability precision and reporting practices.

\section{Characteristics that influence reliability estimates}

\section{1.a. Characteristics of individuals}

This first aim of the current study was to determine research study characteristics that can have an impact on reliability estimates. These include individual, situational, and test characteristics. Reliability is a feature of test scores and data rather than the administered instruments (Rowley, 1976; Crocker \& Algina, 1986; Eason, 1991). Davis (1987) and Thomson (1994) added that because total score variance is an important aspect of reliability the participants involved in studies will themselves affect score reliability. For instance, using a cognitive ability example, Thomson explained that the 
"same WISC-R that yields reliable scores for some adults on a given occasion of measurement will not do so when the same test is administered to first-graders" (p.2). Individual differences on reliability estimates have been found in previous RG studies. For example, in a study of the Survey of Perceived Organizational Support (SPOS), Hellman, Fuqua, and Worley (2006) found significant effects for age on reliability coefficients. These findings support a previous notion that there can be a positive relationship between age and certain work attitudes such as job satisfaction, job involvement, and organizational commitment (see Rhodes, 1983 for a review). Other RG studies also found that reliability varied in terms of individual characteristics such as gender (Caruso, 2000; Caruso, Witkiewitz, Belcourt-Dittloff, \& Gottlieb, 2001; Caruso \& Edwards, 2001; Beretvas, Suizzo, Durham, \& Yarnell, 2008) age (Caruso \& Edwards, 2001; Caruso, Witkiewitz, Belcourt-Dittloff, \& Gottlieb, 2001), and other individual features such as student and clinical samples (e.g., Caruso, 2000; Vacha-Haase, Kogan, Tani, \& Woodall, 2001). Another important feature of individual test-takers that has been less studied in terms of variation in reliability is the ethnic/cultural distribution of study samples and as such, the present study examined whether these characteristics had an impact on reliability coefficients.

\section{1.b. Characteristics of testing situations}

Researchers constantly have to make decisions on the methods they will use in order to test hypotheses and provide meaningful results that are reliable and valid. The resulting choices often involve considerations of feasibility, cost, duration, and adherence to ethical standards. Moreover, because there are inherent benefits and limitations within different methods, I/O researchers have to resolve the dilemmas that inevitably come 
with the methodological decisions they make (Stone-Romero, 2002). For example, choosing to conduct a lab experiment over a field study or using a questionnaire that was adapted and translated from another culture will provide advantages and disadvantages for certain types of validity. Lab experiments offer strict control over measurement constructs and provide strong internal validity but this strictness of research characteristics puts into question the generalizability (external validity) of the resulting data. On the other hand, conducting a field survey across organizations typically brings to mind issues of causality and common method variance rather than generalization problems associated with using student samples. In a meta-analysis of study limitations, Brutus, Gill, and Duniewicz (2010) found there are indeed correlations between methodological choices and different reported limitations. They found that the use of survey was positively associated with internal validity issues and negatively associated with external validity issues whereas experiments demonstrated the same relationships in opposite directions. The authors also found that low reliability was reported in five percent of their sample ( $N=1903$, from 1995 to 2008) and was significantly more often reported in surveys than other methods.

The testing environment can have special significance to test-takers. For example, if a test environment is perceived as being evaluative in nature, it is more likely that highanxious individuals experience threat perceptions and anticipate negative consequences that will affect their test performance (Sarason \& Pierce, 1995). As such, individuals may perceive high-stakes testing conditions such as those that involve personnel decisions (e.g., hiring and promotions) as anxiety evoking whereas typical student lab experiments may not elicit the same emotions that can lead to variance. Because lab experiments often 
use student samples that are more homogeneous than working samples, it is expected that reliability estimates will be higher for tests administered during lab experiments than for tests administered in the field and/or used alongside other non-survey methods such as interviews and observations.

Also, since it has been previously found that the language of administration can impact reliability (Caruso \& Edwards, 2001), my study compared reliability estimates reported in studies conducted outside of North America in order to determine whether or not construct measurement varied according to the area in which the psychometric test was administered (e.g., by losing reliability in translation or by geographical/cultural differences).

\section{1.c. Characteristics of actual tests}

Test characteristics that can contribute to error in measurement include the complexity of items (e.g., Traub, 1994), the number of test items (e.g., Caruso \& Edwards, 2001), and survey decisions such as the range of scale points (e.g., Anastasi, 1976; Eysenck, 1982; Covington \& Omelich, 1987). Because of the difficulty of comparing test difficulty in a global meta-analysis, my study focused on the number of test items and scale points.

The number of items in a measure has a direct impact on reliability. According to Cortina (1993), there is a tendency for reliability to increase as a function of the number of items in a psychometric scale. It is generally understood by the Spearman-Brown prophecy that adding similar items in a test increases internal consistency estimates. Psychometricians traditionally use the Spearman-Brown formula to determine scale reliability after changing the length of a scale. Because the relationship between test 
length and test reliability is nonlinear, the number of items required grows increasingly larger the more precise the desired reliability. The test length and reliability relationship indicates the importance of taking into account inter-item correlations because the true precision of alpha is measured in terms of the standard error of inter-item correlations. High inter-item correlations indicate that the items are measuring the same underlying construct and hence, as inter-item correlations increase, Cronbach's alpha increases as well (Kuder \& Richardson, 1937; Deese, 1959). Accounting for inter-item correlations is important because these correlations determine reliability while accounting for the number of items. For example, a measure with 30 items, with an inter-item correlation of .30 would yield a higher alpha $(\alpha=.93)$ than a measure of 10 items with an inter-item correlation of .50 $(\alpha=.89)$, though the inter-item correlations are much lower. As such, the current study also incorporated inter-item correlations as coefficient alpha by itself provides an incomplete assessment of scale reliability.

Another common theme in psychometric decisions is the range of scaled items. It has been previously speculated that the number of anchor points does not make much of a difference in terms of the internal consistency and stability of a scale (e.g., Komorita, 1963; Matell \& Jacoby, 1972; Shutz \& Rucker, 1975). On the other hand, Bass, Cascio, and O'Connor (1974) found that the percentage of overlap in test-takers' judgments of frequency increased as the number of anchor points increased, suggesting there may be an effect on reliability. Having more anchor points allowed for finer judgments that subsequently improved reliability estimates. In a computer simulation study of a clinical scale, Cicchetti, Showalter, and Tyrer (1985) found that dichotomous scales provided the lowest reliability and that reliability increased with the number of scale points but 
differences in reliability between seven-to-ten and 100-point scales were negligible. Symonds (1924) originally recommended seven categories as the optimal number of scale points (albeit for inter-rater reliability specifically) and Miller (1956) later supported this view by indicating that the human brain is limited to process around seven different items (plus or minus two), suggesting that adding more categories to scale items would not provide more useful information. Conversely, other researchers have suggested that the optimal number can be as high as 20 to 25 scale points (e.g., Guilford, 1954; Garner, 1960). Using a Monte-Carlo approach, Lissitz and Green (1975) simulated the effects of different numbers of scale points on three reliability measures. They found that coefficient alpha estimates leveled off after five scale points and recommended that researchers do not exceed five scale points because of the negligible increase in reliability precision. Oaster (1989) came to a similar conclusion with seven scale points in regards to test-retest and inter-item consistency. In terms of user preferences, Preston and Colman (2000) found that test-takers preferred scales with five, seven and 10 scale points over scales with 11 or more although the test-takers perceived that 11 and 101 scale points "allowed you to express your feelings [more] adequately" (p.11). In sum, although there is no general agreement on one optimal number of scale points, it seems that two or three scale points are inadequate in providing enough meaningful information and more than nine scale points provide minimal improvements in statistical precision (see Cox, 1980 for a review).

My study examined the characteristics of actual tests such as the number of test items and scale points on average inter-item correlations and reliability. Further, because few or no studies have examined the effects of the type of anchor scale used, this study 
compared reliability estimates and inter-item correlations according to different types of anchor scales (e.g., agreement, frequency, and magnitude). An additional consideration of this study was to determine whether the study authors themselves had an impact on reliability precision by recording their affiliation, or specifically, if they were researchers/academics, consultants/organization-based, or mixed.

\section{Reliability according to measured I/O constructs}

The second aim of the current study was to compare construct-level attributes because reliability estimates can also vary as a function of the constructs being measured. Variables in I/O research can be classified into construct categories and these categories could potentially be used as benchmarks for comparing reliability estimates. For example, Mischel (1969) made a compelling argument that behaviors are less stable than personality traits and therefore lower reliability estimates can be expected. The measurement of personality was argued to be represented by stable, reliable, and highly generalizable response patterns whereas the unreliability of behavioral measures was interpreted to be due to the inconsistent and unstable nature of human behavior, rater errors, and various methodological problems. Epstein $(1979,1980)$ later suggested that measurement error and reliability in behavioral assessments can be stabilized by aggregating ratings over situations and occasions. He found that measures of personality and attitudes had low correlations with single direct observations of behaviors and that reliability and stability increased when behavior was averaged over multiple events and ratings. Corresponding closely to the Spearman-Brown formula, aggregating data (e.g., over subjects, situations, stimuli, or time), reduces measurement error, improves reliability, and broadens the range of data generalizability. However, using an 
aggregation strategy, Henson, Kogan, and Vacha-Haase (2001) found substantial variation in reliability estimates of different scales for measuring teacher behaviors and effectiveness, supporting the notion that behaviors may indeed be less stable than other construct groups.

In accordance with Mischel (1969), if personality traits are more stable and enduring than behaviors and abilities, then the tools researchers use to measure stable constructs should demonstrate similar psychometric stability and precision. In fact, previous studies have shown the opposite. Caruso (2000) found a large amount of variability in reliability estimates of NEO personality scales. Specifically, agreeableness provided the lowest reliability estimates, especially for males and clinical samples. In other RG studies, researchers found an effect of age and student sampling to contribute to variation in reliability scores of the Eysenck Personality Questionnaire (Caruso, Witkiewitz, Belcourt-Dittloff, \& Gottlieb, 2001) as well as scale length, gender, language of administration, and age for the Junior Eysenck Personality Questionnaire (Caruso \& Edwards, 2001). Vacha-Haase, Kogan, Tani, and Woodall (2001) found that reliability varied in terms of age, clinical/non-clinical samples, and different versions of the Minnesota Multiphasic Personality Inventory (MMPI). Reliability was also found to vary (e.g., due to gender effects) in a study comparing locus of control scales (Beretvas, Suizzo, Durham, \& Yarnell, 2008). These research examples indicate there is at least some instability in reliability estimates within personality measurement.

There are fewer RG studies that have examined constructs within the realms of behaviors, abilities, and attitudes. Surprisingly, considering that one of the most relevant and studied variable in I/O research is job performance (Campbell, Gasser, \& Oswald, 
1996). Viswesvaran, Ones, and Schmidt (1996) found reliability differences between peer and supervisor ratings as well as between interrater and intrarater ratings of job performance. Also, as mentioned, Henson, et. al. (2001) found variations among different measures of teacher effectiveness. Their data allowed the authors to determine which scales were most biased by low reliability as a consequence of sampling (e.g., in this case, gender) and psychometric properties to make recommendations for which scales best represent the underlying construct (e.g., teacher effectiveness). It was also previously mentioned that cognitive ability had a direct relationship with reliability and as such, it is expected that like behaviors, ability measures are often involved in evaluative decisionmaking (e.g., hiring/promotion) and are prone to response and rater errors. In the current study, it was expected that behaviors and abilities constructs would yield lower reliability estimates than personality and attitude constructs.

In terms of attitudes, Wallace and Wheeler (2002) provided support for the stability of this type of construct. In an RG study of the Life Satisfaction Index (LSI), the authors found adequate average reliability across studies, and found no significant effect of other sample or psychometric attributes (e.g., age, gender, ethnicity, language, number of items, length of scale, etc.). The authors did mention that an important limitation to their findings was missing data and poor reporting practices. Fittingly, in the study by Henson and colleagues (2002), the authors also conceded that their results may have been inflated by poor reporting practices, noting that many studies in their sample did not report reliability estimates and/or relied on past estimates in validation studies. The current study compared reliability estimates and inter-item correlations among categories of I/O constructs including: behaviors, abilities, attitudes, personality traits, and health- 
related outcomes and examined trends and reporting practices such as missing data, discussed next.

\section{Trends in internal consistency precision and reporting practices}

The final aim of the current study was to explore trends in reliability precision and reporting practices as well as to offer recommendations for improvements in the communication and interpretation of estimates. With the passing of time, technological and theoretical advances should improve the precision of psychometric assessments, assuming that researchers are motivated by achieving scientific rigor and work on improving the measurement of psychological constructs. Better scales and higher standards/benchmarks for reliability estimation should be apparent over time and as such, it was expected that, generally, construct measurement in terms of reliability precision improved over time.

Examining trends in precision will most likely be affected by statistics reporting practices. It is not a novel concept that researchers have argued that many scales described in various journals articles do not include adequate reports of psychometric properties (e.g., Vacha-Haase, Kogan, \& Thompson, 2000; Henson, 2001; Meier \& Davis, 1990; Wilson, 1980). For example, Vacha-Haase, Kogan, and Thompson (2000) argued that many researchers practice 'reliability induction', that is the process of relying on test manual or test validation reliability coefficients for actual study data. Henson (2001) added that few studies report adequate psychometric data that can be useful for future meta-analytical efforts. In a study on reliability reporting practices, Meier and Davis (1990) found an alarmingly low number of reported estimates in a counseling journal, although they did notice an increase over time. Fortunately, some journals are 
more stringent in regards to data reporting practices. Journal editors increasingly recognize the weakness in publication manuals and encourage authors to report adequate coefficients and effect size information (Baugh, 2000). For example, in an editorial on policies of the Journal of Applied Psychology, Murphy (1997) declared "So far, I have not heard a good argument against presenting effect sizes. Therefore, unless there is a real impediment to doing so, you should routinely include effect size information in the papers you submit" (p. 4). Baugh (2000) also noted that although reporting effect size is becoming increasingly recognized as a necessary practice, many researchers do not fully understand the critical factors that determine these estimates. Score reliability is one such factor that is fundamental in statistical measurement and can have a potentially detrimental influence on effect size interpretations (Henson, 2001).

Aside from the general prescription of publication manuals for researchers to report score reliability in their findings, little attention has been given to the appropriateness of reliability estimate reporting in order to allow for adequate coefficient interpretation and future meta-analytical use. Meier and Davis (1990) made the following observations to researchers: First, many authors use the term 'internal consistency' loosely when reporting estimates. Internal consistency covers various different techniques including split-half, KR-20, coefficient alpha, as well as other techniques based on analysis of variance models. They recommended that journal editors insist that authors identify the specific reliability method employed. Second, in accordance with Henson (2001), because the source of many reliability estimates are unclear, readers may make the erroneous assumption that the estimate derived from the study cited. Hence, they recommended that authors explicitly report their own estimates because reliability is not a 
characteristic of psychometrics but rather of individual test scores. Reliability estimates differ in accordance to changes in sample composition and/or score variability and researchers should compare their estimates with the sample composition and score variability of previously reported coefficients (Thomson \& Vacha-Hasse, 2000). Another recommendation offered by Meier and Davis (1990) is to reinforce reader understanding

of sampling variance by encouraging authors to routinely report confidence intervals and their related estimation methods alongside test score reliability. If such discussions on reliability reporting have had an impact on actual reporting practices, then the proliferation of using precise coefficient terms, reporting current study estimates, and even reporting effect sizes should be apparent over time. My study examined such trends in reliability reporting practices.

\section{PRESENT STUDY}

Overall, my study describes the state and trends of reliability estimation in $\mathrm{I} / \mathrm{O}$ research. Advantages of examining the state of reliability include adding to our understanding of characteristics that influence test reliability and the development of benchmarks for I/O construct measurement through a depository of reliability estimates. Advantages of analyzing the trends in reliability include determining the level of progress in reliability measurement precision and the evolution of statistical data reporting practices.

\section{METHOD}

\section{Sample}

Journal articles that report reliability coefficients were collected using the electronic database 'PsycArticles'. The sample consists of all the articles published in the 
Journal of Applied Psychology during the years 1975, 1980, 1985, 1990, 1995, 2000, 2005, and 2010. The target journal was selected because of its' reputation for publishing influential articles in I/O psychology (Zickar \& Highhouse, 2001) and hence should adhere to stricter guidelines for reporting statistical information. The decision to sample data every five years provided the opportunity to go back a longer period of time in an attempt to capture changes of measurement precision over time while maintaining a manageable number of articles to be coded. Only quantitative research articles that included at least one psychometric survey were coded, thus qualitative articles, book reviews, and other commentaries were excluded. Out of the 773 articles published, 480 articles met these criteria and were included in the present study yielding 1427 coefficients from 934 samples. Further, because a small number of articles used the same sample and in order not to violate the assumption of independence, data were aggregated and reported at the sample level for each variable (e.g., turnover intentions) and construct group (e.g., behaviors) level. Specifically, reliability and inter-item correlations estimates were aggregated to ensure each level of analysis did not violate the assumption of independence.

\section{Coding procedure}

I conducted the coding in this study. Thirty studies that met the selection criteria were chosen randomly and coded by a subject matter expert (SME; e.g., advanced doctoral student) to establish preliminary coder inter-reliability. Coder agreement was estimated using Cohen's kappa, a statistical measure for inter-rater agreement for categorical variables (Fleiss, 1971). Thus inter-rater agreement was determined as disagreement vs. agreement for each piece of information coded (e.g., $0=$ disagreement, 
$1=$ agreement). As a consequence of the objective nature of the study variables (e.g., sample sizes, coefficient estimates), inter-rater agreement was relatively high $(K=.89)$ following the guidelines of Landis and Koch (1977) and instances of disagreement were discussed and resolved in order to improve subsequent coding. Thus, having the coding performed by one individual in this study seemed sufficient. Content analysis was used to transform textual material into quantifiable data. Content analysis has become a common approach for transforming textual information into interpretable data (Patton \& Johns, 1997). Coding included the following variables:

\section{a) Sample size and descriptive variables}

The number of participants of each sample was recorded alongside any descriptive information about the sample. Specifically, sample mean age, sample gender distribution (e.g., percentage of female participants), ethnicity distribution of the sample (e.g., percentage of White participants), whether the sample was comprised of students, and whether the study was conducted inside or outside of North America were coded. In addition, in order to provide additional information and a more robust index of participants' age, the standard deviation of age was recorded when reported. Finally, author affiliation was coded using a method for multiple authors similar to that used by Silzer and Parson (2012), which indicates whether authors are academic/researchers only, consultant/organization-based authors only, or a mix of both.

\section{b) Test characteristics}

The number of items used to measure each variable and the number of scale points was recorded. Also, the type of scale used (e.g., agreement, frequency, magnitudeextent, and quality) was coded. For example, an author reporting items measured on a 
seven point Likert-type scale ranging from (1='not at all' to 7='to a great extent') was coded as seven anchor points in a magnitude-extent scale.

\section{c) Construct characteristics}

The variables measured (e.g., as reported by the study authors) were recorded and then classified into the five main construct categories: Behaviors, abilities, personality traits, attitudes, and health outcomes. The classification of variables into construct groups was performed by two independent SME's (e.g., the author and the same doctoral student used for coder reliability). For a more exhaustive inclusion of $\mathrm{I} / \mathrm{O}$ variables, the classification was conducted post-hoc. The list of measured variables was generated from literature and the data and then the two SME's separated the most commonly measured variables into their respective construct groups. Coder agreement was verified using Cohen's kappa. Total agreement was relatively high $(K=.83)$ and instances of disagreement were discussed and resolved in order to improve the distribution of variables in their respective groups.

\section{d) Reliability characteristics}

The type (e.g., KR-20, coefficient alpha) and estimated reliability (e.g., .70, .95) for each study variable was recorded. On the basis of this information and the number of items used to measure a variable, average inter-item correlations were also calculated using the appropriate mathematical permutations.

\section{e) Reporting style}

The presentation and communication of reliability estimates were recorded by coding whether a study author used actual coefficient terms or vague descriptions such as internal consistency. Also, whether authors explicitly reported that reliability estimates 
derived from actual study data or from previous validation studies or test developers was coded. Coefficients that did not correspond to actual study samples were omitted from analysis. Missing information at the level of any variable was also recorded and analyzed over time by transforming all values into binary code (e.g., and value $=$ ' 1 ' for present and ' 0 ' for absent).

\section{Analyses}

Reliability coefficients and their properties (e.g., sample and test characteristics) were first cumulated and descriptive information was generated to indicate the numbers and types of studies in the sample in relation to all variables. Exploratory analyses were conducted using a variety of statistical techniques. For example, reliability differences among categorical variables (e.g., I/O construct group, type of anchor scale) were evaluated by examining the means, standard deviations, and 95\% confidence interval overlap of reliability and average inter-item correlation coefficients (as in Visweswaran $\&$ Ones, 2000). The sampling error associated with the coefficients was calculated as the standard deviation divided by the square root of the number of estimates. A matrix of correlations was computed to determine relations among scale variables (e.g., age, gender, number of items, etc.). The predictive power of all scale variables on reliability outcomes was determined using regression analysis. Regressions were used to statistically demonstrate whether specific sample or test characteristics had a unique or incremental predictive impact on reliability estimates. Using regressions analyses allowed for linear modeling that determined which variable(s) best fit(s) the data and predicted the magnitude of score reliability. Regression analyses were also used to measure trends 
over time. Subsequent analyses using this method were also used to determine any trends at the discrete variable level such as specific scales used and journal content analysis.

Finally, because of the exploratory nature of this study, power analyses were conducted in order to determine the likelihood of making statistical inference errors and avoid making erroneous inferences. 'Type I' errors occur when a true null hypothesis is rejected and 'Type II' errors occur when a false null hypothesis is not rejected (see Cohen, 1994, Sedlmeier \& Gigerenzer, 1989, and Zwick \& Marascuilo, 1984 for reviews). Determining statistical power, in this case, consisted of estimating effect sizes (e.g., small, medium, or large) derived from hypothesis criteria (e.g., null hypothesis or small/medium-effect test), and the desired level of power using the $F$ statistic. Statistical packages such as SPSS provide the $F$ statistic for regressions so mathematical permutations following the work of Murphy and Myors (1998) were conducted to solve for $F$ in correlational data (e.g., by computing and applying the correlation coefficient and the degrees of freedom). In order to determine acceptable power, the resulting $F$ statistic was compared to Murphy and Myors (1998) One Stop F Table describing power estimates below .50 (low effect), between .50 and .80 (moderate effect), and above .80 (large effect).

\section{RESULTS}

The present study results include a description of data regarding [1] study characteristics such as those of test-takers, research settings, and actual tests, [2] a metaanalytic summary of reliability estimates according to study variables, and [3] an examination of trends and reporting practices. In addition, the data were collapsed in terms of the appropriate level of analysis in order to avoid violation of the independence 
assumption, namely at the level of the construct group (e.g., behaviors) and at the level of each individual variable (e.g., turnover intentions). Notably, statistics such as means and standard deviations described below are unweighted meta-analytic means, SD's, etc. According to Fuller and Hester (1999) the unweighted method provides a more conservative meta-analytic approach when generating observed variance and mean sample variance, while offering larger confidence intervals, especially when accounting for large sample outliers (in accordance with Osburn \& Callender, 1992). Fuller and Hester (1999) concluded that the unweighted method had negligible differences over the weighted-sample method unless moderation-mediation models were utilized.

\section{Characteristics of test-takers, research settings, and actual tests}

Descriptive statistics regarding test-takers samples are summarized in Table 1. The most common construct groups measured were attitudes $(\mathrm{K}=501)$ and behaviors $(\mathrm{K}=372)$. When the data were collapsed at the construct group level, the largest sample sizes were in abilities $(M=843.7$, Median $=220.5)$ and attitudes $(M=652.8$, Median $=$ 256.0); the average age of participants was between 31.7 and 35.4 years, the average percentage of females ranged from $47.8 \%$ to $55.7 \%$, and the average percentage of White participants ranged from $59.5 \%$ to $69.3 \%$.

Notably, when the data were collapsed at the variable level and at least 10 samples were recorded, the youngest participants (27.2 years) were in personality measures of self-efficacy and the oldest (36.6 years) were in health outcome measures of role conflict/role ambiguity; the highest proportion of females $(90.2 \%)$ involved behavioral harassment measures, and the lowest (38.4\%) involved trust ability measures. In terms of ethnic distribution, the highest proportions of White participants were in 
measures of harassment and cognitive ability ( $75.3 \%$ and $72.7 \%$, respectively) and the lowest were in measures of job performance $(48.0 \%)$.

Descriptive statistics for test characteristics are summarized in Table 2. The number of items used to measure variables ranged from two to $300(\mathrm{M}=9.1, \mathrm{SD}=14.1)$ and the number of scale anchor points ranged from two to $100(\mathrm{M}=5.9, \mathrm{SD}=3.3)$. Notably, when there were at least 10 samples in the population, the highest number of items was used to measure cognitive ability $(\mathrm{M}=52.5, \mathrm{SD}=65.7)$ and the lowest number of items was used to measure distributive justice $(\mathrm{M}=3.6, \mathrm{SD}=1.5)$. Although the range of anchor points was 98 , the most commonly measured variables used five or seven anchor scale points ( $\mathrm{N}=256$, or $26.23 \%$ of all reported anchor points).

To demonstrate the effects of individual and test characteristics on reliability and average inter-item correlations, the overall means, standard deviations, and intercorrelations (pairwise) are reported in Table 3, in which the data were collapsed at the variable level, and Table 4, in which the data was collapsed at the construct group-level. Notably, the number of items and reliability were significantly correlated both at the variable-level, $r(1235)=.12, p<.01$, and at the construct group-level, $r(818)=.12, p<$ .01. Further, when the data were collapsed at the variable-level, reliability correlated significantly with gender, $r(1132)=.09 p<.01$ as well as ethnicity, $r(408)=-.10 p<.05$; when the data were collapsed at the construct group-level, reliability correlated significantly with gender, $r(731)=.13 p<.01$, but not with ethnicity, $r(262)=-.09 p=$ ns. However, this change in significance is most likely due to a decrease in sample size and thus power (e.g., $r(408)=-.10 p<.05$ vs. $r(262)=-.09 p=n s$ ). Further, in terms of power, the correlations among ethnicity and reliability and average inter-item correlations 
were below .50. Using a standard for no effect (e.g., to reject the null hypothesis) and an alpha of .01 , power was above .80 for the correlation between gender and reliability.

In order to determine differences in categorical variables, reliability and average inter-item correlation estimates distributions were constructed and are summarized in Table 5. Categorical variables include the construct groups (e.g., behaviors, abilities, personality traits, attitudes, and health outcomes), author affiliation (e.g., academic, consultant, and mixed), primary research method (e.g., survey, experimental, interviews, archival, and simulations), student sample or workers, scale type (e.g., agreement, frequency, magnitude, and quality), study location (e.g., North America or outside), and whether coefficients were presented in-text only or also in a chart.

In terms of research properties, the $95 \%$ confidence interval overlap suggests no significant difference between students and workers, whether surveys were used alone or in combination with other methods, whether coefficients were reported in-text or in a chart, and whether the study was conducted in North America or elsewhere. In terms of author affiliation for reliability, there was no overlap between confidence intervals of academic authors $(\mathrm{M}=.82, \mathrm{SD}=.11)$ and consultant authors $(\mathrm{M}=.69, \mathrm{SD}=.14)$. Also, there was no overlap in confidence intervals for inter-item correlation estimates of the magnitude-extent type of anchor scale $(\mathrm{M}=.55, \mathrm{SD}=.18)$ compared to frequency $(\mathrm{M}=$ $.46, \mathrm{SD}=.16)$ and agreement $(\mathrm{M}=.45, \mathrm{SD}=.18)$ types.

In order to determine the predictive strength of the combination of scale variables on reliability and average inter-item correlations, regression analyses (conducted listwise in order to allow for more predictive variables) were conducted and summarized in Tables 6 through 9. Table 6 demonstrates regression results for predictive variables when 
the data were collapsed at the variable level and Table 7 when the data were collapsed at the construct group level. Notably, sample size, $\beta=0.14, t(233)=2.17, p=.03$ predicted reliability estimates. The model also explained a significant proportion of reliability, $R^{2}=$ $.06, F(7,233)=2.13, p=.04$. Sample size $\beta=0.18, t(236)=2.81, p<.01$ and the number of scale points $\beta=0.17, t(236)=2.67, p<.01$ predicted average inter-item correlations.

The model also explained a significant proportion of average inter-item correlations, $R^{2}=$ $.07, F(6,236)=2.81, p=.01$. In terms of power, the models for predicting reliability and average inter-item correlations were only above .50 when the null effect size was estimated.

Regression analyses using the same predictive variables were conducted for each construct group and its' individual variables. Ethnicity and student samples were omitted in analyses at the variable level because of small samples. Also, number of items was omitted as a predictor of inter-item correlations because the number of items is directly related to estimating average inter-item correlations. There were no significant effects for any construct group and all significant results for individual variables are summarized in Table 8 for inter-item correlations and Table 9 for reliability estimates. In order to provide stable measurements, only variables with ten or more estimates were analyzed.

\section{Reliability according to measured $\mathrm{I} / \mathrm{O}$ constructs}

Descriptive statistics and distributions of reliability estimates and average interitem correlations for $\mathrm{I} / \mathrm{O}$ variables and construct groups are summarized in Table 10. In terms of construct groups, the highest reliability estimates $(\mathrm{M}=.82, \mathrm{SD}=.10)$ and average inter-item correlations $(\mathrm{M}=.48, \mathrm{SD}=.02)$ were for attitude measures. The lowest average inter-item correlations were for personality measures $(\mathrm{M}=.37, \mathrm{SD}=.15)$. 
The $95 \%$ confidence overlap for reliability estimates suggests no significant differences among construct groups. There was no confidence interval overlap for average inter-item correlations between personality $(\mathrm{M}=.37, \mathrm{SD}=.15)$ and all other construct groups suggesting that inter-item correlations for personality trait measures were significantly lower than measures of behaviors, abilities, attitudes, and health outcomes.

At the individual variable level when at least five samples were coded $(\mathrm{K}>=5)$, the highest reliability $(\mathrm{M}=.87, \mathrm{SD}=.09)$ and average inter-item correlations $(\mathrm{M}=.66$, $\mathrm{SD}=.20$ ) for behaviors involved measures of effort while the lowest reliability involved withdrawal from work $(\mathrm{M}=.70, \mathrm{SD}=.10)$ and the lowest average inter-item correlations involved ingratiation $(\mathrm{M}=.18, \mathrm{SD}=.08)$. For abilities, the highest reliability estimates were for measures of empowerment $(\mathrm{M}=.90, \mathrm{SD}=.07)$, the highest average inter-item correlations were for trust $(\mathrm{M}=.55, \mathrm{SD}=.12)$ while the lowest estimates involved cognitive ability (reliability $\mathrm{M}=.78, \mathrm{SD}=.17$; average inter-item correlations $\mathrm{M}=.17$, $\mathrm{SD}=.23)$. For personality traits, the highest reliability estimates were for negative affect $(\mathrm{M}=.85, \mathrm{SD}=.05)$ and measures of self-efficacy had the highest average inter-item correlations $(\mathrm{M}=.42, \mathrm{SD}=.14)$. Measures of locus of control had the lowest reliability $(\mathrm{M}=.69, \mathrm{SD}=.12)$ and measures of openness to experience and agreeableness had the lowest observed average inter-item correlations at $.24(\mathrm{SD}=.11, .15$, respectively). For attitudes, interactional justice had the highest reliability $(\mathrm{M}=.88, \mathrm{SD}=.04)$ and measures of distributive justice had the highest average inter-item correlations $(\mathrm{M}=.67$, $\mathrm{SD}=.20$ ) while engagement had the lowest estimates (reliability $\mathrm{M}=.71, \mathrm{SD}=.25$; average inter-item correlations $\mathrm{M}=.36, \mathrm{SD}=.19$ ). For health outcomes, measures of anxiety had the highest reliability $(\mathrm{M}=.90, \mathrm{SD}=.03)$ and measures of depression had 
the highest average inter-item correlations $(\mathrm{M}=.54, \mathrm{SD}=.09)$ whereas measures of work demands had the lowest estimates (reliability $\mathrm{M}=.73, \mathrm{SD}=.21$; average inter-item correlations $\mathrm{M}=.41, \mathrm{SD}=.12$ ).

Descriptive statistics and distributions displaying the number of items and scale points as well as means, standard deviations, and $95 \%$ confidence intervals for reliabilities and average inter-item correlations for specific scales are summarized in Table 11. Authors that used various versions of Costa and McCrae's (1992) NEO personality inventory to measure agreeableness had the highest number of items ( $M=$ $20.5)$ and had the second lowest average inter-item correlations $(\mathrm{M}=.14)$ behind Bateman and Crant's (1993) measure of proactive personality $(M=.13)$. Hom, Griffeth, and Sellaro's (1984) measure of turnover used the least number of items $(\mathrm{M}=2.3)$ and had the highest average inter-item correlations $(\mathrm{M}=.73)$. In terms of reliability, Caplan, Cobb, French, Harrison, and Pinneau's (1975) measure of job stress had the highest estimates $(M=.95)$ whereas Bateman and Crant's (1993) measure of proactive personality had the lowest estimates $(\mathrm{M}=.68)$. An observation of confidence interval overlap indicated a few significant differences among individual scales but the small number of samples suggests these differences should be interpreted with caution. Notably, when there were at least 10 observed samples $(K>10)$, there was no confidence interval overlap between average inter-item correlations of Smith, Kendall, and Hulin (1969) and Hackman and Oldham's (1975) measures of job satisfaction $(\mathrm{M}=.32, .51$; SD $=.14, .12 ; \mathrm{K}=12,12$, respectively) suggesting that Hackman and Oldham's measure had significantly higher average inter-item correlations. 


\section{Trends in internal consistency precision and reporting practices}

Tables 12 and 13 describe means and standard deviations for reliability and average inter-item correlations, respectively, by year and for each construct group. Among all construct groups, the lowest means for both reliability and average inter-item correlations were found in earlier years. For example, in 1975, measures of behaviors (M $=.73, \mathrm{SD}=.12)$, abilities $(\mathrm{M}=.76, \mathrm{SD}=16)$, personality $(\mathrm{M}=.67, \mathrm{SD}=.06)$, attitudes $(\mathrm{M}=.79, \mathrm{SD}=.10)$, and health outcomes $(\mathrm{M}=.73, \mathrm{SD}=.17)$ were all significantly lower than in 2010 during which means for behaviors $(\mathrm{M}=.85, \mathrm{SD}=.07)$, abilities $(\mathrm{M}=$ $.86, \mathrm{SD}=.07)$, personality $(\mathrm{M}=.83, \mathrm{SD}=.07)$, attitudes $(\mathrm{M}=.84, \mathrm{SD}=.09)$, and health outcomes $(\mathrm{M}=.82, \mathrm{SD}=.06)$ were all significantly higher. Subsequent trends analyses using linear regression resulted in a main effect for the passing of time. Each variable listed received a separate regression over the year of publication. Table 14 summarizes these regression analyses, indicating that both reliability estimates, $\beta=0.30, t(932)=$ 9.52, $p<.01$, and average inter-item correlations, $\beta=0.26, t(844)=7.95, p<.01$, increased as a function of time. Further, using year of publication as the predictor variable explained a significant proportion of reliability, $R^{2}=.09, F(1,932)=90.70, p<$ .01 , and average inter-item correlations, $R^{2}=.07, F(1,844)=63.23, p<.01$. Power for reliability over time was above .80 when estimating for a small to moderate effect size (five percent of variance) at an alpha level of .05 and power was above .80 for average inter-item correlations over time when a small effect size (less than one percent variance) at an alpha level of .01 was estimated.

Next, results concerning authors' reporting format of reliability coefficients, missing data, and content analysis are described. In terms of reporting format, most 
authors explicitly identified the type of coefficient they used. Specifically, the coefficients identified in for all samples included percentages $(N=2), K R 20(N=14)$, and coefficient alpha $(\mathrm{N}=788)$. Notably, in 17 cases or $2 \%$ of the sample, the coefficient was undeclared and, in 91 cases or $10 \%$ of the sample, the authors used terms such as 'internal consistency' or 'reliability' instead of the actual coefficient type.

In terms of missing data, the data were transformed to binary values (e.g., ' 0 ' when a value was absent and ' 1 ' when a value was present). Means and standard deviations for missing data by year are summarized in Table 15. Overall, the sample distribution in terms of ethnicity (corresponding to $24 \%$ of reliability estimates) and the type of anchor scale used (52\%) were the least present. The number of items (84\%) to measure each variable was the most present. Table 16 demonstrates regression analyses for trends in missing data. Each variable listed for missing data had a separate regression over the year of publication. For all relevant variables, there was a significant decrease in missing data over time. For example, the reporting of sample ethnicity distribution increased over time, $\beta=0.05, t(931)=6.38, p<.01$ and the passing of time explained a significant proportion of the data $R^{2}=.04, F(1,931)=40.66, p<.01$. In other words, over time, authors have increased the reporting of relevant sample and test characteristics.

Finally, in order to demonstrate trends in the proportion of $\mathrm{I} / \mathrm{O}$ content measured, Table 17 describes the number and percentage of content by year for each variable and construct group in the sample and Table 18 summarizes regression analyses for trends in the frequency and percentage of overall content that were statistically significant. Measures of affect (e.g., negative and positive), the Big-Five personality traits, justice (e.g., procedural, distributive, and interactional), and commitment (e.g., goal, affective, 
continuance, and organizational) were collapsed (e.g., to have only one reliability estimate per sample) into their respective global constructs in order to increase the sample size. Over time, there was a significant increase in the percentage of overall content for measures of OCB's $(\beta=0.81, p<.05)$, charisma $(\beta=0.73, p<.05)$, the BigFive personality traits $(\beta=0.92, p<.01)$, justice $(\beta=0.88, p<.01)$, work-family conflict $(\beta=0.78, p<.05)$, and perceptions of job alternatives $(\beta=0.05, p<.01)$, as well as a decrease in dependability measures $(\beta=-0.78, p<.05)$ and overall health outcome measures $(\beta=-0.24, p<.05)$.

\section{DISCUSSION}

The present study demonstrates some interesting aspects of survey reliability precision for research articles published in the Journal of Applied Psychology. The results identify various characteristics that have an impact on reliability precision and provide a depository delineating these characteristics for the most commonly measured variables in I/O psychology. Importantly, the findings suggest that test characteristics such as the number of items and the type of anchor scale used have a greater impact on reliability than sample demographics (e.g., gender, age, ethnicity, and students vs. workers) and study settings such as using surveys alone or alongside experiments and interviews, and whether the study was conducted in North America. The following sections review and discuss findings concerning characteristics that influence reliability, differences among construct groups and variables, as well as trends and reporting practices. Specifically, it appears that psychometric surveys in this study show negligible bias towards individuals. Rather, it is the number of items and the type of anchor scale points that influence reliability the most. Next, a rationale is provided for findings regarding characteristics of 
test-takers, testing situations, and actual tests. Then, the depository of reliability precision is discussed, trends in reliability estimation and reporting practices are interpreted, and recommendations for data reporting are provided. Finally, limitations of the current study are provided alongside suggestions for future research.

\section{Characteristics of individual test-takers (sample-level)}

Participant age did not have any predictive impact on reliability and although gender and ethnicity were found to be correlated with reliability, gender did not correlate significantly with average inter-item correlations and the correlation between ethnicity and reliability became non-significant when the data were collapsed at the construct group level. One possible explanation of these inconsistent findings is that analyses of ethnicity and average inter-item correlations data both suffered from missing data and hence, smaller samples were analyzed. Another explanation concerns sources of measurement error relating to individual differences such as cognitive strain and test anxiety. Because individuals tend to vary in terms of cognitive ability and anxiety, sample demographics such as gender, age, and ethnicity were expected to contribute to responding differences (e.g., error) that impact the reliability of test scores.

Guion (1965) argued that respondents with low cognitive ability tend to yield lower reliability scores due to frustration resulting in random responding. Using a military sample, Stone, Gueutal, and Stone (1990) assessed differences in reliability determining cognitive ability (e.g., using the Wonderlic test) on a variety of attitude variables such as job satisfaction and job commitment. The authors found a significant effect of cognitive ability on reliability estimates in 14 out of 27 measures, indicating that cognitive ability can have an effect on reliability measurement precision. In terms of 
demographics, there is little evidence for gender differences in cognitive ability but in terms of ethnicity, Whites typically outperform Black and Hispanic test takers on cognitive ability tests (e.g., Berry, Clark, \& McClure, 2011). If these ethnic differences in cognitive ability truly have an impact on reliability, the current study found evidence of the opposite. In fact, ethnicity correlated with reliability in an unexpected direction. NonWhites yielded slightly higher reliability estimates, but only when their data were collapsed at the variable level. Given the relatively small effect sizes, these findings suggest that ethnic differences may not impact reliability a great deal for $\mathrm{I} / \mathrm{O}$ variables, putting into question the relationships between cognitive ability and ethnicity in regards to the reliability of workplace measures.

In terms of anxiety, according to Lazarus (1993), test-anxious individuals tend to react with negative perceptions, reduced feelings of self-efficacy, and intense emotional reactions to the potential threat of low performance such as the associated consequences of failure. Blacks and Hispanics have been found in numerous studies to be more testanxious due to various socializing factors contributing to negative test attitudes (e.g., Phillips, 1975, Samuda, 1975, Hill \& Wigfield, 1984; Zeidner \& Safir, 1989). Also, women are typically said to be more sensitive to evaluation situations than men and as a consequence show more test anxiety yet previous meta-analytical findings (e.g., Hembree, 1988; Benson, et. al., 1992) and the current study results suggest modest gender group differences. In fact, Women, as with non-Whites, yielded slightly higher reliability estimates but gender did not have an effect on average inter-item correlations (e.g., that are a more robust estimate of reliability precision). Elderly subjects have also been understood to be more anxious than their younger counterparts, especially in 
cognitive ability tests, due to their perceptions of declining abilities. Yet, previous experimental findings suggest that test anxiety may not affect the performance of elderly subjects a great deal more than younger persons (e.g., Mueller, Kausler, Faherty, \& Oliveri, 1980). The current meta-analytic findings did not find a significant effect of age on overall reliability estimates and average inter-item correlations. As such, these findings suggest that although there may be individual differences in anxiety, these differences have modest, if any, impact on reliability estimates and current power analyses support this notion.

Power analyses provided support for a minimal effect of test-taker characteristics on reliability and average inter-item correlations. For example, although the correlation between gender and reliability achieved acceptable power when estimating a null effect, simply rejecting the null hypothesis has been criticized because of the implausibility that a treatment has no effect whatsoever (Murphy, 1990). In the current study, the effect of age, gender, and ethnicity on reliability did not achieve acceptable power when the effect size was estimated to be less than $1 \%$ of variance explained, indicating that sample characteristics have a negligible effect on the reliability of most I/O survey measures.

\section{Characteristics of testing situations}

It was previously mentioned that testing environments that are perceived as evaluative in nature can have an impact on test performance (Sarason \& Pierce, 1995). Typical lab experiments that use student samples were expected to elicit higher reliability estimates, yet the results of the current study did not find support for any differences between student and working samples in terms of reliability precision. Also, there were no differences in terms of study design. Neither reliability estimates nor average inter- 
item correlations were significantly different when survey measures were administered alongside other research methods. Inter-item correlations effectively control for test length but there were no significant differences in the number of items between surveys administered alone or alongside experimental procedures or interviews. It has been previously suggested that surveys make greater cognitive demands on individuals than other research methods such as interviews (Anastasi, 1976). According to Anastasi, when research subjects lack the ability to properly understand tests, they lose motivation to complete the test resulting in unanswered items, higher random error variance, and lower internal consistency. The current study focused solely on survey measures so it would be interesting for future studies to examine why and how different combinations of psychometrics affect reliability. The complexity of test items could offer one explanation yet the effect of test difficulty on reliability remains to be determined.

Also, it was previously mentioned that the language of test administration in studies could have an impact on reliability (e.g., Caruso \& Edwards, 2001). The findings in the current study do not support this notion because reliability and average inter-item correlations were not significantly lower for studies conducted outside of North America. According to these results, reliability precision was not compromised when variables were measured in other countries. These results were unexpected because of the anticipated effect of language understanding differences, translation issues, cultural inconsistencies in the interpretation of variables, and/or higher test anxiety in foreign countries. Previous research has found that test anxiety is a relatively heterogeneous cross-cultural phenomenon (Benson, et. al, 1992). Based on a sample of 14 nations, Benson et al. reported that the highest test-anxiety values were found in Egypt, Jordan, 
and Hungary, followed by Puerto Rico, Korea, and Germany. The lowest anxiety levels were reported for China, Italy, Japan, and the Netherlands. When data were grouped into geographical regions, the highest mean anxiety was observed in Islamic countries, South America, and Eastern Europe. Unfortunately, the small sample size for studies conducted outside of North America did not allow for such a more fine-grained comparison between nations so such comparisons and the variables that contribute to any cultural reliability differences remain to be examined in future studies.

\section{Characteristics of the actual tests}

Results from the current study supported the notion that test characteristics such as the number of items and the type of anchor scales used had an impact on reliability precision. The number of items in a measure correlated significantly with reliability estimates and average inter-item correlations. Also, the number of items was the strongest predictor of reliability which was not surprising considering that adding similar items to a scale will improve reliability (i.e., Spearman-Brown prophecy). Yet, the current study emphasizes the use of average inter-item correlations because simply adding more items can distort the overall picture of internal consistency. It is recommended that authors routinely provide inter-item correlations alongside reliability estimates in order to give clearer and more robust information for overall scale reliability precision.

The non-significant results concerning the number of scale points were unexpected. There were very few samples that used two or three anchor points or more than nine so this study provides little evidence as to whether using too few or too many anchor points has any detrimental impact on either reliability or inter-item correlations. Interestingly, the type of scale anchor points used did make a difference for inter-item 
correlations. Specifically, magnitude-extent types of anchor points (e.g., 1 = to a small extent, 5 = to a large extent) provided the strongest average inter-item correlations and hence, scale users and developers should be encouraged to use these types over others such as agreement (e.g., $1=$ strongly disagree, $5=$ strongly agree) or quality-accuracy (e.g., $1=$ very inaccurate, $5=$ very accurate) types. A possible explanation may be that magnitude-extent scales are used more often in specific types of construct measurement or had significantly less or more items than other types. Post hoc examinations revealed that magnitude-extend scales were used in most construct groups. However, they had significantly less items $(M=6.79, \mathrm{SD}=6.10)$ than frequency type anchor scales $(\mathrm{M}=$ $10.41, \mathrm{SD}=18.99$; and approaching significance for having fewer items than agreement scales; $\mathrm{M}=7.60, \mathrm{SD}=7.17$ ), indicating that scale length contributed to higher average inter-item correlations in magnitude-extent types of anchor scales.

Reliability and average inter-item correlations also varied based on author affiliation. Although the number of samples used by consultant-only and mixed authors was rather small, reliability and inter-item correlations were generally lower when consultants were involved. This may indicate that academic authors have a higher standard for reliability estimates and other scale psychometrics than consultants (e.g., resulting from basic research objectives), whereas the latter may focus more on general survey content and sampling procedures (e.g., resulting from applied research objectives). Nonetheless, due to the small number of samples, it was difficult to determine why these group differences occurred and power analyses did not achieve acceptable levels beyond rejecting the null hypothesis (i.e., below .5 when estimating a small to moderate effect size). 


\section{The reliability depository}

One of the greatest contributions of the current study was to develop a depository of reliability precision for future scale uses and development. Having the averages, standard deviations, and confidence intervals for reliability and average inter-item correlations at the levels of variables, constructs, and actual scales should be a useful reference tool for academics and practitioners in making important decisions on which scales to use, for general variable measurement, construct development, and to provide information for future VG and meta-analytical studies.

Further, results show that measures of personality have important shortcomings in terms of average inter-item correlations over other types of constructs. Specifically, measures used to assess variables such as locus of control (LOC), openness to experience, and agreeableness all had average inter-item correlations below .28. Notably, measures of the Big-Five personality traits were among constructs that had significant predictors (e.g., number of scale points and age) for average inter-item correlations, with $43 \%$ of variance explained that can account for the low estimates of personality measures. So, for example, researchers and practitioners using personality measures may be able to increase the inter-item correlations of these measures by ensuring an adequate number of anchor points (e.g., seven or nine). Also, the age of participants seemed to matter for inter-item correlations of personality measures but these results should be interpreted with caution because significant results occurred only when the standard deviation for age was entered as a predictor (i.e., age in years did not significantly predict the reliability of personality measures). Lower standard deviations in age resulted in higher average inter-item correlations. In other words, smaller distributions of 
participants' age predicted higher average inter-item correlations in personality measures, supporting the notion that homogeneous samples typically yield higher internal consistency than heterogeneous samples (Traub, 1994).

Overall, the resultant depository offers interesting descriptive information for researchers and practitioners; however, the predictive models fall short in explaining meaningful levels of variance in reliability estimates. These results suggest that psychometric surveys have been developed and improved over time in order to be relatively unbiased in regards to sample characteristics such as age, gender, and ethnicity.

\section{Missing data, trends, and content analysis}

Missing data at the level of any variable is problematic for any study (e.g., primary studies such as survey research and secondary data analysis such as metaanalyses), especially when conducting pairwise and/or listwise analyses with multiple variables. In the current study, information concerning the ethnic distribution of the sample was the least reported, followed by the number and type of anchor points. Whether or not such variables and other test and test-taker characteristics matter or not to authors, they provide important pieces of information that can be used for the interpretation of primary data and in subsequent analyses. For example, researchers desiring to conduct VG studies or similar meta-analyses would be limited in making inferences about ethnicity effects (.e.g., as a moderator) because more than half the studies found in this journal did not include usable information. Fortunately, trends analysis results show a general decrease in missing data for all measured variables in the current study, indicating that authors are reporting more information and/or that journal editors have become stricter in regulating missing data. Notably, some authors provided 
partial information in terms of test-taker characteristics. For example, some authors would provide the age range rather than the mean. Such partial information, although informative, does not allow for full interpretation of primary data or for subsequent analyses without imposing important limitations on the data. As such, authors and journal editors should abide to higher standards of descriptive data reporting (e.g., means and standard deviations) and these standards should be included in all publication manuals.

Another important finding of this study is the general increase in reliability and average inter-item correlations for most groups of constructs over time. Aside for interitem correlations for health outcome constructs, all other groups of measures increased as a function of time, indicating that our standards and practice for measurement precision and reliability have generally improved. The non-significant results for health outcome construct inter-item correlations may be due to a relatively small sample (e.g., due to missing number of items data) that prevented significant trend results.

Finally, the content analysis performed in this study provides interesting additional descriptive information to readers of the Journal of Applied Psychology and for the depository of reliability precision included in this manuscript. Content analysis allows I/O researchers and practitioners to track the frequency of usage of old and new constructs. For example, results show that over time, there was an increase in the usage of measures of OCBs, charisma, the Big-Five personality traits, justice, work-family conflict, and perceptions of job alternatives, whereas measures of dependability have fallen out of favor. Also, when solely looking at the frequency of measured constructs (e.g., as opposed to the percentage of content), results show a general increase in content 
for most I/O measures, meaning that over time, authors are using more combinations of measures in their research studies ${ }^{1}$.

\section{Recommendations for reliability precision}

To complement the aforementioned implications of this study, the following recommendations are proposed concerning the reporting of reliability. First, as mentioned previously, despite the decrease in missing data, journal and publication manual guidelines do not specifically address issues regarding the reporting of reliability and especially, inter-item correlations data. All relevant information, including test-taker demographic information and test characteristics should be made readily available in all manuscripts that conduct survey assessments. Not only will this practice provide clearer information concerning reliability precision and interpretation of primary study data, it will also allow for subsequent meta-analytical efforts to be conducted without the loss of important data. Second, aside from using adequate sample sizes, authors and reviewers should be cognizant of the effect of the number of items on reliability and inter-item correlations. Increasing the number of similar items in a measure will likely increase the reliability coefficient and this effect highlights the importance of reporting inter-item correlations to better interpret and understand the level of reliability precision in each measure. Third, although this study did not find significant results for what the ideal number of anchor points is, it is recommended that any number between five and nine would be effective, providing support for earlier work (e.g., Lissitz \& Green, 1975; Oaster, 1989).

\footnotetext{
${ }^{1}$ There was no significant increase in articles published in the Journal of Applied Psychology in the sample.
} 


\section{Limitations and future research}

In conclusion, a few limitations and recommendations for future research deserve consideration. First, the exploratory nature of the current study and its mixed results bring to mind the concepts of statistical inference errors. For example, making statements regarding significant correlations between reliability and ethnicity could be conceived as a false positive, or 'Type I' error because although the correlations may have been significant, they were low in magnitude, indicating that ethnicity may only have a marginal effect on reliability. Conversely, suggesting that surveys are unbiased based on the mixed results between reliability and average inter-item correlations could be regarded as a false negative, or 'Type II' error when a true null hypothesis was not rejected (e.g., making inferences based on the non-significant results among variables and reliability/inter-item correlations). In order to reduce the chance of making such errors, power analyses were conducted in order to avoid making erroneous conclusions and to help explain the overall significance of these mixed results. Johns (2006) noted that the functional relationship between variables is dependent on research context that is likely responsible for variations in research findings. One possible solution for reducing such result variations in this particular context would be to increase the sample size of published studies and develop a more comprehensive analysis of the variables that impact reliability.

Second, the current study was limited to only one journal and noteworthy, one of the prominent journals in the field of I/O psychology. As such, besides the aforementioned problems associated with the small number of samples, especially regarding comparisons of actual scales, extremely low or high numbers of anchor points, 
and a lack of consulting and mixed authorship affiliations and authors from foreign countries, articles within this journal may not accurately represent the state-of-science of I/O construct reliability. However, analyzing one of the most prominent journals in the field of I/O psychology provides an important example in hopes to strengthen publication standards and avoid data communication flaws in other journals. Future research should consider analyzing samples from more I/O and business journals to improve the generalizability of results. Adding more journals would allow for meaningful comparisons between measured variables, construct groups, actual scales used, as well as between different journal content and publication standards. For example, adding journals such as the Journal of Occupational Health Psychology would increase the current study's low incidence of health outcome constructs and allow for cross-journal comparisons of standards in internal consistency precision.

Third, coding data every five years may only provide snapshots of the state of reliability precision over time. As mentioned in the introduction, methodological decisions inevitably impact study limitations (Stone-Romero, 2002). Using five year intervals allowed for a longer period of analysis dating back to 1975 in order to capture long-term changes in reliability and journal content. Future research should consider coding and analyzing all journal issues by using multiple coders/authors. This more exhaustive research initiative would allow for a more comprehensive analysis of trends and avoid circumstances such as the occurrence of special journal issues with restricted content (e.g., with a limited burden of multiple coder issues because of the straightforward nature of the coding task) alongside correcting for range restrictions such as those presented in the current study. 
Fourth, the current study only examined one type of reliability: item-level survey reliability. Future research should consider comparing item-level reliability with other types, such as inter-rater and test-retest reliability, as well as their relationships with other types of validity (e.g., internal, statistical conclusion, external). Subsequent studies examining differences among the types of surveys, item complexity, and the usage of surveys alongside other research methods such as observations, experiments, and interviews in the measurement of $\mathrm{I} / \mathrm{O}$ variables will help researchers and practitioners to develop reliable and valid psychometric tools that impact important workplace decisions such as hiring and promotion.

In conclusion, the current study demonstrates an important meta-analytic outlook on the past and current state of reliability precision. The depository of reliability and average inter-item correlations should provide researchers and practitioners a valuable reference tool for future research and applied objectives; and the recommendations for reliability data reporting should be a beneficial guide for authors and journal editors in improving the communication and interpretation of reliability statistics. 


\section{REFERENCES}

Anastasi, A. (1976). Psychological testing. New York: Macmillan.

Allen, N.J., \& Meyer, J.P. (1990). The measurement and antecedents of affective, continuance and normative commitment to the organization. Journal of Occupational Psychology, 63, 1-18.

Avolio, B.J., Bass, B.M., \& Jung, D.I. (1999). Re-examining the components of transformational leadership and transactional leadership using the Multifactor Leadership Questionnaire. Journal of Occupational and Organizational Psychology, 72, 441-462.

Bass, B.M. (1985). Leadership and performance beyond expectations. New York: Free Press.

Bass, B.M., Cascio, W.F., \& O'Connor, E.J. (1974). Magnitude estimations of expressions of frequency and amount. Journal of Applied Psychology, 59, 313320.

Bateman, T.S., \& Crant, J.M. (1993). The proactive component of organizational behavior. Journal of Organizational Behavior, 14, 103-118

Baugh, F. (2000). Correcting effect sizes for score reliability: A reminder that measurement and substantive issues are linked inextricably. Educational and Psychological Measurement, 62, 254-263.

Benson, J., Moulin-Julian, M., Schwarzer, C., Seipp, B., \& El-Zahhar, N. (1992). Crossvalidation of a revised test anxiety scale using multi-national samples. In Hagtvet, K.A., Johnsen, A., \& Backer, T. (Eds.) Advances in test anxiety research, vol. 7. Lisse, Netherlands: Swets \& Zeitlinger Publishers.

Beretvas, N., Suizzo, M.A., Durham, J.A., \& Yarnell, L.M. (2008). A reliability generalization study of scores on Rotter's and Nowicki-Strickland's Locus of Control Scales. Educational and Psychological Measurement, 68, 97-119.

Berry, C.M., Clark, M.A., \& McClure, T.K. (2011). Racial/ethnic differences in the criterion-related validity of cognitive ability tests: A qualitative and quantitative review. Journal of Applied Psychology, 96, 881-906.

Brayfield, A.H., \& Rothe, H.F. (1951). An index of job satisfaction. Journal of Applied Psychology, 35, 307-311. 
Brutus, S., Harjinder, G., \& Duniewicz, K. (2010). State of science in industrial and organizational psychology: A review of self-reported limitations. Personnel Psychology, 63, 907-936.

Cambell, J.P., Gasser, M.B., \& Oswald, F.L. (1996). The substantive nature of job performance variability. In Murphy, K. (Ed.), Individual differences and behavior in organizations (pp. 258-299). San Francisco: Jossey-Bass.

Cammann, C., Fichman, M., Jenkins, D., \& Klesh, J. (1979). The Michigan Organizational Assessment Questionnaire. Unpublished manuscript, University of Michigan, Ann Arbor.

Caplan, R.D., Cobb, S., French, J.R.P., Harrison, R., \& Pinneau, S.R. (1975). Job demands and worker health. (NIOSH Publication No. 75-160). Washington, DC: Department of Health, Education, and Welfare.

Caruso, J.C. (2000). Reliability generalization of the Neo Personality Scales. Educational and Psychological Measurement, 60, 236-254.

Caruso, J.C. \& Edwards, S. (2001). Reliability generalization of the Junior Eysenck Personality Questionnaire. Personality and Individual Differences, 31, 173-184.

Caruso, J.C., Witkiewitz, K., Belcourt-Dittloff, A. \& Gottblieb, J.D. (2001). Reliability of scores from the Eysenck Personality Questionnaire: A reliability generalization study. Educational and Psychological Measurement, 61, 675-689.

Cicchetti, D.V., Showalter, D., \& Tyrer, P.J. (1985). The effect of number of rating scale categories on levels of inter-rater reliability: a Monte-Carlo investigation. Applied Psychological Measurement, 9, 31-36.

Cohen, J. (1994). The earth is round ( $\mathrm{p}<.05)$. American Psychologist, 49, 997-1003.

Colarelli, S.M. (1984). Methods of communication and mediating processes in realistic job previews. Journal of Applied Psychology, 69, 633-642.

Colquitt, J.A. (2001). On the dimensionality of organizational justice: A construct validation of a measure. Journal of Applied Psychology, 86, 386-400.

Cook T.D. \& Campbell D.T. (1976). The design and conduct of quasi-experiments and true experiments in field settings. In Dunnette, M. (Ed.), Handbook of industrial and organizational psychology (pp. 223-336). Chicago: Rand McNally.

Cortina, J.M. (1993). What is coefficient alpha? An examination of theory and applications. Journal of Applied Psychology, 78, 98-104. 
Costa, P.T. \& McCrae, R.R. (1989). The NEO PI/FFI manual supplement: Personality Inventory manual. Odessa, FL: Psychological Assessment Resources.

Costa, P.T. \& McCrae, R.R. (1991). NEO Five-Factor Inventory (Form S). Odessa, FL: Psychological Assessment Resources.

Costa, P.T. \& McCrae, R.R. (1992). NEO PI-R professional manual. Odessa, FL: Psychological Assessment Resources.

Covington, M.V. \& Omelich, C.L. (1987). Item difficulty and test performance among high-anxious and low-anxious students. In Scwarzer, R., Van der Ploeg, H.M., \& Spielberger, C.D. (Eds.), Advances in test anxiety research, vol. 5. Berwyn, PA: Swets North America.

Cox, E.P. (1980). The optimal number of response alternatives for a scale: a review. Journal of Marketing Research, 17, 407-422.

Crocker, L. \& Algina, J. (1996). Introduction to Classical and Modern Test Theory. New York: Holt, Rinehart and Winston.

Cronbach, L.J. (1951). Coefficient alpha and the internal structure of tests. Psychometrika, 16, 297-334.

Cronbach, L.J. \& Shavelson, R.J. (2004). My current thoughts on coefficient alpha and successor procedures. Educational and Psychological Measurement, 64, 391-418.

Deese, J. (1959). Influence of inter-item associative strength upon immediate free recall. Psychological Reports, 5, 305-312.

Eason, S. (1991). Why generalizability theory yields better results than classical test theory: A primer with concrete examples. In Thomson, B. (Ed.), Advances in educational research: Substantive findings, methodological developments, (Vol. 1, p. 83-98). Greenwich, CT: JAI Press.

Eden, D., \& Aviram, A. (1993). Self-efficacy training to speed reemployment: Helping people to help themselves. Journal of Applied Psychology, 78, 352-360.

Eden, D., \& Zuk, Y. (1995). Seasickness as a self-fulfilling prophecy: Raising selfefficacy to boost performance at sea. Journal of Applied Psychology, 80, 628-635

Epstein, S. (1979). The stability of behavior: I. On predicting most of the people much of the time. Journal of Personality and Social Psychology, 37, 1097-1126.

Epstein, S. (1980). The stability of behavior: Implications for psychological research. American Psychologist, 9, 790-806. 
Eysenck, M.W. (1982). Attention, and arousal: Cognition and performance. New York, NY: Springer-Verlag.

Eysenck, H.J. \& Eysenck, S.B.G. (1968). Manual for the Eysenck Personality Inventory. San Diego, CA: Educational and Industrial Testing Service.

Fisher, R. (1918). Studies in crop variation: An examination of the yield of dressed grain from Broadbalk. Journal of Agricultural Science, 11, 107-135.

Fleiss, J.L. (1971). Measuring nominal scale agreement among many raters. Psychological Bulletin, 76, 378-382.

Fuller, J.B. \& Hester, K. (1999). Comparing the sample-weighted and unweighted metaanalysis: An applied perspective. Journal of Management, 25, 803-828.

Garner, W.R. (1960). Rating scales, discriminability, and information transmission. Psychological Review, 67, 343-352.

Goldberg, L.R. (1992). The development of markers for the Big-Five factor structure. Psychological Assessment, 4, 26-42.

Goldberg, L.R. (1999). A broad-bandwidth, public domain, personality inventory measuring the lower-level facets of several five-factor models. In Merviedle, I., Deary, I.J., Fruyt, F.D., \& Osetendorf, F. (Eds.), Personality psychology in Europe (Vol. 7, pp. 7-28). Tilburg, the Netherlands: Tilburg University Press.

Graen, G.B., \& Uhl-Bien, M. (1995). Relationship-based approach to leadership: Development of leader-member exchange (LMX) theory of leadership over 25 years: Applying a multi-level multi-domain perspective. Leadership Quarterly, 6, 219-247.

Graen, G., Liden, R., \& Hoel, W. (1982). Role of leadership in the employee withdrawal process. Journal of Applied Psychology, 67, 868-872.

Guilford, J.P. (1954). Psychometric Methods, $2^{\text {nd }}$ Edition. New York, NY: McGraw-Hill.

Guion, R.M. (1965). Personnel testing. New York, NY: McGraw-Hill.

Hackman, J.R. \& Oldham, G.R. (1975). Development of the Job Diagnostic Survey. Journal of Applied Psychology, 60, 159-170.

Hanisch, K.A., \& Hulin, C.L. (1990). Job attitudes and organizational withdrawal: An examination of retirement and other voluntary withdrawal behavior. Journal of Vocational Behavior, 37, 60-78. 
Hellman, C.M., Fuqua, D.R., \& Worley, J. (2006). A reliability generalization study on the Survey of Perceived Organizational Support: The effects of mean age and number f items on score reliability. Educational and Psychological Measurement, 66, 631-642.

Hembree, R. (1988). Corelates, causes, effects, and treatment of test anxiety. Review of Educational Research, 58, 47-77

Henson, R.K. (2001). Understanding internal consistency reliability estimates: A conceptual primer on coefficient alpha. Measurement and Evaluation in Counseling and Development, 34, 177-198.

Henson, R.K., Kogan, L.R., \& Vacha-Haase, T. (2001). A reliability generalization study of the teach efficacy scale and related instruments. Educational and Psychological Measurement, 61, 404-420.

Hill, K.T. \& Wigfield, A. (1984). Test anxiety: A major educational problem and what can be done about it. The Elementary School Journal, 85, 105-126.

Hogan, T.P., Benjamin, A., \& Brezinski, K.L. (2000). Reliability methods: A note on the frequency of use of various types. Educational and Psychological Measurement, $60,523-531$.

Hom, P.W., Griffeth, R.W., \& Sellaro, L. (1984). The validity of Mobley's (1977) turnover model. Organizational Behavior and Human Performance, 34, 141-174.

House, R.J. \& Rizzo, J.R. (1972). Role conflict and ambiguity as critical variables in a model of organizational behavior. Organizational Behavior and Human Performance, 7, 467-505.

Hunter, J.E. \& Schmidt, F.L. (2004). Methods of meta-analysis: Correcting for bias in research findings, $2^{\text {nd }}$ edition. London, UK: Sage Publishing Inc.

Iyengar, S. \& Greenhouse, J. (1988). Selection models and the file drawer problem. Statistical Science, 3, 109-135.

Johns, G. (2006). The essential impact of context on organizational behavior. Academy of Management Review, 31, 386-408.

Judge, T.A., Locke, E.A., Durham, C.C., \& Kluger, A.N. (1998). Dispositional effects on job and life satisfaction: The role of core evaluations. Journal of Applied Psychology, 83, 17-34.

Komorita, S.S. (1963). Attitude content, intensity, and the neutral point on a Likert scale. Journal of Social Psychology, 61, 327-334. 
Kuder, G. F. \& Richardson, M.W. (1937). The theory of the estimation of test reliability. Psychometrika, 2, 151-160.

Landis, J.R. \& Koch, G.C. (1977). The measurement of observer agreement for categorical data. Biometrics, 33, 159-174.

Lazarus, R.S. (1993). From psychological stress to the emotions: A history of changing outlooks. Annual Review of Psychology, 44, 1-21.

Lee, K. \& Allen, N.J. (2002). Organizational citizenship behavior and workplace deviance: The role of affect and cognitions. Journal of Applied Psychology, 87, $131-142$.

Levenson, H. (1981). Differentiating among internality, powerful others, and chance. In Lefcourt, H.M. (Ed.). Research with the locus of control construct (pp. 15-63). New York: Academic Press.

Liden, R.C. \& Maslyn, J.M. (1998). Multidimensionality of leader-member exchange: An empirical assessment through scale development. Journal of Management, 24, 43-72.

Lissitz, R.W. \& Green, S.B. (1975). Effect of the number of scale points on reliability: A Monte Carlo approach. Journal of Applied Psychology, 60, 10-13.

Matell, M.S. \& Jacoby, J. (1972). Is there an optimal number of alternatives for Likertscale items? Effects of testing time and scale properties. Journal of Applied Psychology, 56, 506-509.

Meier, S.T., \& Davis, S.R. (1990). Trends in reporting psychometric properties of scales used in counseling psychology research. Journal of Counseling Psychology, 37, 113-115.

Meyer, J.P. \& Allen, N.J. (1984). Testing the "side-bet theory" of organizational commitment: Some methodological considerations. Journal of Applied Psychology, 69, 372-378.

Miller, G.A. (1956). The magical number seven, plus or minus two: Some limits on our capacity for processing information. Psychological Review, 63, 81-97.

Miller, B.K., Byrne, Z.S., Rutherford, M.A., \& Hansen, A.M. (2009). Perceptions of organizational politics: A demonstration of the reliability generalization technique. Journal of Managerial Issues, 21, 280-300.

Mischel, W. (1969). Continuity and change in personality. American Psychologist, 24, 1012-1018. 
Mowday, R.T., Steers, R.M., \& Porter, L.W. (1979). The measurement of organizational commitment. Journal of Vocational Behavior, 14, 224-247.

Mowday, R.T, Porter, L.W., \& Steers, R.M. (1982). Employee-organization linkages. New York: Academic Press.

Mueller, J.H., Kausler, D.H., Faherty, A., \& Oliveri, M. (1980). Reaction time as a function of age, anxiety, and typicality. Bulletin of the Psychometrics Society, 16, 473-476.

Murphy, K. (1990). If the null hypothesis is impossible, why test it? American Psychologist, 45, 403-404.

Murphy, K. (1997). Editorial. Journal of Applied Psychology, 82, 3-5.

Murphy, K. \& Myors, B. (1998). Statistical power analysis: A simple and general model for traditional and modern hypothesis tests. Mahwah, NJ: Lawrence Erlbaum.

Niehoff, B.P. \& Moorman, R.H. (1993). Justice as a mediator of the relationship between methods of monitoring and organizational citizenship behavior. Academy of Management Journal, 36, 527-556.

Oaster, T.R. (1989). Number of alternatives per choice point and stability of Likert-type scales. Perceptual and Motor Skills, 68, 549-550.

Osburn, H.G. \& Callender, G.W. (1992). A meta-analysis of the relationship between individual job satisfaction and individual performance. Academy of Management Review, 9, 712-721.

Ostroff, C. \& Kozlowski, S.W.J. (1992). Organizational socialization as a learning process: The role of information acquisition. Personnel Psychology, 45, 849-874

Parker, D.F., \& DeCotiis, T.A. (1983). Organizational determinants of job stress. Organizational Behavior and Human Decision Processes, 32, 160-177.

Patton, E. \& Johns, G. (2007). Women's absenteeism in the popular press: Evidence for a gender-specific absence culture. Human Relations, 60, 1579-1612.

Peterson, R.A. (1994). A meta-analysis of Cronbach's coefficient alpha. Journal of Consumer Research, 21, 381-391.

Phillips, W.M. (1975). Educational policy, community participation, and race. Journal of Negro Education, 3, 257-267. 
Porter, L.W. \& Smith, F.J. (1970). The etiology of organizational commitment. Unpublished manuscript, University of California at Irvine.

Porter, L.W., Steers, R.M., Mowday, R.T., \& Boulian, P V. (1974). Organizational commitment, job satisfaction, and turnover among psychiatric technicians. Journal of Applied Psychology, 59, 603-609.

Preston, C.C. \& Colman, A.M. (2000). Optimal number of response categories in rating scales: Reliability, validity, discriminating power, and respondent preferences. Acta Psychologica, 104, 1-15.

Rexrode, K.R., Peterson, S., \& O’Toole, S. (2008). The Ways of Coping Scale: A reliability generalization study. Educational and Psychological Measurement, 68, 262-280.

Rhodes, S.R. (1983). Age-related differences in work attitudes and behavior: A review and conceptual analysis. Psychological Bulleting, 93, 328-367.

Riggs, M.L., Warka, J., Babasa, B., Betancourt, R., \& Hooker, S. (1994). Development and validation of self-efficacy and outcome expectancy scales for job-related applications. Educational and Psychological Measurement, 58, 1017-1034.

Rizzo, J.R., House, R.J., \& Lirtzman, S.I. (1970). Role conflict and ambiguity in complex organizations. Administrative Science Quarterly, 15, 150-163.

Rodriguez, M.C. \& Maeda, Y. (2006). Meta-analysis of coefficient alpha. Psychological Methods, 11, 306-322.

Rosenthal, R. (1979). The file drawer problem and tolerance for null results. Psychological Bulletin, 86, 638-641.

Rotter, J.B. (1966). Generalized expectancies for internal versus external control of reinforcement. Psychological Monographs, 80, 1-28.

Roznowski, M. (1989). An examination of the measurement properties of the Job Descriptive Index with experimental items. Journal of Applied Psychology, 74, 805-814.

Samuda, R.J. (1975). Psychological testing of American minorities: Issues and consequences. Oxford, England: Dodd-Mead.

Sarason, I.G. \& Pierce, G.R. (1995). Social and personal relationships: Current issues, future directions. Journal of Social and Personal Relationships, 12, 613-619. 
Scandura, T.A., \& Graen, G.B. (1984). Moderating effects of initial leader-member exchange status on the effects of a leadership intervention. Journal of Applied Psychology, 69, 428-436.

Scandura T.A. \& Williams E.A. (2000). Research methodology in management: Current practices, trends, and implications for future research. Academy of Management Journal, 43, 1248-1264.

Scargle, J.D. (2000). Publication bias: The file-drawer problem in scientific inference. Journal of Scientific Exploration, 14, 94-106.

Schutz, H.G. \& Rucker, M.H. (1975). A comparison of variable configuration across scale lengths: An empirical study. Educational and Psychological Measurement, $35,319-324$.

Sedlmeier, P. \& Gigerenzer, G. (1989). Do studies of statistical power have an effect on the power of studies? Psychological Bulletin, 105, 309-316.

Silzer, R. \& Parson, C. (2012). Industrial-organizational psychology journals and the science-practitioner gap. The Industrial-Organizational Psychologist, 49, 97-117.

Smith, P.C., Kendall, L.M., \& Hulin, C.L. (1969). The measurement of satisfaction in work and retirement: A strategy for the study of attitudes. Skokie, IL: RandMcNally.

Smith, P.C., Sademan, B., \& McCrary, L. (1992). Development and validation of the Stress in General (SIG) scale. Paper presented at Society for Industrial and Organizational Psychology, Montreal, Quebec, Canada.

Spearman, C.C. (1910). Correlation calculated from faulty data. British Journal of Psychology, 3, 271-295.

Spielberger, C.D. (1979). Preliminary manual for the State-Trait Personality Inventory (STPI). Unpublished manuscript, University of South Florida, Tampa.

Spielberger, C.D., Gorsuch, R.L., \& Lushene, R.E. (1970). STAI manual for the StateTrait Anxiety Inventory. Palo Alto, CA: Consulting Psychologists Press.

Stone, E.F., Gueutal, H.G., \& Stone, D.L. (1990). Influence of cognitive ability on responses to questionnaire measures: Measurement precision and missing response problems. Journal of Applied Psychology, 75, 418-427.

Stone-Romero, E.F. (2002). The relative validity and usefulness of various research designs. In Rogelberg, S.G. (Ed.). Handbook of research methods in industrial and organizational psychology. London: Blackwell. 
Symonds, P.M. (1924). On the loss of reliability in ratings due to coarseness of the scale. Journal of Experimental Psychology, 7, 456-461.

Thomson, B. (1994). Common methodology mistakes in dissertations, revisited. Paper presented at the annual meeting of the American Educational Research Association, New Orleans.

Traub, R.E. (1994). Reliability for the Social Sciences: Theory and Applications, Vol. 3. London: Sage.

Thomson, B. \& Vacha-Haase., T. (2000). Psychometrics is datametrics: The test is not reliable. Educational and Psychological Measurement, 60, 174-195.

Vacha-Haase, T., Kogan, L.R., Tani, C.R., \& Woodall, R.A. (2001). Reliability generalization: Exploring variation of reliability coefficients of MMPI clinical scales scores. Educational and Psychological Measurement, 61, 45-59.

Vacha-Haase, T., Kogan, L.R., \& Thompson, B. (2000). Sample compositions and variabilities in published studies versus those in test manuals: Validity of score reliability induction. Educational and Psychological Measurement, 60, 509-522.

Vassar, M. \& Bradley, G. (2010). A reliability generalization study of coefficient alpha for the Life Orientation Test. Journal of Personality Assessment, 92, 362-370.

Vassar, M. \& Crosby, J.W. (2008). A reliability generalization study of coefficient alpha for the UCLA Loneliness Scale. Journal of Personality Assessment, 90, 601-607.

Viswesvaran, C. \& Ones, D.S. (2000). Measurement error in "Big Five Factors" personality assessment: Reliability generalization across studies and measures. Educational and Psychological Measurement, 60, 224-235

Viswesvaran, C., Ones, D.S., \& Schmidt, F.L. (1996). Comparative analysis of the reliability of job performance ratings. Journal of Applied Psychology, 81, 557574.

Wallace, K.A. \& Wheeler, A.J. (2002). Reliability generalization of the Life Satisfaction Index. Educational and Psychological Measurement, 62, 674-684.

Warr, P. \& Routledge, T. (1969). An opinion scale for the measurement of managers' job satisfaction. Occupational Psychology, 43, 95-109.

Warr, P., Cook, J.D., \& Wall, T.D. (1979). Scales for the measurement of work attitudes and aspects of psychological well-being. Journal of Occupational Psychology, 52, $129-148$. 
Watson, D. \& Clark, L.A. (1984). Negative affectivity: The disposition to experience aversive emotional states. Psychological Bulletin, 96, 465-490.

Watson, D., Clark, L.A., \& Tellegen, A. (1988). Development and validation of brief measures of positive and negative affect: The PANAS scales. Journal of Personality and Social Psychology, 54, 1063-1070.

Weiss, D.J., Dawis, R.V., England, G.W., \& Lofquist, L.H. (1967). Manual for the Minnesota Satisfaction Questionnaire. Minneapolis: University of Minnesota, Industrial Relations Center.

Wheeler, D.L., Vassar, M., Worley, J.A., \& Barnes, L.L. (2011). A reliability generalization meta-analysis of coefficient alpha for the Maslach Burnout Inventory. Educational and Psychological Measurement, 71, 231-244.

Williams, L.J. \& Anderson, S.E. (1991). Job satisfaction and organizational commitment as predictors of organizational citizenship and in-role behaviors. Journal of Management, 17, 601-617.

Wilson, V.L. (1980). Research techniques in AERJ articles: 1969 to 1978. Educational Researcher, 9, 5-10.

Zeidner, M. \& Safir, M.P. (1989). Sex, ethnic, and social differences in test anxiety among Israeli adolescents. Journal of Genetic Psychology: Research and Theory on Human Development, 150, 175-185.

Zickar, M.J. \& Highhouse, S. (2001). Measuring prestige of journals in industrialorganizational psychology. The Industrial-Organizational Psychologist, 38, 2936.

Zwick, R. \& Marascuilo, L. (1984). Selection of pairwise comparison procedures for parametric and nonparametric analysis of variance models. Psychological Bulletin, 95, 148-155. 
Table 1

Descriptive Statistics for Test Takers of I/O Constructs and Construct Groups

\begin{tabular}{|c|c|c|c|c|c|c|c|c|c|c|c|c|}
\hline \multirow[b]{2}{*}{ Variable } & \multicolumn{3}{|c|}{ Sample Size } & \multicolumn{3}{|c|}{ Age } & \multicolumn{3}{|c|}{ Gender } & \multicolumn{3}{|c|}{ Ethnicity } \\
\hline & $\mathrm{K}$ & $\mathrm{M}$ & SD & $\mathrm{K}$ & $\mathrm{M}$ & SD & $\mathrm{K}$ & $M$ & SD & $\mathrm{K}$ & $\mathrm{M}$ & SD \\
\hline Behaviors & 372 & 452.53 & 1282.781 & 230 & 32.531 & 8.9587 & 304 & 55.387 & 29.3962 & 131 & 62.1 & 38.0 \\
\hline job performance & 45 & 608.6 & 2114.9 & 28 & 33.7 & 9.2 & 33 & 51.6 & 30.0 & 10 & 48.0 & 42.2 \\
\hline leader effectiveness & 37 & 284.6 & 312.7 & 22 & 32.3 & 7.8 & 29 & 57.1 & 30.0 & 9 & 49.9 & 36.5 \\
\hline turnover & 28 & 319.0 & 291.8 & 21 & 31.4 & 6.8 & 24 & 53.3 & 28.0 & 17 & 49.1 & 39.5 \\
\hline OCB & 18 & 329.6 & 274.5 & 16 & 33.0 & 9.0 & 16 & 56.3 & 27.1 & 5 & 50.0 & 46.5 \\
\hline harassment & 14 & 1177.6 & 3000.2 & 4 & 38.3 & 13.5 & 13 & 90.2 & 15.6 & 12 & 75.3 & 31.4 \\
\hline withdrawal & 10 & 504.1 & 416.7 & 8 & 31.7 & 9.9 & 10 & 63.2 & 36.5 & 9 & 72.2 & 41.2 \\
\hline goal setting & 9 & 205.4 & 59.0 & 4 & 26.2 & 9.0 & 7 & 53.3 & 24.2 & 0 & 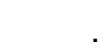 & . \\
\hline CWB & 8 & 384.5 & 397.6 & 7 & 36.3 & 8.1 & 7 & 61.3 & 9.6 & 0 & & . \\
\hline negotiation & 8 & 129.8 & 76.4 & 4 & 29.9 & 0.2 & 8 & 75.0 & 26.7 & 4 & 75.0 & 50.0 \\
\hline cooperation & 7 & 1530.9 & 3454.0 & 2 & 24.4 & 3.3 & 4 & 39.1 & 22.2 & 3 & 54.7 & 48.2 \\
\hline ingratiation & 7 & 266.1 & 126.5 & 5 & 21.6 & 3.0 & 5 & 39.0 & 23.5 & 2 & 78.5 & 7.8 \\
\hline effort & 5 & 389.2 & 476.8 & 2 & 20.6 & 0.6 & 3 & 56.0 & 15.6 & 2 & 84.5 & 9.2 \\
\hline abusive supervision & 4 & 189.0 & 140.3 & 4 & 37.0 & 8.1 & 4 & 66.9 & 7.0 & 0 & . & . \\
\hline conflict resolution & 4 & 160.8 & 141.3 & 1 & 30.9 & . & 3 & 23.6 & 22.0 & 0 & . & . \\
\hline denial & 4 & 140.5 & 83.6 & 0 & & & 4 & 100.0 & 0.0 & 4 & 75.0 & 50.0 \\
\hline achievement striving & 3 & 151.0 & 34.8 & 3 & 26.3 & 11.7 & 3 & 40.0 & 32.7 & 1 & 100.0 & . \\
\hline agency & 3 & 187.3 & 118.3 & 2 & 23.0 & 1.4 & 3 & 68.0 & 7.2 & 1 & 95.0 & . \\
\hline rejecting & 3 & 218.0 & 68.7 & 3 & 30.7 & 5.7 & 3 & 54.0 & 34.4 & 2 & 39.9 & 11.7 \\
\hline unethical pro org beh & 3 & 286.0 & 67.0 & 3 & 35.5 & 10.7 & 3 & 64.2 & 12.8 & 1 & 68.0 & \\
\hline aggression & 2 & 98.5 & 26.2 & 2 & 30.2 & 16.8 & 2 & 72.5 & 38.9 & 1 & 70.0 & . \\
\hline incivility & 2 & 1129.0 & 418.6 & 2 & 44.7 & 6.2 & 2 & 100.0 & 0.0 & 2 & 90.5 & 3.5 \\
\hline prosocial beh & 2 & 243.5 & 14.8 & 0 & 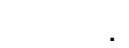 & . & 0 & . & . & 0 & . & . \\
\hline aap intentions & 2 & 498.0 & 132.9 & 0 & & . & 1 & 45.0 & . & 1 & 66.0 & \\
\hline absenteeism & 1 & 194.0 & & 0 & & & 1 & 0.0 & . & 0 & & . \\
\hline other behaviors & 143 & 454.0 & 1158.8 & 87 & 33.4 & 9.3 & 116 & 49.7 & 28.9 & 45 & 62.7 & 38.4 \\
\hline Abilities & 222 & 843.7 & 2120.8 & 124 & 31.7 & 10.0 & 177 & 47.8 & 27.1 & 73 & 63.5 & 34.0 \\
\hline$G$ & 19 & 1920.1 & 3476.6 & 6 & 20.1 & 17.9 & 14 & 47.7 & 16.8 & 7 & 72.7 & 15.9 \\
\hline
\end{tabular}




\begin{tabular}{|c|c|c|c|c|c|c|c|c|c|c|c|c|}
\hline LMX & 11 & 233.3 & 89.3 & 9 & 36.5 & 7.8 & 11 & 48.9 & 26.8 & 7 & 20.1 & 34.4 \\
\hline transformational & 7 & 558.7 & 567.6 & 5 & 38.6 & 1.7 & 6 & 61.7 & 38.8 & 0 & & \\
\hline other leader & 13 & 805.2 & 1901.7 & 10 & 27.2 & 8.8 & 11 & 50.7 & 34.5 & 1 & 67.0 & \\
\hline learning & 16 & 1371.3 & 3468.5 & 8 & 27.9 & 8.1 & 11 & 40.0 & 29.8 & 5 & 41.8 & 43.8 \\
\hline trust & 13 & 271.8 & 189.7 & 10 & 33.6 & 8.9 & 10 & 38.4 & 26.2 & 5 & 70.4 & 40.6 \\
\hline coping & 10 & 487.9 & 1033.1 & 4 & 28.6 & 11.3 & 10 & 68.4 & 32.8 & 6 & 62.5 & 47.9 \\
\hline influence & 7 & 376.4 & 508.1 & 1 & 26.0 & & 6 & 62.0 & 21.3 & 0 & . & \\
\hline empowerment & 6 & 251.2 & 45.8 & 6 & 29.5 & 7.0 & 6 & 35.7 & 19.5 & 4 & 42.8 & 50.8 \\
\hline creativity & 4 & 1005.3 & 1613.0 & 4 & 37.5 & 9.1 & 4 & 34.8 & 18.7 & 3 & 86.0 & 13.9 \\
\hline charisma & 3 & 243.3 & 209.8 & 3 & 31.3 & 9.2 & 3 & 70.6 & 10.1 & 0 & & \\
\hline integrity & 3 & 161.3 & 76.0 & 2 & 23.5 & 4.6 & 2 & 40.0 & 45.3 & 2 & 76.5 & 4.9 \\
\hline dependability & 3 & 367.3 & 72.7 & 0 & & & 1 & 38.0 & & 1 & 91.0 & \\
\hline altruism & 2 & 171.0 & 39.6 & 2 & 32.0 & 12.7 & 1 & 85.0 & & 1 & 89.0 & \\
\hline ability attributions & 2 & 47.0 & 31.1 & 1 & 19.0 & & 2 & 32.0 & 45.3 & 1 & 100.0 & \\
\hline adaptability & 2 & 3422.0 & 0.0 & 2 & 25.0 & 0.0 & 2 & 34.0 & 0.0 & 2 & 70.0 & 0.0 \\
\hline psyc detachment & 1 & 107.0 & & 1 & 45.0 & & 1 & 85.0 & & 0 & & \\
\hline assertiveness & 1 & 80.0 & & 1 & 18.3 & & 1 & 100.0 & & 1 & 70.0 & \\
\hline other abilities & 99 & 864.4 & 2192.0 & 49 & 33.7 & 9.5 & 75 & 44.9 & 24.9 & 27 & 70.7 & 25.1 \\
\hline Personality & 198 & 560.3 & 1578.9 & 134 & 32.8 & 10.3 & 152 & 52.6 & 24.8 & 56 & 69.3 & 30.2 \\
\hline personality & 1 & 123.0 & & 1 & 33.6 & & 1 & 42.4 & & 0 & & \\
\hline conscientiousness & 18 & 839.3 & 2149.2 & 11 & 33.2 & 10.4 & 14 & 53.0 & 27.3 & 8 & 76.6 & 17.1 \\
\hline neuroticism & 18 & 855.9 & 2143.1 & 11 & 34.9 & 10.1 & 11 & 52.3 & 24.4 & 5 & 65.8 & 38.0 \\
\hline extraversion & 11 & 290.5 & 241.2 & 6 & 34.9 & 12.5 & 8 & 52.4 & 24.5 & 3 & 86.0 & 8.7 \\
\hline openness & 11 & 240.9 & 133.2 & 8 & 38.4 & 9.3 & 10 & 52.6 & 23.0 & 4 & 67.0 & 45.2 \\
\hline agreeableness & 9 & 243.9 & 172.8 & 5 & 32.4 & 12.3 & 7 & 58.6 & 18.4 & 2 & 81.0 & 1.4 \\
\hline affect & 8 & 323.8 & 259.7 & 3 & 37.2 & 11.6 & 6 & 51.3 & 22.8 & 1 & 69.0 & \\
\hline pos affect & 14 & 192.1 & 78.9 & 8 & 35.0 & 8.7 & 13 & 59.8 & 22.1 & 2 & 94.5 & 7.8 \\
\hline neg affect & 8 & 209.5 & 69.2 & 4 & 43.1 & 9.9 & 6 & 40.6 & 24.2 & 0 & & \\
\hline self-efficacy & 23 & 272.0 & 191.8 & 19 & 27.2 & 9.3 & 17 & 58.2 & 29.7 & 5 & 65.4 & 38.2 \\
\hline self-esteem & 17 & 870.1 & 2234.4 & 12 & 29.4 & 11.0 & 12 & 57.5 & 28.1 & 3 & 86.0 & 15.1 \\
\hline LOC & 12 & 1120.5 & 2618.8 & 9 & 29.5 & 10.2 & 7 & 51.6 & 29.3 & 4 & 69.8 & 20.5 \\
\hline proactive personality & 5 & 204.0 & 69.6 & 5 & 37.5 & 5.6 & 5 & 54.1 & 6.2 & 3 & 13.7 & 23.7 \\
\hline
\end{tabular}




\begin{tabular}{|c|c|c|c|c|c|c|c|c|c|c|c|c|}
\hline CSE & 4 & 290.0 & 408.7 & 1 & 42.7 & & 3 & 57.6 & 8.6 & 1 & 84.0 & \\
\hline type A & 3 & 224.7 & 117.0 & 3 & 36.3 & 11.9 & 3 & 2.0 & 3.5 & 1 & 96.0 & . \\
\hline machiavellianism & 2 & 437.0 & 65.1 & 2 & 21.0 & 0.0 & 2 & 46.0 & 0.0 & 0 & & \\
\hline dominant personality & 2 & 4788.0 & 6464.4 & 1 & 24.0 & & 1 & 77.0 & & 1 & 93.0 & \\
\hline moral identity & 1 & 185.0 & & 1 & 28.5 & & 1 & 31.0 & & 0 & & \\
\hline other traits & 31 & 558.7 & 1639.7 & 24 & 33.4 & 10.5 & 25 & 50.7 & 25.2 & 13 & 62.5 & 31.9 \\
\hline Attitudes & 501 & 652.8 & 3117.9 & 313 & 34.0 & 8.8 & 394 & 51.7 & 27.3 & 173 & 61.0 & 36.8 \\
\hline job sat & 90 & 642.9 & 1766.2 & 51 & 34.7 & 7.3 & 64 & 60.7 & 28.5 & 37 & 66.9 & 38.1 \\
\hline life sat & 11 & 353.7 & 245.3 & 7 & 39.7 & 15.3 & 10 & 65.2 & 33.1 & 5 & 73.0 & 38.5 \\
\hline other sats & 18 & 5127.9 & 14781.9 & 8 & 35.0 & 8.0 & 14 & 69.9 & 30.5 & 9 & 77.4 & 17.6 \\
\hline org commit & 36 & 592.1 & 1879.2 & 25 & 32.9 & 6.4 & 30 & 48.6 & 26.2 & 14 & 55.5 & 39.1 \\
\hline affective commit & 13 & 479.3 & 360.4 & 11 & 35.2 & 8.1 & 11 & 51.0 & 28.9 & 4 & 40.5 & 47.2 \\
\hline continuance commit & 6 & 503.7 & 542.2 & 3 & 30.9 & 6.5 & 3 & 87.3 & 17.6 & 2 & 89.5 & 0.7 \\
\hline goal commit & 2 & 253.5 & 91.2 & 1 & 38.0 & & 2 & 66.7 & 9.4 & 0 & & \\
\hline justice & 4 & 788.0 & 1078.1 & 2 & 30.6 & 10.1 & 4 & 48.8 & 17.5 & 2 & 66.0 & 4.2 \\
\hline proc justice & 27 & 224.1 & 155.7 & 22 & 33.5 & 8.4 & 26 & 43.3 & 17.8 & 9 & 44.1 & 42.9 \\
\hline distr justice & 12 & 206.8 & 107.9 & 10 & 31.7 & 10.4 & 12 & 43.6 & 17.0 & 5 & 41.9 & 38.3 \\
\hline interac justice & 5 & 188.2 & 100.5 & 5 & 33.0 & 10.9 & 5 & 58.9 & 16.3 & 2 & 43.5 & 61.5 \\
\hline social support & 25 & 302.0 & 460.6 & 15 & 35.7 & 11.0 & 16 & 42.2 & 34.2 & 3 & 21.0 & 36.4 \\
\hline motivation & 16 & 369.2 & 457.4 & 9 & 27.1 & 8.8 & 11 & 49.0 & 20.2 & 3 & 60.3 & 53.1 \\
\hline eval attitudes & 11 & 184.8 & 82.6 & 4 & 41.0 & 1.4 & 8 & 51.8 & 24.3 & 5 & 74.8 & 9.5 \\
\hline engagement & 10 & 243.6 & 131.5 & 8 & 37.8 & 5.9 & 8 & 42.0 & 34.1 & 4 & 66.5 & 44.8 \\
\hline climate & 10 & 718.9 & 1156.3 & 6 & 36.3 & 4.4 & 8 & 53.5 & 37.2 & 2 & 94.5 & 7.8 \\
\hline WFC & 10 & 825.7 & 1003.5 & 5 & 33.7 & 3.6 & 8 & 47.5 & 25.2 & 4 & 35.5 & 41.5 \\
\hline mood & 5 & 251.6 & 248.2 & 4 & 22.7 & 7.8 & 5 & 68.8 & 24.6 & 2 & 84.0 & 5.7 \\
\hline job alternatives & 4 & 1028.5 & 940.7 & 1 & 33.0 & & 2 & 38.2 & 18.2 & 3 & 50.0 & 44.9 \\
\hline aap attitudes & 4 & 320.8 & 219.5 & 2 & 31.6 & 9.1 & 3 & 41.7 & 10.4 & 3 & 76.0 & 8.7 \\
\hline job embedd & 3 & 390.7 & 76.7 & 1 & 42.5 & & 1 & 57.0 & & 1 & 0.0 & \\
\hline other attitudes & 179 & 492.2 & 1336.4 & 113 & 33.9 & 9.4 & 143 & 48.5 & 26.9 & 54 & 61.2 & 35.8 \\
\hline Health outcomes & 124 & 353.1 & 337.9 & 77 & 35.4 & 10.8 & 103 & 55.7 & 33.5 & 37 & 59.5 & 41.0 \\
\hline role conflict & 30 & 302.0 & 260.7 & 15 & 36.6 & 8.0 & 19 & 52.7 & 35.2 & 5 & 52.2 & 48.4 \\
\hline stress & 26 & 407.0 & 390.2 & 15 & 36.3 & 10.4 & 21 & 54.3 & 36.9 & 11 & 66.6 & 43.2 \\
\hline
\end{tabular}




\begin{tabular}{|c|c|c|c|c|c|c|c|c|c|c|c|c|}
\hline burnout & 13 & 401.2 & 473.5 & 9 & 39.9 & 9.5 & 11 & 70.5 & 15.3 & 4 & 42.3 & 50.4 \\
\hline anxiety & 10 & 401.3 & 364.3 & 9 & 23.6 & 4.9 & 9 & 59.1 & 37.9 & 3 & 38.0 & 39.6 \\
\hline depression & 8 & 429.5 & 390.2 & 8 & 30.4 & 10.1 & 8 & 50.8 & 37.7 & 5 & 60.4 & 41.7 \\
\hline work demands & 7 & 215.4 & 125.4 & 5 & 28.1 & 8.3 & 7 & 50.6 & 39.0 & 1 & 91.0 & \\
\hline psyc complaints & 6 & 485.7 & 402.8 & 5 & 42.4 & 8.8 & 6 & 49.9 & 35.5 & 1 & 35.0 & \\
\hline mental health & 4 & 261.5 & 100.9 & 0 & & & 4 & 67.5 & 47.2 & 2 & 94.5 & 7.8 \\
\hline frustration & 4 & 442.3 & 560.6 & 4 & 31.4 & 11.8 & 4 & 61.7 & 21.2 & 1 & 35.0 & \\
\hline job strain & 3 & 160.7 & 132.7 & 2 & 41.4 & 5.5 & 3 & 69.1 & 10.8 & 0 & & \\
\hline other outcomes & 13 & 288.8 & 237.6 & 5 & 51.0 & 9.0 & 11 & 45.5 & 34.1 & 4 & 68.0 & 45.9 \\
\hline Other & 7 & 1162.9 & 2590.9 & 4 & 23.0 & 4.9 & 4 & 48.2 & 20.6 & 4.0 & 74.7 & 7.4 \\
\hline Total & 1424 & 593.8 & 2224.8 & 882 & 33.2 & 9.5 & 1134 & 52.6 & 28.2 & 474.0 & 62.6 & 36.2 \\
\hline
\end{tabular}

* Note: Gender and ethnicity are represented by the reported percentage of females and Whites, respectively. 
Table 2

Descriptive Statistics for Scale Properties of I/O Constructs and Construct Groups

\begin{tabular}{|c|c|c|c|c|c|c|c|c|c|c|}
\hline \multirow[b]{2}{*}{ Variable } & \multicolumn{5}{|c|}{ Items } & \multicolumn{5}{|c|}{ Scale Points } \\
\hline & $\mathrm{K}$ & $\mathrm{M}$ & SD & MIN & MAX & $\mathrm{K}$ & $\mathrm{M}$ & SD & MIN & MAX \\
\hline Behaviors & 326 & 7.6 & 17.9 & 2 & 300 & 281 & 5.8 & 1.2 & 2 & 11 \\
\hline job performance & 38 & 6.8 & 3.6 & 2 & 15 & 35 & 5.7 & 1.1 & 3 & 8 \\
\hline leader effectiveness & 32 & 6.8 & 11.7 & 2 & 70 & 25 & 6.2 & 1.2 & 5 & 9 \\
\hline turnover & 28 & 4.1 & 2.4 & 2 & 12 & 15 & 5.7 & 1.2 & 3 & 7 \\
\hline OCB & 17 & 7.3 & 4.8 & 3 & 21 & 16 & 5.3 & 0.7 & 5 & 7 \\
\hline harassment & 11 & 9.8 & 7.1 & 2 & 23 & 14 & 5.1 & 0.5 & 5 & 7 \\
\hline goal setting & 9 & 4.7 & 2.4 & 2 & 8 & 5 & 5.2 & 0.4 & 5 & 6 \\
\hline CWB & 8 & 8.5 & 2.3 & 5 & 12 & 8 & 6.5 & 0.9 & 5 & 7 \\
\hline negotiation & 8 & 2.5 & 0.5 & 2 & 3 & 8 & 6.0 & 1.1 & 5 & 7 \\
\hline withdrawal & 5 & 6.0 & 3.7 & 3 & 12 & 10 & 5.8 & 1.0 & 5 & 7 \\
\hline cooperation & 5 & 6.0 & 6.7 & 2 & 18 & 5 & 5.4 & 0.9 & 5 & 7 \\
\hline effort & 5 & 4.4 & 1.5 & 2 & 6 & 3 & 6.3 & 1.2 & 5 & 7 \\
\hline ingratiation & 5 & 20.0 & 0.0 & 20 & 20 & 5 & 6.2 & 1.1 & 5 & 7 \\
\hline abusive supervision & 4 & 7.5 & 5.0 & 5 & 15 & 4 & 6.5 & 1.0 & 5 & 7 \\
\hline conflict resolution & 4 & 3.3 & 1.5 & 2 & 5 & 3 & 7.0 & 2.0 & 5 & 9 \\
\hline denial & 4 & 3.0 & 1.2 & 2 & 4 & 4 & 5.0 & 0.0 & 5 & 5 \\
\hline achievement striving & 3 & 6.3 & 1.2 & 5 & 7 & 3 & 5.0 & 0.0 & 5 & 5 \\
\hline rejecting & 3 & 4.0 & 0.0 & 4 & 4 & 3 & 7.0 & 0.0 & 7 & 7 \\
\hline unethical pro org beh & 3 & 6.0 & 0.0 & 6 & 6 & 3 & 7.0 & 0.0 & 7 & 7 \\
\hline agency & 2 & 5.0 & 0.0 & 5 & 5 & 2 & 7.0 & 0.0 & 7 & 7 \\
\hline incivility & 2 & 4.5 & 0.7 & 4 & 5 & 2 & 5.0 & 0.0 & 5 & 5 \\
\hline prosocial beh & 2 & 7.5 & 3.5 & 5 & 10 & 2 & 5.0 & 0.0 & 5 & 5 \\
\hline aap intentions & 2 & 5.0 & 0.0 & 5 & 5 & 2 & 7.0 & 0.0 & 7 & 7 \\
\hline
\end{tabular}




\begin{tabular}{|c|c|c|c|c|c|c|c|c|c|c|}
\hline absenteeism & 1 & 4.0 & . & 4 & 4 & 1 & 3.0 & . & 3 & 3 \\
\hline aggression & 1 & 4.0 & . & 4 & 4 & 2 & 5.0 & 0.0 & 5 & 5 \\
\hline Other behaviors & 124 & 9.6 & 27.9 & 2 & 300 & 101 & 5.9 & 1.4 & 2 & 11 \\
\hline Abilities & 185 & 12.0 & 22.3 & 2 & 186 & 127 & 5.9 & 1.4 & 2 & 10 \\
\hline G & 10 & 52.5 & 65.7 & 2 & 186 & 2 & 5.0 & 0.0 & 5 & 5 \\
\hline LMX & 10 & 7.9 & 2.3 & 5 & 12 & 10 & 5.9 & 1.2 & 4 & 7 \\
\hline transformational & 6 & 7.2 & 5.6 & 3 & 18 & 6 & 5.3 & 0.8 & 5 & 7 \\
\hline other leader & 11 & 6.5 & 5.6 & 2 & 17 & 10 & 6.2 & 1.4 & 5 & 9 \\
\hline learning & 15 & 6.7 & 5.8 & 3 & 25 & 7 & 5.9 & 1.1 & 5 & 7 \\
\hline trust & 11 & 5.6 & 2.4 & 2 & 11 & 10 & 5.4 & 0.8 & 5 & 7 \\
\hline coping & 10 & 6.6 & 4.7 & 3 & 17 & 8 & 5.1 & 0.8 & 4 & 7 \\
\hline influence & 7 & 9.1 & 8.8 & 2 & 24 & 6 & 7.3 & 2.0 & 5 & 9 \\
\hline empowerment & 6 & 11.3 & 5.7 & 3 & 15 & 1 & 7.0 & . & 7 & 7 \\
\hline creativity & 4 & 5.0 & 2.8 & 3 & 9 & 3 & 6.3 & 1.2 & 5 & 7 \\
\hline charisma & 3 & 6.3 & 3.5 & 3 & 10 & 3 & 5.7 & 1.2 & 5 & 7 \\
\hline ability attributions & 2 & 10.5 & 7.8 & 5 & 16 & 1 & 10.0 & & 10 & 10 \\
\hline adaptability & 2 & 9.0 & 0.0 & 9 & 9 & 2 & 5.0 & 0.0 & 5 & 5 \\
\hline dependability & 2 & 5.0 & 4.2 & 2 & 8 & 2 & 7.0 & 0.0 & 7 & 7 \\
\hline altruism & 1 & 8.0 & . & 8 & 8 & 1 & 5.0 & . & 5 & 5 \\
\hline psyc detachment & 1 & 4.0 & . & 4 & 4 & 1 & 5.0 & & 5 & 5 \\
\hline assertiveness & 1 & 30.0 & . & 30 & 30 & 1 & 6.0 & & 6 & 6 \\
\hline integrity & 0 & & . & . & . & 2 & 5.0 & 0.0 & 5 & 5 \\
\hline other abilities & 83 & 12.1 & 19.7 & 2 & 110 & 51 & 5.8 & 1.6 & 2 & 9 \\
\hline Personality & 175 & 12.0 & 9.0 & 2 & 50 & 133 & 6.5 & 8.3 & 2 & 100 \\
\hline personality & 1 & 50.0 & & 50 & 50 & 1 & 5.0 & & 5 & 5 \\
\hline neuroticism & 17 & 14.3 & 9.1 & 8 & 48 & 12 & 5.7 & 1.0 & 5 & 7 \\
\hline conscientiousness & 15 & 16.2 & 11.3 & 4 & 48 & 11 & 6.2 & 1.0 & 5 & 7 \\
\hline openness & 10 & 14.7 & 11.9 & 7 & 48 & 6 & 6.7 & 0.8 & 5 & 7 \\
\hline extraversion & 9 & 14.7 & 12.6 & 8 & 48 & 6 & 6.0 & 1.1 & 5 & 7 \\
\hline agreeableness & 7 & 15.1 & 14.7 & 4 & 48 & 6 & 6.0 & 1.1 & 5 & 7 \\
\hline affect & 6 & 6.0 & 4.4 & 2 & 10 & 6 & 6.0 & 1.1 & 5 & 7 \\
\hline
\end{tabular}




\begin{tabular}{|c|c|c|c|}
\hline pos affect & 14 & 11.4 & 5.1 \\
\hline neg affect & 8 & 8.0 & 2.6 \\
\hline self-efficacy & 22 & 12.4 & 9.4 \\
\hline self-esteem & 15 & 10.9 & 5.7 \\
\hline LOC & 10 & 9.9 & 7.8 \\
\hline proactive personality & 5 & 11.6 & 5.1 \\
\hline CSE & 4 & 12.0 & 0.0 \\
\hline type A & 2 & 6.5 & 3.5 \\
\hline machiavellianism & 2 & 20.0 & 0.0 \\
\hline dominant personality & 1 & 12.0 & . \\
\hline moral identity & 1 & 5.0 & . \\
\hline other traits & 26 & 7.7 & 5.3 \\
\hline Attitudes & 444 & 8.0 & 7.8 \\
\hline job sat & 75 & 8.7 & 10.5 \\
\hline life sat & 11 & 7.4 & 5.2 \\
\hline other sats & 14 & 6.7 & 4.5 \\
\hline org commit & 30 & 9.1 & 3.6 \\
\hline affective commit & 10 & 7.3 & 1.2 \\
\hline continuance commit & 6 & 7.2 & 2.6 \\
\hline goal commit & 2 & 6.5 & 2.1 \\
\hline justice & 4 & 10.5 & 6.4 \\
\hline proc justice & 26 & 5.9 & 3.3 \\
\hline distr justice & 12 & 3.6 & 1.5 \\
\hline interac justice & 5 & 6.0 & 3.9 \\
\hline social support & 22 & 10.0 & 6.1 \\
\hline motivation & 15 & 9.4 & 6.4 \\
\hline WFC & 10 & 7.1 & 4.9 \\
\hline eval attitudes & 10 & 19.9 & 25.0 \\
\hline engagement & 9 & 7.1 & 4.0 \\
\hline climate & 8 & 9.0 & 5.4 \\
\hline mood & 4 & 9.0 & 7.5 \\
\hline job alternatives & 4 & 2.3 & 0.5 \\
\hline
\end{tabular}

\begin{tabular}{r|rrrrr}
23 & 10 & 5.1 & 1.1 & 4 & 7 \\
10 & 6 & 5.2 & 1.0 & 4 & 7 \\
47 & 16 & 5.4 & 1.5 & 4 & 11 \\
25 & 12 & 5.0 & 1.0 & 4 & 7 \\
29 & 7 & 5.0 & 1.5 & 2 & 7 \\
17 & 4 & 6.5 & 1.0 & 5 & 7 \\
12 & 4 & 6.5 & 1.0 & 5 & 7 \\
9 & 2 & 7.0 & 0.0 & 7 & 7 \\
20 & 2 & 7.0 & 0.0 & 7 & 7 \\
12 & 0 & & &. & 5 \\
5 & 1 & 5.0 &. & 5 & 5 \\
20 & 21 & 10.5 & 20.6 & 5 & 100 \\
72 & 346 & 5.8 & 1.4 & 2 & 12 \\
72 & 57 & 5.3 & 1.5 & 3 & 7 \\
20 & 8 & 5.5 & 1.4 & 3 & 7 \\
16 & 12 & 5.2 & 1.6 & 3 & 7 \\
15 & 23 & 6.1 & 1.2 & 3 & 7 \\
9 & 10 & 6.2 & 1.0 & 5 & 7 \\
9 & 6 & 5.7 & 1.0 & 5 & 7 \\
8 & 2 & 6.0 & 1.4 & 5 & 7 \\
20 & 3 & 5.0 & 0.0 & 5 & 5 \\
20 & 25 & 6.0 & 1.3 & 5 & 10 \\
7 & 10 & 6.5 & 2.1 & 5 & 10 \\
13 & 4 & 6.5 & 1.0 & 5 & 7 \\
21 & 14 & 5.9 & 1.5 & 2 & 7 \\
21 & 8 & 6.8 & 1.3 & 5 & 9 \\
16 & 9 & 5.2 & 1.6 & 2 & 7 \\
58 & 9 & 7.1 & 2.0 & 4 & 10 \\
15 & 7 & 5.4 & 0.8 & 5 & 7 \\
16 & 7 & 5.6 & 1.0 & 5 & 7 \\
20 & 3 & 4.7 & 0.6 & 4 & 5 \\
3 & 1 & 5.0 & 5 & 5 & 5
\end{tabular}




\begin{tabular}{|c|c|c|c|c|c|c|c|c|c|c|}
\hline aap attitudes & 4 & 5.0 & 0.0 & 5 & 5 & 4 & 7.5 & 0.6 & 7 & 8 \\
\hline job embedd & 3 & 23.0 & 13.9 & 7 & 31 & 1 & 5.0 & & 5 & 5 \\
\hline Other Attitudes & 160 & 7.3 & 6.4 & 2 & 45 & 123 & 5.9 & 1.4 & 3 & 12 \\
\hline Health Outcomes & 101 & 7.6 & 5.1 & 2 & 21 & 84 & 5.2 & 1.4 & 3 & 10 \\
\hline role conflict & 27 & 5.6 & 2.5 & 2 & 14 & 20 & 5.7 & 1.2 & 4 & 9 \\
\hline stress & 16 & 8.7 & 5.6 & 2 & 18 & 18 & 4.6 & 1.6 & 3 & 7 \\
\hline burnout & 12 & 7.0 & 2.4 & 4 & 12 & 10 & 6.1 & 1.1 & 4 & 7 \\
\hline anxiety & 8 & 10.6 & 5.7 & 4 & 20 & 7 & 4.6 & 0.5 & 4 & 5 \\
\hline depression & 6 & 12.7 & 8.5 & 3 & 21 & 5 & 4.6 & 0.5 & 4 & 5 \\
\hline work demands & 6 & 5.0 & 3.5 & 2 & 11 & 5 & 5.2 & 1.1 & 4 & 7 \\
\hline psyc complaints & 5 & 8.4 & 6.5 & 3 & 19 & 1 & 5.0 & & 5 & 5 \\
\hline mental health & 4 & 16.5 & 5.2 & 12 & 21 & 4 & 5.0 & 1.2 & 4 & 6 \\
\hline frustration & 4 & 2.8 & 0.5 & 2 & 3 & 4 & 5.3 & 1.0 & 4 & 6 \\
\hline job strain & 3 & 8.0 & 4.0 & 4 & 12 & 1 & 7.0 & & 7 & 7 \\
\hline other outcomes & 10 & 6.2 & 4.5 & 2 & 13 & 9 & 4.7 & 2.2 & 3 & 10 \\
\hline Other & 6 & 9.3 & 14.2 & 2 & 38 & 5 & 5.8 & 1.1 & 5 & 7 \\
\hline Total & 1237 & 9.1 & 14.1 & 2 & 300 & 976 & 5.9 & 3.3 & 2 & 100 \\
\hline
\end{tabular}


Table 3

Means, standard deviations, and pairwise correlations among variables

\begin{tabular}{|c|c|c|c|c|c|c|c|c|c|c|c|}
\hline & Variable & $M$ & $S D$ & 1 & 2 & 3 & 4 & 5 & 6 & 7 & 8 \\
\hline 1 & Sample size & 605.62 & 1952.61 & & & & & & & & \\
\hline 2 & Age & 32.63 & 9.51 & .12 & & & & & & & \\
\hline 3 & Age (sd) & 6.89 & 3.53 & .06 & $.79^{\star *}$ & & & & & & \\
\hline 4 & Gender & 50.07 & 28.63 & .02 & $-.11^{* *}$ & $-.09^{*}$ & & & & & \\
\hline 5 & Ethnicity & 64.11 & 34.22 & .04 & $.17^{* *}$ & .07 & $.13^{\star *}$ & & & & \\
\hline 6 & Items & 8.42 & 12.47 & $.10^{* *}$ & $-.10^{* *}$ & -.07 & .01 & .06 & & & \\
\hline 7 & Scale points & 5.92 & 3.58 & -.02 & -.02 & .01 & $-.07^{* *}$ & .05 & .01 & & \\
\hline 8 & Reliability & 0.81 & 0.11 & .05 & -.01 & .03 & $.09^{* *}$ & -.08 & $.12^{* *}$ & .01 & \\
\hline 9 & Inter-item cor. & 0.45 & 0.18 & .02 & .02 & .07 & .02 & $-.10^{*}$ & $-.38^{* *}$ & .00 & $.60^{* *}$ \\
\hline
\end{tabular}

Note: ${ }^{*} p<.05^{* *} p<.01$ : Data collapsed at the variable level. Gender and ethnicity were measured by the reported percentage of females and Whites, respectively. $\mathrm{N}$ range $=411$ to 1427 . 
Table 4

Means, standard deviations, and pairwise correlations among variables

\begin{tabular}{|c|c|c|c|c|c|c|c|c|c|c|c|}
\hline & Variable & $M$ & $S D$ & 1 & 2 & 3 & 4 & 5 & 6 & 7 & 8 \\
\hline 1 & Sample size & 605.62 & 1952.61 & & & & & & & & \\
\hline 2 & Age & 32.63 & 9.51 & .12 & & & & & & & \\
\hline 3 & Age (sd) & 6.89 & 3.53 & .06 & $.79^{* *}$ & & & & & & \\
\hline 4 & Gender & 50.07 & 28.63 & .02 & $-.11^{* *}$ & $-.09^{*}$ & & & & & \\
\hline 5 & Ethnicity & 64.11 & 34.22 & .04 & $.17^{* *}$ & .07 & $.13^{* *}$ & & & & \\
\hline 6 & Items & 8.42 & 12.47 & $.10^{* *}$ & $-.10^{* *}$ & -.07 & .01 & .06 & & & \\
\hline 7 & Scale points & 5.92 & 3.58 & -.02 & -.02 & .01 & $-.07^{* *}$ & .05 & .01 & & \\
\hline 8 & Reliability & 0.81 & 0.11 & .06 & .00 & .01 & $.13^{* *}$ & $-.14^{*}$ & $.12^{* *}$ & .01 & \\
\hline 9 & Inter-item cor. & 0.45 & 0.18 & .07 & .06 & .06 & .07 & -.09 & $-.36^{* *}$ & .07 & $.61^{* *}$ \\
\hline
\end{tabular}

Note: ${ }^{*} p<.05^{* *} p<.01$ : Data collapsed at the construct group level. Gender and ethnicity were measured by the reported percentage of females and Whites, respectively. $\mathrm{N}$ range $=279$ to 930 . 
Table 5

Summary of Reliability and Inter-Item Correlation Coefficient Distributions for Categorical Variables

\begin{tabular}{|c|c|c|c|c|c|c|c|c|c|c|}
\hline \multirow[b]{2}{*}{ Category } & \multicolumn{5}{|c|}{ Reliability } & \multicolumn{5}{|c|}{ Inter-item Correlations } \\
\hline & $\mathrm{K}$ & M & SD & $\mathrm{HCl}$ & $\mathrm{L} \mathrm{Cl}$ & $\mathrm{K}$ & M & $\mathrm{SD}$ & $\mathrm{H} \mathrm{Cl}$ & $\mathrm{LCl}$ \\
\hline \multicolumn{11}{|l|}{ IO Construct Group } \\
\hline Behaviors & 268 & 0.80 & 0.10 & 0.81 & 0.79 & 241 & 0.47 & 0.17 & 0.49 & 0.45 \\
\hline Abilities & 171 & 0.80 & 0.10 & 0.82 & 0.78 & 152 & 0.45 & 0.21 & 0.48 & 0.42 \\
\hline Personality & 114 & 0.80 & 0.09 & 0.82 & 0.78 & 105 & 0.37 & 0.15 & 0.40 & 0.34 \\
\hline Attitudes & 297 & 0.82 & 0.10 & 0.83 & 0.81 & 276 & 0.48 & 0.18 & 0.50 & 0.46 \\
\hline Health Outcomes & 77 & 0.81 & 0.09 & 0.83 & 0.79 & 66 & 0.47 & 0.15 & 0.51 & 0.43 \\
\hline \multicolumn{11}{|l|}{ Authorship } \\
\hline Academics & 1288 & 0.81 & 0.11 & 0.82 & 0.80 & 1119 & 0.46 & 0.18 & 0.47 & 0.45 \\
\hline Consultants & 11 & 0.69 & 0.14 & 0.77 & 0.61 & 10 & 0.39 & 0.26 & 0.55 & 0.23 \\
\hline Mixed & 128 & 0.79 & 0.10 & 0.81 & 0.77 & 118 & 0.41 & 0.17 & 0.44 & 0.38 \\
\hline \multicolumn{11}{|l|}{ Research Method } \\
\hline Survey only & 1097 & 0.81 & 0.11 & 0.82 & 0.80 & 954 & 0.45 & 0.18 & 0.46 & 0.44 \\
\hline Survey w Experiment & 252 & 0.81 & 0.11 & 0.82 & 0.80 & 228 & 0.46 & 0.19 & 0.48 & 0.44 \\
\hline Survey w Archival & 13 & 0.81 & 0.12 & 0.88 & 0.74 & 9 & 0.47 & 0.26 & 0.64 & 0.30 \\
\hline Survey w Interview & 24 & 0.74 & 0.14 & 0.80 & 0.68 & 21 & 0.43 & 0.15 & 0.49 & 0.37 \\
\hline Survey w Simulation & 2 & 0.78 & 0.14 & 0.98 & 0.58 & 1 & 0.18 & & & \\
\hline \multicolumn{11}{|l|}{ Students } \\
\hline Student sample & 287 & 0.80 & 0.11 & 0.81 & 0.79 & 249 & 0.43 & 0.21 & 0.46 & 0.40 \\
\hline Working sample & 1140 & 0.81 & 0.10 & 0.82 & 0.80 & 998 & 0.46 & 0.18 & 0.47 & 0.45 \\
\hline \multicolumn{11}{|l|}{ Study Location } \\
\hline North America & 1271 & 0.81 & 0.11 & 0.82 & 0.80 & 1111 & 0.45 & 0.19 & 0.46 & 0.44 \\
\hline Rest of the world & 156 & 0.82 & 0.09 & 0.83 & 0.81 & 136 & 0.48 & 0.16 & 0.51 & 0.45 \\
\hline Scale Type & & & & & & & & & & \\
\hline
\end{tabular}




\begin{tabular}{lrllll|rllll} 
Agreement & 550 & 0.82 & 0.09 & 0.83 & 0.81 & 520 & 0.45 & 0.18 & 0.47 & 0.43 \\
Frequency & 164 & 0.81 & 0.10 & 0.83 & 0.79 & 152 & 0.46 & 0.16 & 0.49 & 0.43 \\
Magnitude & 85 & 0.84 & 0.08 & 0.86 & 0.82 & 81 & 0.55 & 0.18 & 0.59 & 0.51 \\
Quality & 81 & 0.83 & 0.09 & 0.85 & 0.81 & 72 & 0.50 & 0.16 & 0.54 & 0.46 \\
Coefficient Location & & & & & & & & & & \\
In text only & 1391 & 0.81 & 0.11 & 1.02 & 0.60 & & & & & \\
In chart & 36 & 0.83 & 0.09 & 1.00 & 0.66 & & & & & \\
\hline
\end{tabular}

Note: $\mathrm{Cl}=$ Confidence Intervals (95\%). Data were collapsed at the variable level for all categories except for $1 \mathrm{O}$ construct groups (data collapsed at the construct group level). 
Table 6

Summary for Listwise Linear Regression Analysis for Predictive Variables

\begin{tabular}{|c|c|c|c|c|c|c|c|c|}
\hline \multirow[b]{2}{*}{ Variable } & \multicolumn{3}{|c|}{ Reliability } & \multicolumn{5}{|c|}{ Inter-Item Correlations } \\
\hline & $B$ & SE B & 8 & & $B$ & SE B & 8 & \\
\hline Sample size & 2.24 & 0.00 & 0.14 & * & 5.53 & 0.00 & 0.18 & ** \\
\hline Scale points & 0.00 & 0.00 & 0.02 & & 0.02 & 0.01 & 0.17 & ** \\
\hline Age & 0.00 & 0.00 & -0.17 & & 0.00 & 0.00 & 0.12 & \\
\hline Gender & -6.33 & 0.00 & -0.02 & & -5.06 & 0.00 & -0.01 & \\
\hline Ethnicity & 0.00 & 0.00 & -0.08 & & 0.00 & 0.00 & -0.07 & \\
\hline Students & -0.02 & 0.02 & -0.10 & & 0.01 & 0.04 & 0.01 & \\
\hline Items & 0.00 & 0.00 & 0.07 & & & & & \\
\hline $\mathrm{N}$ & 241 & & & & 243 & & & \\
\hline$R^{2}$ & 0.06 & & & & 0.07 & & & \\
\hline$F$ for change in $R^{2}$ & 2.13 & * & & & 2.81 & ** & & \\
\hline
\end{tabular}


Table 7

Summary for Listwise Linear Regression Analysis for Predictive Variables

\begin{tabular}{|c|c|c|c|c|c|c|}
\hline \multirow[b]{2}{*}{ Variable } & \multicolumn{3}{|c|}{ Reliability } & \multicolumn{3}{|c|}{ Inter-Item Correlations } \\
\hline & $B$ & SE B & 8 & $B$ & SE B & 8 \\
\hline Sample size & -5.67 & 0.00 & -0.03 & 2.04 & 0.00 & 0.05 \\
\hline Scale points & 0.00 & 0.00 & 0.03 & 0.01 & 0.01 & 0.05 \\
\hline Age & 0.00 & 0.00 & -0.12 & 0.00 & 0.00 & 0.16 \\
\hline Gender & 3.17 & 0.00 & 0.01 & 0.00 & 0.00 & 0.04 \\
\hline Ethnicity & 0.00 & 0.00 & -0.11 & 0.00 & 0.00 & 0.09 \\
\hline Students & 0.00 & 0.02 & 0.01 & 0.01 & 0.04 & 0.09 \\
\hline Items & 0.00 & 0.00 & 0.09 & & & \\
\hline $\mathrm{N}$ & 153 & & & 162 & & \\
\hline$R^{2}$ & 0.05 & & & 0.02 & & \\
\hline$F$ for change in $R^{2}$ & 1.07 & & & 0.62 & & \\
\hline
\end{tabular}


Table 8

Summary for Linear Regression Analysis for Variables Predicting Inter-Item Correlations

\begin{tabular}{|c|c|c|c|c|c|c|c|c|c|c|c|c|}
\hline \multirow[b]{2}{*}{ Variable } & \multicolumn{3}{|c|}{ Leader Behaviors } & & \multicolumn{3}{|c|}{ Big-Five } & \multicolumn{5}{|c|}{ Job Satisfaction } \\
\hline & $B$ & SE B & b & & $B$ & SE B & b & & $B$ & SE B & $B$ & \\
\hline Sample size & 2.22 & 0.00 & 0.01 & * & 0.00 & 0.00 & -0.37 & & 9.09 & 0.00 & 0.17 & \\
\hline Scale points & 0.05 & 0.03 & 0.32 & & 0.03 & 0.03 & 0.91 & ** & 0.07 & 0.02 & 0.58 & $* *$ \\
\hline Age & 0.00 & 0.01 & 0.29 & & -0.02 & 0.01 & -0.83 & * & 0.00 & 0.00 & -0.08 & \\
\hline Gender & 0.00 & 0.00 & 0.42 & * & 0.00 & 0.00 & -0.13 & & 0.00 & 0.00 & 0.13 & \\
\hline $\mathrm{N}$ & 14 & & & & 24 & & & & 35 & & & \\
\hline $\begin{array}{l}\mathrm{R}^{2} \\
\mathrm{~F} \text { for change in }\end{array}$ & 0.79 & & & & 0.43 & & & & 0.31 & & & \\
\hline $\mathrm{R}^{2}$ & 6.01 & ** & & & 3.52 & * & & & 3.43 & * & & \\
\hline
\end{tabular}

Note: ${ }^{*} p<.05$ ** $p<.01$ (Standard deviation for Age was used in Big-5 analysis). Gender was measured using the reported percentage of female participants. Only variables with $\mathrm{N}>10$ were observed. 
Table 9

Summary for Linear Regression Analysis for

Variables Predicting Reliability

\begin{tabular}{lccc}
\hline & \multicolumn{3}{c}{ Justice/Fairness } \\
\cline { 2 - 4 } Variable & $B$ & SE B & 6 \\
\hline Sample size & -9.69 & 0.00 & -0.16 \\
Scale points & -0.01 & 0.01 & -0.22 \\
Age & 0.00 & 0.00 & -0.05 \\
Gender & 0.00 & 0.00 & 0.46 \\
Items & 0.00 & 0.01 & 0.01 \\
& & & \\
$\mathrm{~N}$ & 34 & & \\
$\mathrm{R}^{2}$ & 0.31 & \\
$\mathrm{~F}$ for change in $\mathrm{R}^{2}$ & $2.55 *$ \\
\hline Note: ${ }^{*} \mathrm{p}<.05{ }^{* *} \mathrm{p}<.01$. Gender was measured \\
using the reported percentage of female \\
participants. Only constructs with $\mathrm{N}>10$ were \\
Observed.
\end{tabular}


Table 10

Summary of I/O Construct Reliability and Inter-Item Correlations Coefficient Distributions

\begin{tabular}{|c|c|c|c|c|c|c|c|c|c|c|}
\hline \multirow[b]{2}{*}{ Variable } & \multicolumn{5}{|c|}{ Reliability } & \multicolumn{5}{|c|}{ Inter-Item Correlations } \\
\hline & $\mathrm{K}$ & M & SD & $\mathrm{HCl}$ & $\mathrm{L} \mathrm{Cl}$ & $\mathrm{K}$ & $\mathrm{M}$ & SD & $\mathrm{HCl}$ & $\mathrm{L} \mathrm{Cl}$ \\
\hline Behaviors & 268 & 0.80 & 0.10 & 0.81 & 0.79 & 241 & 0.47 & 0.17 & 0.49 & 0.45 \\
\hline job performance & 45 & 0.82 & 0.13 & 0.86 & 0.78 & 39 & 0.51 & 0.19 & 0.57 & 0.45 \\
\hline leader effectiveness & 37 & 0.83 & 0.10 & 0.86 & 0.79 & 33 & 0.54 & 0.16 & 0.59 & 0.48 \\
\hline turnover & 28 & 0.83 & 0.08 & 0.86 & 0.80 & 28 & 0.59 & 0.14 & 0.64 & 0.54 \\
\hline OCB & 18 & 0.84 & 0.07 & 0.87 & 0.81 & 17 & 0.48 & 0.15 & 0.55 & 0.41 \\
\hline harrassment & 14 & 0.82 & 0.06 & 0.86 & 0.79 & 11 & 0.40 & 0.12 & 0.47 & 0.34 \\
\hline goal setting & 9 & 0.74 & 0.10 & 0.80 & 0.67 & 9 & 0.41 & 0.19 & 0.53 & 0.28 \\
\hline CWB & 8 & 0.85 & 0.07 & 0.90 & 0.80 & 8 & 0.41 & 0.13 & 0.51 & 0.32 \\
\hline negotiation & 8 & 0.74 & 0.09 & 0.80 & 0.68 & 8 & 0.55 & 0.16 & 0.65 & 0.44 \\
\hline withdrawal & 10 & 0.70 & 0.10 & 0.76 & 0.64 & 5 & 0.33 & 0.16 & 0.47 & 0.19 \\
\hline cooperation & 7 & 0.72 & 0.11 & 0.80 & 0.64 & 5 & 0.41 & 0.20 & 0.58 & 0.23 \\
\hline effort & 5 & 0.87 & 0.09 & 0.95 & 0.79 & 5 & 0.66 & 0.20 & 0.83 & 0.49 \\
\hline ingratiation & 7 & 0.73 & 0.11 & 0.82 & 0.65 & 5 & 0.18 & 0.08 & 0.26 & 0.11 \\
\hline Abilities & 171 & 0.80 & 0.10 & 0.82 & 0.78 & 152 & 0.45 & 0.21 & 0.48 & 0.42 \\
\hline G & 19 & 0.78 & 0.17 & 0.85 & 0.70 & 10 & 0.17 & 0.23 & 0.31 & 0.03 \\
\hline LMX & 11 & 0.88 & 0.04 & 0.90 & 0.85 & 10 & 0.47 & 0.10 & 0.53 & 0.40 \\
\hline transformational & 7 & 0.86 & 0.04 & 0.89 & 0.82 & 6 & 0.53 & 0.12 & 0.63 & 0.43 \\
\hline other leader & 13 & 0.86 & 0.08 & 0.90 & 0.81 & 11 & 0.60 & 0.17 & 0.70 & 0.50 \\
\hline learning & 16 & 0.79 & 0.09 & 0.84 & 0.74 & 15 & 0.46 & 0.17 & 0.55 & 0.38 \\
\hline trust & 13 & 0.83 & 0.09 & 0.89 & 0.78 & 11 & 0.55 & 0.12 & 0.62 & 0.48 \\
\hline coping & 10 & 0.80 & 0.09 & 0.86 & 0.74 & 10 & 0.47 & 0.21 & 0.60 & 0.34 \\
\hline influence & 7 & 0.81 & 0.07 & 0.86 & 0.76 & 7 & 0.51 & 0.21 & 0.66 & 0.35 \\
\hline empowerment & 6 & 0.90 & 0.07 & 0.95 & 0.84 & 6 & 0.53 & 0.09 & 0.61 & 0.46 \\
\hline Personality & 114 & 0.80 & 0.09 & 0.82 & 0.78 & 105 & 0.37 & 0.15 & 0.40 & 0.34 \\
\hline
\end{tabular}




\begin{tabular}{|c|c|c|c|c|c|c|c|c|c|c|}
\hline neuroticism & 18 & 0.82 & 0.08 & 0.86 & 0.78 & 17 & 0.31 & 0.11 & 0.36 & 0.25 \\
\hline conscientiousness & 18 & 0.81 & 0.07 & 0.84 & 0.78 & 15 & 0.27 & 0.19 & 0.37 & 0.18 \\
\hline openness & 11 & 0.77 & 0.09 & 0.82 & 0.71 & 10 & 0.24 & 0.11 & 0.30 & 0.17 \\
\hline extraversion & 11 & 0.80 & 0.07 & 0.84 & 0.76 & 9 & 0.28 & 0.14 & 0.37 & 0.19 \\
\hline agreeableness & 9 & 0.79 & 0.09 & 0.84 & 0.73 & 7 & 0.24 & 0.15 & 0.35 & 0.13 \\
\hline affect & 8 & 0.84 & 0.11 & 0.92 & 0.77 & 6 & 0.55 & 0.13 & 0.65 & 0.44 \\
\hline pos affect & 8 & 0.82 & 0.08 & 0.88 & 0.76 & 8 & 0.41 & 0.14 & 0.51 & 0.31 \\
\hline neg affect & 14 & 0.85 & 0.05 & 0.88 & 0.82 & 14 & 0.38 & 0.13 & 0.45 & 0.31 \\
\hline self-efficacy & 23 & 0.84 & 0.09 & 0.88 & 0.81 & 22 & 0.42 & 0.14 & 0.47 & 0.36 \\
\hline self-esteem & 17 & 0.82 & 0.08 & 0.86 & 0.78 & 15 & 0.36 & 0.16 & 0.44 & 0.28 \\
\hline LOC & 12 & 0.69 & 0.12 & 0.76 & 0.63 & 10 & 0.27 & 0.11 & 0.33 & 0.20 \\
\hline proactive personality & 5 & 0.84 & 0.08 & 0.91 & 0.77 & 5 & 0.34 & 0.04 & 0.38 & 0.31 \\
\hline Attitudes & 297 & 0.82 & 0.10 & 0.83 & 0.81 & 276 & 0.48 & 0.18 & 0.50 & 0.46 \\
\hline job sat & 90 & 0.83 & 0.09 & 0.85 & 0.81 & 75 & 0.50 & 0.18 & 0.54 & 0.46 \\
\hline life sat & 11 & 0.86 & 0.03 & 0.88 & 0.84 & 11 & 0.50 & 0.11 & 0.57 & 0.44 \\
\hline other sats & 18 & 0.81 & 0.10 & 0.86 & 0.77 & 14 & 0.51 & 0.22 & 0.62 & 0.39 \\
\hline org commit & 36 & 0.84 & 0.08 & 0.86 & 0.81 & 30 & 0.41 & 0.12 & 0.45 & 0.36 \\
\hline affective commit & 13 & 0.83 & 0.05 & 0.86 & 0.81 & 10 & 0.45 & 0.13 & 0.52 & 0.37 \\
\hline continuance commit & 6 & 0.78 & 0.06 & 0.83 & 0.73 & 6 & 0.39 & 0.21 & 0.56 & 0.22 \\
\hline proc justice & 27 & 0.84 & 0.10 & 0.87 & 0.80 & 26 & 0.52 & 0.17 & 0.58 & 0.45 \\
\hline distr justice & 12 & 0.85 & 0.12 & 0.91 & 0.78 & 12 & 0.67 & 0.20 & 0.78 & 0.55 \\
\hline interac justice & 5 & 0.88 & 0.04 & 0.92 & 0.85 & 5 & 0.60 & 0.13 & 0.71 & 0.48 \\
\hline social support & 25 & 0.84 & 0.13 & 0.89 & 0.78 & 22 & 0.46 & 0.19 & 0.54 & 0.39 \\
\hline motivation & 16 & 0.81 & 0.10 & 0.86 & 0.76 & 15 & 0.42 & 0.22 & 0.53 & 0.31 \\
\hline WFC & 10 & 0.81 & 0.10 & 0.87 & 0.75 & 10 & 0.48 & 0.22 & 0.61 & 0.34 \\
\hline eval attitudes & 11 & 0.77 & 0.12 & 0.84 & 0.70 & 10 & 0.38 & 0.26 & 0.54 & 0.22 \\
\hline engagement & 10 & 0.71 & 0.25 & 0.86 & 0.56 & 10 & 0.36 & 0.19 & 0.48 & 0.25 \\
\hline climate & 10 & 0.87 & 0.07 & 0.91 & 0.83 & 8 & 0.55 & 0.09 & 0.62 & 0.49 \\
\hline mood & 5 & 0.77 & 0.08 & 0.84 & 0.69 & 4 & 0.37 & 0.17 & 0.53 & 0.20 \\
\hline
\end{tabular}




\begin{tabular}{lrllll|rrrrr} 
Health Outcomes & $\mathbf{7 7}$ & $\mathbf{0 . 8 1}$ & $\mathbf{0 . 0 9}$ & $\mathbf{0 . 8 3}$ & $\mathbf{0 . 7 9}$ & $\mathbf{6 6}$ & $\mathbf{0 . 4 7}$ & $\mathbf{0 . 1 5}$ & $\mathbf{0 . 5 1}$ & $\mathbf{0 . 4 3}$ \\
role conflict & 30 & 0.79 & 0.07 & 0.81 & 0.76 & 26 & 0.44 & 0.13 & 0.49 & 0.39 \\
stress & 26 & 0.80 & 0.10 & 0.84 & 0.76 & 17 & 0.46 & 0.13 & 0.52 & 0.40 \\
burnout & 13 & 0.84 & 0.05 & 0.87 & 0.81 & 12 & 0.45 & 0.11 & 0.51 & 0.39 \\
anxiety & 10 & 0.90 & 0.03 & 0.92 & 0.88 & 8 & 0.50 & 0.14 & 0.59 & 0.40 \\
depression & 8 & 0.84 & 0.13 & 0.94 & 0.75 & 6 & 0.54 & 0.09 & 0.62 & 0.47 \\
work demands & 7 & 0.73 & 0.21 & 0.88 & 0.57 & 6 & 0.41 & 0.12 & 0.50 & 0.32 \\
psyc complaints & 6 & 0.86 & 0.04 & 0.90 & 0.82 & 5 & 0.47 & 0.14 & 0.59 & 0.35 \\
\hline
\end{tabular}

Note: Only constructs with $\mathrm{K}>=5$ are included in this table. $\mathrm{Cl}=$ Confidence intervals (95\%). Data for construct groups and variables were collapsed at their respective levels. 
Table 11

Summary of Scale-Specific Descriptives, Reliability, and Inter-Item Correlations Coefficient Distributions

\begin{tabular}{|c|c|c|c|c|c|c|c|c|c|c|c|c|c|c|}
\hline \multirow[b]{2}{*}{ Variable } & \multicolumn{2}{|c|}{ Items } & \multicolumn{2}{|c|}{$\begin{array}{l}\text { Scale } \\
\text { points }\end{array}$} & \multicolumn{5}{|c|}{ Reliability } & \multicolumn{5}{|c|}{ Inter-item correlations } \\
\hline & $\mathrm{K}$ & $M$ & $\mathrm{~K}$ & $M$ & $\mathrm{~K}$ & $M$ & SD & $\mathrm{HCl}$ & $\mathrm{L} \mathrm{Cl}$ & $\mathrm{K}$ & $M$ & SD & $\mathrm{H} \mathrm{Cl}$ & $\mathrm{L} \mathrm{Cl}$ \\
\hline \multicolumn{15}{|l|}{ Behaviors } \\
\hline \multicolumn{15}{|l|}{$\frac{\text { Organizational Citizenship }}{\text { Behaviors }}$} \\
\hline Moorman (1993) & 4 & 9.8 & 4 & 5.0 & 4 & 0.77 & 0.07 & 0.84 & 0.70 & 4 & 0.33 & 0.13 & 0.45 & 0.20 \\
\hline Williams \& Anderson (1991) & 4 & 5.5 & 4 & 6.0 & 2 & 0.84 & 0.08 & 0.95 & 0.73 & 2 & 0.51 & 0.08 & 0.61 & 0.40 \\
\hline \multicolumn{15}{|l|}{ Turnover intentions } \\
\hline Colarelli, S. M. (1984) & 3 & 3.0 & 3 & 7.0 & 2 & 0.76 & 0.04 & 0.80 & 0.71 & 2 & 0.51 & 0.05 & 0.58 & 0.44 \\
\hline Hom, Griffeth, \& Sellaro (1984) & 7 & 2.3 & 5 & 5.0 & 4 & 0.87 & 0.05 & 0.91 & 0.82 & 4 & 0.73 & 0.05 & 1.17 & 0.29 \\
\hline Ostroff \& Kozlowski (1992) & 3 & 3.0 & 1 & 5.0 & 3 & 0.88 & 0.03 & 0.92 & 0.84 & 3 & 0.71 & 0.06 & 0.78 & 0.64 \\
\hline Hanisch \& Hulin (1990) & 5 & 3.6 & 1 & 7.0 & 5 & 0.75 & 0.10 & 0.84 & 0.66 & 5 & 0.49 & 0.12 & 0.59 & 0.39 \\
\hline \multicolumn{15}{|l|}{ Work withdrawal } \\
\hline Hanisch \& Hulin (1990) & 6 & 7.5 & 6 & 6.0 & 4 & 0.78 & 0.10 & 0.88 & 0.68 & 3 & 0.38 & 0.19 & 0.60 & 0.16 \\
\hline \multirow{2}{*}{\multicolumn{15}{|c|}{$\begin{array}{l}\text { Abilities } \\
\text { Leader-Member Exchange (LMX) }\end{array}$}} \\
\hline & & & & & & & & & & & & & & \\
\hline $\begin{array}{l}\text { Graen, Liden, \& Hoel (1982); Scandura \& } \\
\text { Graen (1984); Graen \& Uhl-Bien (1995) }\end{array}$ & 5 & 6.6 & 4 & 5.3 & 5 & 0.87 & 0.05 & 0.91 & 0.83 & 5 & 0.52 & 0.10 & 0.60 & 0.44 \\
\hline Liden \& Maslyn (1998) & 2 & 12.0 & 2 & 7.0 & 2 & 0.86 & 0.02 & 0.88 & 0.83 & 2 & 0.33 & 0.04 & 0.39 & 0.27 \\
\hline \multicolumn{15}{|l|}{ Transformational Leadership } \\
\hline Bass (1985); Avolio, Bass, \& Jung (1999) & 4 & 7.8 & 4 & 5.0 & 3 & 0.86 & 0.03 & 0.89 & 0.83 & 2 & 0.58 & 0.06 & 0.66 & 0.50 \\
\hline \multicolumn{15}{|l|}{ Personality Traits } \\
\hline \multicolumn{15}{|l|}{ Big-5 (Agreeableness) } \\
\hline Goldberg $(1992 ; 1999)$ & 2 & 10.0 & 1 & 5.0 & 3 & 0.86 & 0.06 & 0.92 & 0.80 & 2 & 0.32 & 0.01 & 0.34 & 0.30 \\
\hline Costa \& McCrae (1992) & 4 & 20.5 & 3 & 5.7 & 4 & 0.71 & 0.05 & 0.76 & 0.66 & 4 & 0.14 & 0.06 & 0.20 & 0.08 \\
\hline \multicolumn{15}{|l|}{ Big-5 (Conscientiousness) } \\
\hline Goldberg (1992) & 3 & 10.0 & 2 & 6.0 & 4 & 0.81 & 0.08 & 0.89 & 0.73 & 3 & 0.29 & 0.10 & 0.40 & 0.18 \\
\hline
\end{tabular}


Costa \& McCrae (1989; 1992)

Big-5 (Extraversion)

Goldberg, L. R. (1992)

Costa \& McCrae (1992)

Big-5 (Neuroticism)

Goldberg (1992)

Costa \& McCrae $(1991 ; 1992)$

Eysenck \& Eysenck (1968)

\section{Big-5 (Openness to experience)}

Goldberg (1992; 1999)

Costa \& McCrae (1992)

\section{Proactive personality}

Bateman \& Crant (1993)

\section{Self-efficacy}

Eden \& Zuk (1995); Eden \& Aviram (1993)

Judge, Locke, Durham, \& Kluger (1998)

Riggs, Warka, Babasa, Betancourt, \& Hooker (1994)

\section{Positive Affect}

Watson, Clark, \& Tellegen (1988)

Negative Affect

Watson \& Clark (1984)

\section{Locus of Control (LOC)}

Levenson (1981)

Rotter (1966)

\section{Attitudes}

\section{Job satisfaction}

Brayfield \& Rothe (1951)

Hackman \& Oldham (1975)

\begin{tabular}{|c|c|c|c|c|c|c|c|c|c|c|c|c|c|}
\hline 6 & 17.7 & 4 & 6.3 & 6 & 0.82 & 0.08 & 0.89 & 0.75 & 6 & 0.31 & 0.25 & 0.51 & 0.11 \\
\hline 3 & 10.0 & 1 & 5.0 & 4 & 0.83 & 0.07 & 0.90 & 0.76 & 3 & 0.38 & 0.05 & 0.43 & 0.33 \\
\hline 5 & 18.8 & 3 & 6.3 & 5 & 0.75 & 0.02 & 0.77 & 0.73 & 5 & 0.18 & 0.07 & 0.24 & 0.12 \\
\hline 3 & 10.0 & 1 & 7.0 & 1 & 0.55 & & 0.55 & 0.55 & 0 & & & & \\
\hline 7 & 16.9 & 5 & 5.8 & 7 & 0.81 & 0.04 & 0.84 & 0.78 & 7 & 0.25 & 0.10 & 0.32 & 0.18 \\
\hline 3 & 12.0 & 4 & 5.0 & 3 & 0.90 & 0.01 & 0.91 & 0.89 & 3 & 0.42 & 0.02 & 0.44 & 0.40 \\
\hline 5 & 11.6 & 2 & 7.0 & 3 & 0.84 & 0.07 & 0.97 & 0.71 & 3 & 0.36 & 0.11 & 0.57 & 0.15 \\
\hline 6 & 20.5 & 6 & 6.5 & 6 & 0.83 & 0.05 & 0.87 & 0.79 & 5 & 0.30 & 0.06 & 0.35 & 0.25 \\
\hline 5 & 11.6 & 4 & 6.5 & 4 & 0.68 & 0.09 & 0.77 & 0.59 & 4 & 0.13 & 0.78 & 0.21 & 0.05 \\
\hline 3 & 17.0 & 0 & & 3 & 0.86 & 0.09 & 0.96 & 0.76 & 3 & 0.31 & 0.14 & 0.47 & 0.15 \\
\hline 4 & 7.0 & 4 & 5.0 & 4 & 0.84 & 0.04 & 0.88 & 0.80 & 4 & 0.43 & 0.07 & 0.50 & 0.36 \\
\hline 4 & 9.3 & 4 & 5.5 & 4 & 0.91 & 0.04 & 0.95 & 0.87 & 4 & 0.53 & 0.10 & 0.63 & 0.43 \\
\hline 3 & 8.0 & 2 & 5.0 & 3 & 0.88 & 0.05 & 0.93 & 0.83 & 3 & 0.52 & 0.09 & 0.62 & 0.42 \\
\hline 8 & 10.0 & 6 & 4.7 & 8 & 0.85 & 0.03 & 0.87 & 0.83 & 8 & 0.37 & 0.07 & 0.42 & 0.33 \\
\hline 5 & 5.6 & 5 & 5.4 & 5 & 0.69 & 0.07 & 0.75 & 0.63 & 5 & 0.31 & 0.09 & 0.39 & 0.23 \\
\hline 3 & 17.0 & 1 & 2.0 & 3 & 0.77 & 0.07 & 0.85 & 0.69 & 3 & 0.20 & 0.13 & 0.34 & 0.06 \\
\hline 5 & 5.0 & 5 & 5.8 & 5 & 0.85 & 0.03 & 0.88 & 0.82 & 5 & 0.56 & 0.07 & 0.63 & 0.49 \\
\hline 12 & 4.1 & 7 & 6.3 & 10 & 0.80 & 0.08 & 0.85 & 0.75 & 9 & 0.51 & 0.12 & 0.59 & 0.43 \\
\hline
\end{tabular}


Roznowski (1989)

Smith, Kendall, \& Hulin (1969)

Warr \& Routledge (1969); Warr, Cook, \&

Wall (1979).

Cammann, Fichman, Jenkins, \& Klesh

(1979)

Weiss, Dawis, England, \& Lofquist (1967)

Organizational Commitment

Allen \& Meyer (affective; 1990)

Porter \& Smith (1970) Porter, Steers,

Mowday, \& Boulian (1974); Mowday, Steers,

\& Porter $(1979 ; 1982)$

Meyer \& Allen (1984)

Justice and Fairness

Colquitt (distributive; 2001)

Niehoff \& Moorman (distributive; 1993)

Colquitt (procedural; 2001)

\section{Health Outcomes}

\section{Role ambiguity}

Rizzo, House, \& Lirtzman (1970)

\section{Job stress}

Smith, Sademan, \& McCrary (1992)

Caplan, Cobb, French, Harrison, \& Pinneau (1975)

\section{Anxiety}

Parker \& DeCotiis (1983)

Spielberger, Gorsuch, \& Lushene (1970); Spielberger (1979)

\begin{tabular}{|c|c|c|c|c|c|c|c|c|c|c|c|c|c|}
\hline 3 & 18.7 & 3 & 3.7 & 4 & 0.83 & 0.03 & 0.86 & 0.80 & 3 & 0.32 & 0.18 & 0.52 & 0.12 \\
\hline 12 & 18.6 & 13 & 4.1 & 17 & 0.84 & 0.05 & 0.86 & 0.82 & 12 & 0.32 & 0.14 & 0.40 & 0.24 \\
\hline 2 & 15.5 & 2 & 7.0 & 3 & 0.83 & 0.11 & 0.95 & 0.71 & 2 & 0.36 & 0.06 & 0.45 & 0.27 \\
\hline 6 & 3.0 & 5 & 6.4 & 6 & 0.85 & 0.06 & 0.90 & 0.80 & 6 & 0.67 & 0.11 & 0.76 & 0.58 \\
\hline 3 & 17.0 & 2 & 5.0 & 3 & 0.84 & 0.05 & 0.89 & 0.79 & 3 & 0.27 & 0.10 & 0.38 & 0.16 \\
\hline 2 & 5.5 & 2 & 6.0 & 3 & 0.76 & 0.12 & 0.89 & 0.63 & 2 & 0.36 & 0.00 & 0.36 & 0.36 \\
\hline 13 & 9.7 & 8 & 6.4 & 15 & 0.83 & 0.10 & 0.88 & 0.78 & 13 & 0.38 & 0.16 & 0.46 & 0.30 \\
\hline 3 & 7.3 & 2 & 6.0 & 2 & 0.87 & 0.05 & 0.94 & 0.80 & 2 & 0.54 & 0.01 & 0.56 & 0.52 \\
\hline 3 & 3.3 & 3 & 5.0 & 3 & 0.84 & 0.12 & 0.97 & 0.71 & 3 & 0.67 & 0.24 & 0.94 & 0.40 \\
\hline 2 & 4.5 & 2 & 6.0 & 2 & 0.89 & 0.06 & 0.98 & 0.80 & 2 & 0.72 & 0.30 & 1.13 & 0.31 \\
\hline 12 & 7.3 & 12 & 5.3 & 12 & 0.87 & 0.07 & 0.91 & 0.83 & 12 & 0.52 & 0.18 & 0.62 & 0.42 \\
\hline 8 & 6.9 & 2 & 5.0 & 9 & 0.78 & 0.05 & 0.81 & 0.75 & 8 & 0.39 & 0.06 & 0.43 & 0.35 \\
\hline 2 & 18.0 & 2 & 3.0 & 2 & 0.89 & 0.01 & 0.91 & 0.87 & 2 & 0.31 & 0.03 & 0.35 & 0.27 \\
\hline 2 & 17.0 & 2 & 5.0 & 2 & 0.95 & 0.01 & 0.96 & 0.94 & 2 & 0.51 & 0.04 & 0.56 & 0.46 \\
\hline 2 & 15.0 & 2 & 5.0 & 2 & 0.94 & 0.00 & 0.94 & 0.94 & 2 & 0.51 & 0.00 & 0.51 & 0.51 \\
\hline 3 & 13.3 & 2 & 4.0 & 2 & 0.90 & 0.06 & 1.01 & 0.79 & 1 & 0.23 & & 0.23 & 0.23 \\
\hline
\end{tabular}

: Scales displayed were chosen when $\mathrm{N}>2$ and/or had at least one other meaningful comparison scale by construct

$\mathrm{Cl}=$ confidence intervals $(95 \%)$ 
Table 12

Summary for Average Reliability for I/O Construct Groups by Year

\begin{tabular}{|c|c|c|c|c|c|c|c|c|c|c|c|c|c|c|c|}
\hline \multirow[b]{2}{*}{ Year } & \multicolumn{3}{|c|}{ Behaviors } & \multicolumn{3}{|c|}{ Abilities } & \multicolumn{3}{|c|}{ Personality } & \multicolumn{3}{|c|}{ Attitudes } & \multicolumn{3}{|c|}{ Health outcomes } \\
\hline & $K$ & $M$ & $S D$ & $K$ & $M$ & $S D$ & $K$ & $M$ & $S D$ & $K$ & $M$ & $S D$ & $K$ & $M$ & $S D$ \\
\hline 1975 & 10 & 0.73 & 0.12 & 5 & 0.76 & 0.15 & 4 & 0.67 & 0.06 & 18 & 0.79 & 0.10 & 9 & 0.73 & 0.17 \\
\hline 1980 & 9 & 0.72 & 0.15 & 7 & 0.77 & 0.14 & 4 & 0.68 & 0.08 & 12 & 0.77 & 0.14 & 4 & 0.82 & 0.08 \\
\hline 1985 & 18 & 0.71 & 0.21 & 15 & 0.71 & 0.18 & 2 & 0.88 & 0.01 & 23 & 0.79 & 0.17 & 4 & 0.71 & 0.09 \\
\hline 1990 & 24 & 0.78 & 0.14 & 19 & 0.75 & 0.15 & 9 & 0.73 & 0.08 & 32 & 0.79 & 0.16 & 8 & 0.80 & 0.07 \\
\hline 1995 & 22 & 0.77 & 0.14 & 19 & 0.74 & 0.16 & 11 & 0.77 & 0.12 & 18 & 0.78 & 0.08 & 10 & 0.78 & 0.10 \\
\hline 2000 & 48 & 0.79 & 0.09 & 36 & 0.79 & 0.11 & 24 & 0.82 & 0.09 & 53 & 0.83 & 0.09 & 18 & 0.85 & 0.08 \\
\hline 2005 & 67 & 0.82 & 0.09 & 35 & 0.83 & 0.08 & 31 & 0.82 & 0.06 & 74 & 0.83 & 0.06 & 11 & 0.85 & 0.05 \\
\hline 2010 & 67 & 0.85 & 0.07 & 42 & 0.86 & 0.07 & 29 & 0.83 & 0.07 & 64 & 0.84 & 0.09 & 13 & 0.82 & 0.06 \\
\hline
\end{tabular}

Table 13

Summary for Average Inter-Item Correlations for I/O Construct Groups by Year

\begin{tabular}{|c|c|c|c|c|c|c|c|c|c|c|c|c|c|c|c|}
\hline \multirow[b]{2}{*}{ Year } & \multicolumn{3}{|c|}{ Behaviors } & \multicolumn{3}{|c|}{ Abilities } & \multicolumn{3}{|c|}{ Personality } & \multicolumn{3}{|c|}{ Attitudes } & \multicolumn{3}{|c|}{ Health outcomes } \\
\hline & $K$ & $M$ & $S D$ & $K$ & $M$ & $S D$ & $K$ & $M$ & $S D$ & $K$ & $M$ & $S D$ & $K$ & $M$ & $S D$ \\
\hline 1975 & 6 & 0.43 & 0.14 & 3 & 0.41 & 0.17 & 3 & 0.37 & 0.03 & 12 & 0.38 & 0.17 & 6 & 0.47 & 0.17 \\
\hline 1980 & 7 & 0.34 & 0.12 & 6 & 0.33 & 0.20 & 4 & 0.21 & 0.12 & 11 & 0.38 & 0.17 & 3 & 0.41 & 0.08 \\
\hline 1985 & 14 & 0.38 & 0.20 & 14 & 0.40 & 0.22 & 2 & 0.52 & 0.35 & 20 & 0.43 & 0.12 & 3 & 0.52 & 0.20 \\
\hline 1990 & 19 & 0.42 & 0.25 & 15 & 0.26 & 0.20 & 8 & 0.27 & 0.15 & 31 & 0.44 & 0.24 & 8 & 0.38 & 0.07 \\
\hline 1995 & 20 & 0.44 & 0.15 & 18 & 0.39 & 0.21 & 10 & 0.30 & 0.12 & 17 & 0.45 & 0.15 & 9 & 0.38 & 0.17 \\
\hline 2000 & 44 & 0.44 & 0.18 & 31 & 0.42 & 0.18 & 24 & 0.37 & 0.16 & 50 & 0.50 & 0.17 & 13 & 0.50 & 0.14 \\
\hline 2005 & 65 & 0.51 & 0.17 & 33 & 0.54 & 0.19 & 28 & 0.40 & 0.11 & 72 & 0.49 & 0.15 & 11 & 0.56 & 0.15 \\
\hline 2010 & 61 & 0.52 & 0.15 & 38 & 0.52 & 0.17 & 26 & 0.38 & 0.14 & 62 & 0.56 & 0.16 & 12 & 0.46 & 0.14 \\
\hline
\end{tabular}


Table 14

Summary for Regression Analysis for Trends Among I/O Constructs

\begin{tabular}{|c|c|c|c|c|c|c|c|c|c|c|c|c|c|c|}
\hline \multirow[b]{3}{*}{ Variable } & \multicolumn{7}{|c|}{ Reliability } & \multicolumn{7}{|c|}{ Inter-item correlations } \\
\hline & \multicolumn{4}{|c|}{$S E$} & \multicolumn{3}{|c|}{$F-R^{2}$} & \multicolumn{4}{|c|}{$S E$} & \multicolumn{3}{|c|}{$F-R^{2}$} \\
\hline & 8 & & $B$ & $B$ & $R^{2}$ & chg. & & 8 & & $B$ & $B$ & $R^{2}$ & chg. & \\
\hline Overall & 0.30 & ** & 0.00 & 0.02 & 0.09 & 90.70 & ** & 0.26 & ** & 0.00 & 0.03 & 0.07 & 63.23 & ** \\
\hline Behaviors & 0.33 & ** & 0.00 & 0.02 & 0.11 & 31.77 & ** & 0.23 & ** & 0.01 & 0.33 & 0.06 & 13.78 & ** \\
\hline Abilities & 0.34 & ** & 0.00 & 0.02 & 0.12 & 22.18 & ** & 0.33 & ** & 0.01 & 0.04 & 0.11 & 17.77 & ** \\
\hline Personality & 0.44 & $* *$ & 0.00 & 0.02 & 0.19 & 26.52 & ** & 0.20 & * & 0.01 & 0.02 & 0.04 & 4.41 & * \\
\hline Attitudes & 0.22 & $* *$ & 0.00 & 0.01 & 0.05 & 14.33 & ** & 0.33 & ** & 0.01 & 0.03 & 0.11 & 32.47 & ** \\
\hline Health outcomes & 0.34 & $* *$ & 0.01 & 0.01 & 0.12 & 9.87 & ** & 0.15 & & 0.01 & 0.01 & 0.02 & 1.54 & \\
\hline
\end{tabular}

Note: ${ }^{*} p<.05^{* *} p<.01$.

Separate regressions were conducted for each variable over year of publication

Table 15

Summary for Variable Missing Data by Year

\begin{tabular}{|c|c|c|c|c|c|c|c|c|c|c|c|c|c|}
\hline \multirow[b]{2}{*}{ Year } & \multirow[b]{2}{*}{$K$} & \multicolumn{2}{|c|}{ Age } & \multicolumn{2}{|c|}{ Gender } & \multicolumn{2}{|c|}{ Ethnicity } & \multicolumn{2}{|c|}{ Items } & \multicolumn{2}{|c|}{ Scale points } & \multicolumn{2}{|c|}{ Scale type } \\
\hline & & $M$ & $S D$ & $M$ & $S D$ & $M$ & $S D$ & $M$ & $S D$ & $M$ & $S D$ & $M$ & $S D$ \\
\hline 1975 & 46 & 0.28 & 0.46 & 0.46 & 0.50 & 0.11 & 0.31 & 0.63 & 0.49 & 0.54 & 0.50 & 0.37 & 0.49 \\
\hline 1980 & 36 & 0.14 & 0.35 & 0.33 & 0.48 & 0.08 & 0.28 & 0.81 & 0.40 & 0.33 & 0.48 & 0.28 & 0.45 \\
\hline 1985 & 61 & 0.43 & 0.50 & 0.79 & 0.41 & 0.20 & 0.40 & 0.79 & 0.41 & 0.38 & 0.49 & 0.20 & 0.40 \\
\hline 1990 & 92 & 0.65 & 0.50 & 0.52 & 0.50 & 0.14 & 0.35 & 0.82 & 0.39 & 0.58 & 0.50 & 0.43 & 0.50 \\
\hline 1995 & 80 & 0.71 & 0.48 & 0.84 & 0.37 & 0.18 & 0.38 & 0.91 & 0.28 & 0.75 & 0.44 & 0.68 & 0.47 \\
\hline 2000 & 180 & 0.67 & 0.46 & 0.88 & 0.32 & 0.51 & 0.50 & 0.87 & 0.34 & 0.67 & 0.47 & 0.64 & 0.48 \\
\hline 2005 & 219 & 0.76 & 0.47 & 0.85 & 0.36 & 0.32 & 0.47 & 0.95 & 0.22 & 0.79 & 0.41 & 0.80 & 0.40 \\
\hline 2010 & 219 & 0.61 & 0.43 & 0.87 & 0.33 & 0.39 & 0.49 & 0.90 & 0.30 & 0.82 & 0.38 & 0.77 & 0.42 \\
\hline Total & 933 & 0.53 & 0.45 & 0.69 & 0.41 & 0.24 & 0.40 & 0.84 & 0.35 & 0.61 & 0.46 & 0.52 & 0.45 \\
\hline
\end{tabular}


Table 16

Summary for Regression Analysis for Trends in Missing Data

\begin{tabular}{|c|c|c|c|c|c|c|c|}
\hline Variable & $B$ & & SE B & $B$ & $R^{2}$ & $\begin{array}{l}F-R^{2} \\
\text { chg. }\end{array}$ & \\
\hline Age & 0.32 & $* *$ & 0.01 & 0.08 & 0.10 & 104.99 & ** \\
\hline Gender & 0.31 & $* *$ & 0.01 & 0.06 & 0.09 & 96.30 & ** \\
\hline Ethnicity & 0.21 & $* *$ & 0.01 & 0.05 & 0.04 & 40.66 & ** \\
\hline Items & 0.19 & $* *$ & 0.01 & 0.03 & 0.04 & 34.33 & ** \\
\hline Scale points & 0.27 & $* *$ & 0.01 & 0.06 & 0.08 & 75.43 & $* *$ \\
\hline Scale type & 0.36 & $* *$ & 0.01 & 0.09 & 0.13 & 134.84 & ** \\
\hline
\end{tabular}

Note: ${ }^{*} p<.05^{* *} p<.01$

Separate regressions were conducted for each variable over year of publication. 
Table 17

Distribution of Content in The Journal of Applied Psychology by Year

\begin{tabular}{|c|c|c|c|c|c|c|c|c|c|c|c|c|c|c|c|c|}
\hline & \multicolumn{2}{|c|}{1975} & \multicolumn{2}{|c|}{1980} & \multicolumn{2}{|c|}{1985} & \multicolumn{2}{|c|}{1990} & \multicolumn{2}{|c|}{1995} & \multicolumn{2}{|c|}{2000} & \multicolumn{2}{|c|}{2005} & \multicolumn{2}{|c|}{2010} \\
\hline & K & $\%$ & K & $\%$ & $\mathrm{~K}$ & $\%$ & $\mathrm{~K}$ & $\%$ & $\mathrm{~K}$ & $\%$ & $\mathrm{~K}$ & $\%$ & $\mathrm{~K}$ & $\%$ & $\mathrm{~K}$ & $\%$ \\
\hline Behaviors & 11 & 22.4 & 9 & 21.4 & 15 & 20.5 & 28 & 24.3 & 27 & 25.5 & 54 & 21.1 & 84 & 28.7 & 80 & 29.1 \\
\hline Job performance & 2 & 4.1 & 3 & 7.1 & 1 & 1.4 & 8 & 7.0 & 5 & 4.7 & 3 & 1.2 & 14 & 4.8 & 9 & 3.3 \\
\hline Leader beh. / effectiveness & 4 & 8.2 & 1 & 2.4 & 4 & 5.5 & $\begin{array}{l}2 \\
1\end{array}$ & 1.7 & 2 & 1.9 & $\begin{array}{r}5 \\
12\end{array}$ & 2.0 & 9 & 3.1 & 9 & 3.3 \\
\hline $\begin{array}{l}\text { Turnover intentions / job } \\
\text { search }\end{array}$ & 0 & 0.0 & 0 & 0.0 & 0 & 0.0 & 1 & 0.9 & 4 & 3.8 & 12 & 4.7 & 7 & 2.4 & 4 & 1.5 \\
\hline Org. citizenship beh. & 0 & 0.0 & 0 & 0.0 & 0 & 0.0 & 0 & 0.0 & 0 & 0.0 & 2 & 0.8 & 5 & 1.7 & 10 & 3.6 \\
\hline Harassment & 0 & 0.0 & 0 & 0.0 & 0 & 0.0 & 0 & 0.0 & 0 & 0.0 & 5 & 2.0 & 8 & 2.7 & 1 & 0.4 \\
\hline Work withdrawal & 0 & 0.0 & 0 & 0.0 & 0 & 0.0 & 0 & 0.0 & 0 & 0.0 & 6 & 2.3 & 4 & 1.4 & 0 & 0.0 \\
\hline Goal setting & 0 & 0.0 & 0 & 0.0 & 0 & 0.0 & 0 & 0.0 & 0 & 0.0 & 0 & 0.0 & 4 & 1.4 & 1 & 0.4 \\
\hline Negotiation & 0 & 0.0 & 0 & 0.0 & 0 & 0.0 & 0 & 0.0 & 0 & 0.0 & 0 & 0.0 & 4 & 1.4 & 4 & 1.5 \\
\hline Org. deviance / CWB & 1 & 2.0 & 0 & 0.0 & 0 & 0.0 & 0 & 0.0 & 0 & 0.0 & 2 & 0.8 & 0 & 0.0 & 5 & 1.8 \\
\hline Cooperation & 1 & 2.0 & 1 & 2.4 & 0 & 0.0 & 1 & 0.9 & 0 & 0.0 & 2 & 0.8 & 2 & 0.7 & 0 & 0.0 \\
\hline Effort & 1 & 2.0 & 0 & 0.0 & 0 & 0.0 & 1 & 0.9 & 1 & 0.9 & 1 & 0.4 & 0 & 0.0 & 0 & 0.0 \\
\hline Impression mana./ingratiation & 0 & 0.0 & 0 & 0.0 & 0 & 0.0 & 1 & 0.9 & 2 & 1.9 & 2 & 0.8 & 0 & 0.0 & 0 & 0.0 \\
\hline Abusive supervision & .0 & 0.0 & .0 & 0.0 & .0 & 0.0 & .0 & 0.0 & .0 & 0.0 & .0 & 0.0 & 1 & 0.3 & 3 & 1.1 \\
\hline Conflict resolution & 0 & 0.0 & 1 & 2.4 & 0 & 0.0 & 0 & 0.0 & 1 & 0.9 & 0 & 0.0 & 0 & 0.0 & 2 & 0.7 \\
\hline Denial & .0 & 0.0 & .0 & 0.0 & .0 & 0.0 & .0 & 0.0 & .0 & 0.0 & .0 & 0.0 & 4 & 1.4 & 0 & 0.0 \\
\hline Achievement striving & 0 & 0.0 & 0 & 0.0 & 0 & 0.0 & 1 & 0.9 & 1 & 0.9 & 0 & 0.0 & 1 & 0.3 & 0 & 0.0 \\
\hline Rejecting/excluding & 0 & 0.0 & 0 & 0.0 & 0 & 0.0 & 0 & 0.0 & 0 & 0.0 & 0 & 0.0 & 0 & 0.0 & 3 & 1.1 \\
\hline Unethical pro-org beh. & 0 & 0.0 & 0 & 0.0 & 0 & 0.0 & 0 & 0.0 & 0 & 0.0 & 0 & 0.0 & 0 & 0.0 & 3 & 1.1 \\
\hline $\begin{array}{l}\text { Absenteeism } \\
\text { Affirmative action prg. }\end{array}$ & 0 & 0.0 & 0 & 0.0 & 0 & 0.0 & 1 & 0.9 & 0 & 0.0 & $\begin{array}{l}0 \\
2\end{array}$ & 0.0 & $\begin{array}{l}0 \\
0\end{array}$ & 0.0 & 0 & 0.0 \\
\hline intentions & 0 & 0.0 & 0 & 0.0 & 0 & 0.0 & 0 & 0.0 & 0 & 0.0 & & 0.8 & & 0.0 & 0 & 0.0 \\
\hline Agency & .0 & 0.0 & .0 & 0.0 & .0 & 0.0 & .0 & 0.0 & .0 & 0.0 & .0 & 0.0 & .0 & 0.0 & 2 & 0.7 \\
\hline
\end{tabular}




\begin{tabular}{|c|c|c|c|c|c|c|c|c|c|c|c|c|c|c|c|c|}
\hline Aggression & .0 & 0.0 & .0 & 0.0 & .0 & 0.0 & .0 & 0.0 & 0 & 0.0 & 1 & 0.4 & 0 & 0.0 & 1 & 0.4 \\
\hline Incivility & 0 & 0.0 & 0 & 0.0 & 0 & 0.0 & 0 & 0.0 & 0 & 0.0 & 0 & 0.0 & 2 & 0.7 & 0 & 0.0 \\
\hline Prosocial beh. & 0 & 0.0 & 0 & 0.0 & 0 & 0.0 & 2 & 1.7 & 0 & 0.0 & 0 & 0.0 & 0 & 0.0 & 0 & 0.0 \\
\hline Other behaviors & 2 & 4.1 & 3 & 7.1 & 10 & 13.7 & 10 & 8.7 & 11 & 10.4 & 11 & 4.3 & 19 & 6.5 & 23 & 8.4 \\
\hline Abilities & 6 & 12.2 & 7 & 16.7 & 15 & 20.5 & 17 & 14.8 & 22 & 20.8 & 41 & 16.0 & 35 & 11.9 & 46 & 16.7 \\
\hline Leadership (LMX) & 0 & 0.0 & 0 & 0.0 & 1 & 1.4 & 0 & 0.0 & 1 & 0.9 & 2 & 0.8 & 1 & 0.3 & 6 & 2.2 \\
\hline Leadership (transf./trans.) & 0 & 0.0 & 0 & 0.0 & 0 & 0.0 & 0 & 0.0 & 2 & 1.9 & 1 & 0.4 & 4 & 1.4 & 0 & 0.0 \\
\hline Leadership (other types) & 0 & 0.0 & 2 & 4.8 & 0 & 0.0 & 2 & 1.7 & 3 & 2.8 & 0 & 0.0 & 4 & 1.4 & 2 & 0.7 \\
\hline Cognitive ability & 1 & 2.0 & 1 & 2.4 & 2 & 2.7 & 1 & 0.9 & 1 & 0.9 & 5 & 2.0 & 2 & 0.7 & 6 & 2.2 \\
\hline Learning ability & 1 & 2.0 & 1 & 2.4 & 0 & 0.0 & 1 & 0.9 & 0 & 0.0 & 9 & 3.5 & 3 & 1.0 & 1 & 0.4 \\
\hline Trust & 1 & 2.0 & 0 & 0.0 & 1 & 1.4 & 0 & 0.0 & 1 & 0.9 & 2 & 0.8 & 1 & 0.3 & 7 & 2.5 \\
\hline Coping ability & 0 & 0.0 & 0 & 0.0 & 0 & 0.0 & 2 & 1.7 & 1 & 0.9 & 1 & 0.4 & 5 & 1.7 & 1 & 0.4 \\
\hline Empowerment & 0 & 0.0 & 0 & 0.0 & 0 & 0.0 & 0 & 0.0 & 0 & 0.0 & 5 & 2.0 & 1 & 0.3 & 0 & 0.0 \\
\hline Creativity / innovation & 0 & 0.0 & 0 & 0.0 & 0 & 0.0 & 0 & 0.0 & 0 & 0.0 & 1 & 0.4 & 0 & 0.0 & 3 & 1.1 \\
\hline Adaptability & 0 & 0.0 & 0 & 0.0 & 0 & 0.0 & 0 & 0.0 & 0 & 0.0 & 2 & 0.8 & 0 & 0.0 & 0 & 0.0 \\
\hline Charisma & 0 & 0.0 & 0 & 0.0 & 0 & 0.0 & 0 & 0.0 & 0 & 0.0 & 0 & 0.0 & 1 & 0.3 & 2 & 0.7 \\
\hline Dependability & 1 & 2.0 & 1 & 2.4 & 0 & 0.0 & 1 & 0.9 & 0 & 0.0 & 0 & 0.0 & 0 & 0.0 & 0 & 0.0 \\
\hline Ability attributions & 0 & 0.0 & 0 & 0.0 & 0 & 0.0 & 0 & 0.0 & 2 & 1.9 & 0 & 0.0 & 0 & 0.0 & 0 & 0.0 \\
\hline Altruism & 0 & 0.0 & 0 & 0.0 & 0 & 0.0 & 0 & 0.0 & 0 & 0.0 & 1 & 0.4 & 1 & 0.3 & 0 & 0.0 \\
\hline Assertiveness & 0 & 0.0 & 0 & 0.0 & 0 & 0.0 & 0 & 0.0 & 0 & 0.0 & 1 & 0.4 & 0 & 0.0 & 0 & 0.0 \\
\hline Influence & 0 & 0.0 & 0 & 0.0 & 0 & 0.0 & 1 & 0.9 & 0 & 0.0 & 0 & 0.0 & 0 & 0.0 & 0 & 0.0 \\
\hline Psychological detachment & 0 & 0.0 & 0 & 0.0 & 0 & 0.0 & 0 & 0.0 & 0 & 0.0 & 0 & 0.0 & 0 & 0.0 & 1 & 0.4 \\
\hline Other abilities & 2 & 4.1 & 2 & 4.8 & 11 & 15.1 & 9 & 7.8 & 11 & 10.4 & 11 & 4.3 & 12 & 4.1 & 17 & 6.2 \\
\hline Personality Traits & 4 & 8.2 & 4 & 9.5 & 5 & 6.8 & 12 & 10.4 & 16 & 15.1 & 47 & 18.4 & 53 & 18.1 & 41 & 14.9 \\
\hline Big Five & 0 & 0.0 & 0 & 0.0 & 0 & 0.0 & 2 & 1.7 & 5 & 4.7 & 21 & 8.2 & 18 & 6.1 & 21 & 7.6 \\
\hline Affect & 0 & 0.0 & 0 & 0.0 & 2 & 2.7 & 4 & 3.5 & 0 & 0.0 & 7 & 2.7 & 10 & 3.4 & 7 & 2.5 \\
\hline Self-efficacy & 0 & 0.0 & 0 & 0.0 & 1 & 1.4 & 0 & 0.0 & 3 & 2.8 & 10 & 3.9 & 7 & 2.4 & 2 & 0.7 \\
\hline
\end{tabular}




\begin{tabular}{|c|c|c|c|c|c|c|c|c|c|c|c|c|c|c|c|c|}
\hline Self-esteem & 0 & 0.0 & 1 & 2.4 & 2 & 2.7 & 0 & 0.0 & 3 & 2.8 & 6 & 2.3 & 5 & 1.7 & 0 & 0.0 \\
\hline Locus of control & 0 & 0.0 & 1 & 2.4 & 0 & 0.0 & 3 & 2.6 & 0 & 0.0 & 3 & 1.2 & 4 & 1.4 & 1 & 0.4 \\
\hline Proactive personality & 0 & 0.0 & 0 & 0.0 & 0 & 0.0 & 0 & 0.0 & 0 & 0.0 & 0 & 0.0 & 3 & 1.0 & 1 & 0.4 \\
\hline Core-self evaluations (CSE) & .0 & 0.0 & .0 & 0.0 & .0 & 0.0 & .0 & 0.0 & .0 & 0.0 & 0 & 0.0 & 1 & 0.3 & 3 & 1.1 \\
\hline Dominant personality & .0 & 0.0 & .0 & 0.0 & .0 & 0.0 & 1 & 0.9 & 0 & 0.0 & 0 & 0.0 & 1 & 0.3 & 0 & .0 \\
\hline Machiavellianism & 0 & 0.0 & 0 & 0.0 & 0 & 0.0 & 0 & 0.0 & 2 & 1.9 & 0 & 0.0 & 0 & 0.0 & 0 & .0 \\
\hline Type A & 2 & 4.1 & 0 & 0.0 & 0 & 0.0 & 0 & 0.0 & 0 & 0.0 & 0 & 0.0 & 0 & 0.0 & 0 & 0.0 \\
\hline Moral identity & 0 & 0.0 & 0 & 0.0 & 0 & 0.0 & 0 & 0.0 & 0 & 0.0 & 0 & 0.0 & 0 & 0.0 & 1 & 0.4 \\
\hline Other personality traits & 2 & 4.1 & 2 & 4.8 & 0 & 0.0 & 2 & 1.7 & 3 & 2.8 & 0 & 0.0 & 4 & 1.4 & 5 & 1.8 \\
\hline Attitudes & 14 & 28.6 & 16 & 38.1 & 32 & 43.8 & 43 & 37.4 & 27 & 25.5 & 85 & 33.2 & 109 & 37.2 & 84 & 30.5 \\
\hline Satisfaction (job) & 0 & 0.0 & 5 & 11.9 & 7 & 9.6 & 15 & 13.0 & 5 & 4.7 & 20 & 7.8 & 19 & 6.5 & 11 & 4.0 \\
\hline Satisfaction (life) & 0 & 0.0 & 1 & 2.4 & 1 & 1.4 & 1 & 0.9 & 0 & 0.0 & 2 & 0.8 & 3 & 1.0 & 3 & 1.1 \\
\hline Satisfaction (other types) & 0 & 0.0 & 0 & 0.0 & 2 & 2.7 & 2 & 1.7 & 3 & 2.8 & 4 & 1.6 & 5 & 1.7 & 1 & 0.4 \\
\hline Commitment & 2 & 4.1 & 2 & 4.8 & 3 & 4.1 & 4 & 3.5 & 3 & 2.8 & 10 & 3.9 & 19 & 6.5 & 10 & 3.6 \\
\hline Justice & 0 & 0.0 & 0 & 0.0 & 0 & 0.0 & 0 & 0.0 & 1 & 0.9 & 12 & 4.7 & 12 & 4.1 & 21 & 7.6 \\
\hline Perceptions support & 1 & 2.0 & 0 & 0.0 & 1 & 1.4 & 7 & 6.1 & 1 & 0.9 & 5 & 2.0 & 7 & 2.4 & 3 & 1.1 \\
\hline Motivation & 0 & 0.0 & 1 & 2.4 & 3 & 4.1 & 1 & 0.9 & 1 & 0.9 & 6 & 2.3 & 2 & 0.7 & 2 & 0.7 \\
\hline Climate / safety & 2 & 4.1 & 0 & 0.0 & 1 & 1.4 & 0 & 0.0 & 0 & 0.0 & 2 & 0.8 & 3 & 1.0 & 2 & 0.7 \\
\hline $\begin{array}{l}\text { Performance evaluation } \\
\text { attitudes }\end{array}$ & 1 & 2.0 & 1 & 2.4 & 2 & 2.7 & 0 & 0.0 & 0 & 0.0 & 4 & 1.6 & 0 & 0.0 & 2 & 0.7 \\
\hline Work-family conflict & 0 & 0.0 & 0 & 0.0 & 0 & 0.0 & 0 & 0.0 & 1 & 0.9 & 2 & 0.8 & 5 & 1.7 & 2 & 0.7 \\
\hline Involvement / engagement & 0 & 0.0 & 0 & 0.0 & 0 & 0.0 & 0 & 0.0 & 0 & 0.0 & 0 & 0.0 & 3 & 1.0 & 1 & 0.4 \\
\hline Job embeddedness & 0 & 0.0 & 0 & 0.0 & 0 & 0.0 & 1 & 0.9 & 0 & 0.0 & 0 & 0.0 & 3 & 1.0 & 3 & 1.1 \\
\hline Mood & 0 & 0.0 & 0 & 0.0 & 0 & 0.0 & 1 & 0.9 & 2 & 1.9 & 0 & 0.0 & 1 & 0.3 & 1 & 0.4 \\
\hline $\begin{array}{l}\text { Attitudes twd. affirmative } \\
\text { action }\end{array}$ & 0 & 0.0 & 0 & 0.0 & 0 & 0.0 & 0 & 0.0 & 0 & 0.0 & 4 & 1.6 & 0 & 0.0 & 0 & 0.0 \\
\hline Perceptions of job alternatives & 0 & 0.0 & 0 & 0.0 & 0 & 0.0 & 0 & 0.0 & 0 & 0.0 & 1 & 0.4 & 1 & 0.3 & 2 & 0.7 \\
\hline Other attitudes & 8 & 16.3 & 6 & 14.3 & 12 & 16.4 & 11 & 9.6 & 10 & 9.4 & 13 & 5.1 & 26 & 8.9 & 20 & 7.3 \\
\hline
\end{tabular}




\begin{tabular}{|c|c|c|c|c|c|c|c|c|c|c|c|c|c|c|c|c|}
\hline Health Outcomes & 14 & 28.6 & 6 & 14.3 & 6 & 8.2 & 15 & 13.0 & 14 & 13.2 & 28 & 10.9 & 11 & 3.8 & 20 & 7.3 \\
\hline Role ambiguity / conflict & 4 & 8.2 & 4 & 9.5 & 0 & 0.0 & 3 & 2.6 & 5 & 4.7 & 4 & 1.6 & 4 & 1.4 & 3 & 1.1 \\
\hline Stress & 2 & 4.1 & 1 & 2.4 & 5 & 6.8 & 2 & 1.7 & 0 & 0.0 & 10 & 3.9 & 4 & 1.4 & 3 & 1.1 \\
\hline Anxiety & 1 & 2.0 & 1 & 2.4 & 0 & 0.0 & 0 & 0.0 & 2 & 1.9 & 6 & 2.3 & 0 & 0.0 & 0 & 0.0 \\
\hline Emotional exhaustion & 0 & 0.0 & 0 & 0.0 & 0 & 0.0 & 1 & 0.9 & 0 & 0.0 & 0 & 0.0 & 1 & 0.3 & 5 & 1.8 \\
\hline Depression & 1 & 2.0 & 0 & 0.0 & 0 & 0.0 & 2 & 1.7 & 2 & 1.9 & 2 & 0.8 & 0 & 0.0 & 1 & 0.4 \\
\hline Work demands & 3 & 6.1 & 0 & 0.0 & 0 & 0.0 & 1 & 0.9 & 1 & 0.9 & 0 & 0.0 & 0 & 0.0 & 2 & 0.7 \\
\hline Psychological complaints & 0 & 0.0 & 0 & 0.0 & 0 & 0.0 & 1 & 0.9 & 2 & 1.9 & 0 & 0.0 & 0 & 0.0 & 2 & 0.7 \\
\hline Mental health & 0 & 0.0 & 0 & 0.0 & 0 & 0.0 & 2 & 1.7 & 0 & 0.0 & 2 & 0.8 & 0 & 0.0 & 0 & 0.0 \\
\hline Burnout & 0 & 0.0 & 0 & 0.0 & 0 & 0.0 & 1 & 0.9 & 0 & 0.0 & 0 & 0.0 & 0 & 0.0 & 2 & 0.7 \\
\hline Frustration & 0 & 0.0 & 0 & 0.0 & 0 & 0.0 & 0 & 0.0 & 0 & 0.0 & 3 & 1.2 & 0 & 0.0 & 0 & 0.0 \\
\hline Job strain & 0 & 0.0 & 0 & 0.0 & 1 & 1.4 & 2 & 1.7 & 0 & 0.0 & 0 & 0.0 & 0 & 0.0 & 0 & 0.0 \\
\hline Other health outcomes & 3 & 6.1 & 0 & 0.0 & 0 & 0.0 & 0 & 0.0 & 2 & 1.9 & 1 & 0.4 & 2 & 0.7 & 2 & 0.7 \\
\hline Others & 0 & 0.0 & 0 & 0.0 & 0 & 0.0 & 0 & 0.0 & 0 & 0.0 & 1 & 0.4 & 1 & 0.3 & 4 & 1.5 \\
\hline
\end{tabular}

Notes: Number of measured constructs and percentages are represented by data collapsed at the variable and construct group levels Percentages represent content for each respective year. 
Table 18

Summary of Regression Analyses for Trends in Content within The Journal of Applied Psychology

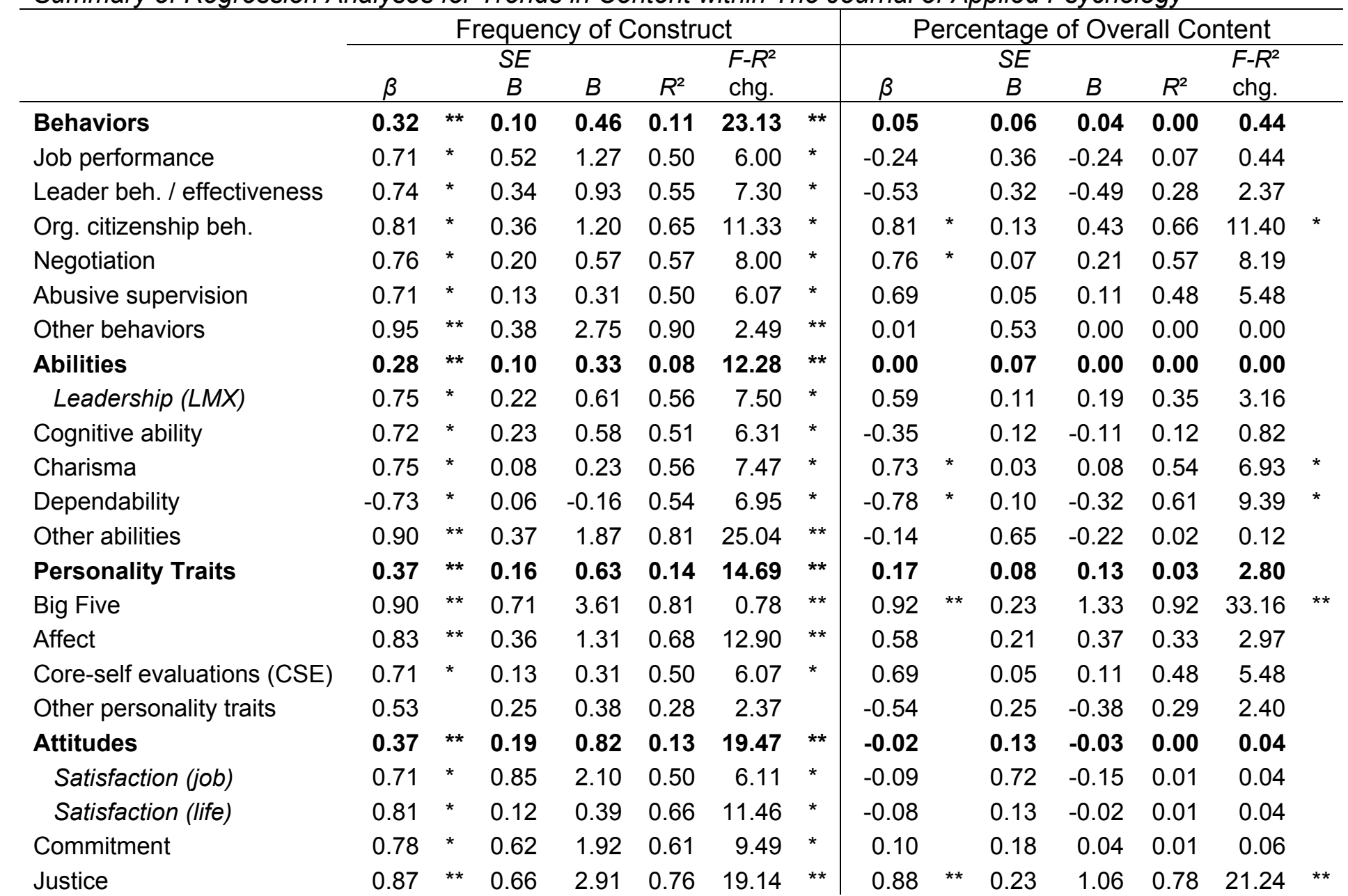




\begin{tabular}{lccccccc|ccccccc} 
Work-family conflict & 0.77 & $*$ & 0.19 & 0.55 & 0.59 & 8.49 & $*$ & 0.78 & $*$ & 0.07 & 0.20 & 0.61 & 9.32 & $*$ \\
Job embeddedness & 0.75 & $*$ & 0.15 & 0.42 & 0.57 & 7.84 & $*$ & 0.66 & & 0.07 & 0.14 & 0.44 & 4.66 & \\
Perceptions of job & & & & & & & & & & & & & & \\
alternatives & 0.85 & $* *$ & 0.07 & 0.26 & 0.72 & 15.45 & $* *$ & 0.83 & $* *$ & 0.02 & 0.09 & 0.70 & 13.64 & $* *$ \\
Other attitudes & 0.82 & $* *$ & 0.63 & 2.21 & 0.67 & 12.41 & $* *$ & -0.86 & $* *$ & 0.37 & -1.48 & 0.73 & 16.26 & $*$ \\
Health Outcomes & $\mathbf{0 . 1 7}$ & & $\mathbf{0 . 0 8}$ & $\mathbf{0 . 1 3}$ & $\mathbf{0 . 0 3}$ & $\mathbf{2 . 9 2}$ & & $-\mathbf{- 0 . 2 4}$ & $*$ & $\mathbf{0 . 0 8}$ & $\mathbf{- 0 . 1 9}$ & $\mathbf{0 . 0 6}$ & $\mathbf{5 . 9 4}$ & $*$ \\
Other health outcomes & 0.20 & & 0.19 & 0.10 & 0.04 & 0.25 & & -0.44 & & 0.31 & -0.37 & 0.19 & 1.44 & \\
Others & 0.76 & $*$ & 0.15 & 0.43 & 0.57 & 8.00 & $*$ & 0.74 & $*$ & 0.06 & 0.16 & 0.55 & 7.25 & $*$ \\
\hline
\end{tabular}

Note: Only significant findings are reported 